\title{
Indoor Air Quality Impacts
}

of Residential HVAC Systems

Phase II.A Report: Baseline

and Preliminary Simulations

Steven J. Emmerich

Andrew K. Persily

Building and Fire Research Laboratory

Gaithersburg, MD 20899

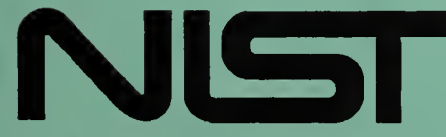

United States Department of Commerce Technology Administration

Institute of Standards and Technology

QC

100

.456

N0.5559

1995 


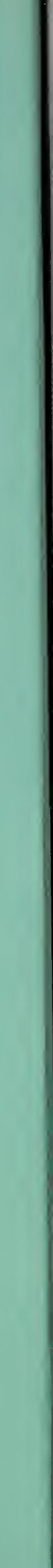




\section{Indoor Air Quality Impacts}

\section{of Residential HVAC Systems}

Phase II.A Report: Baseline and Preliminary Simulations

Steven J. Emmerich

Andrew K. Persily

January 1995

Building and Fire Research Laboratory

National Institute of Standards and Technology

Gaithersburg, MD 20899

U. S. Department of Commerce

Ronald H. Brown, Secretary

Mary L. Good, Under Secretary for Technology

National Institute of Standards and Technology

Arati Prabhakar, Director
Prepared for:

U.S. Consumer Product Safety Commission

Directorate for Engineering Sciences

Division of Mechanical Engineering

Bethesda, MD 20814 



\begin{abstract}
NIST has completed Phase II.A of a project to study the impact of HVAC systems on residential indoor air quality and to assess the potential for using residential forced-air systems to control indoor pollutant levels. In this effort, NIST is performing whole building airflow and contaminant dispersal computer simulations with the program CONTAM93 to assess the ability of modifications of central forced-air heating and cooling systems to control pollutant sources relevant to the residential environment. This report summarizes the results of Phase II.A of this project, which consisted of three major efforts: baseline simulations of contaminant levels without indoor air quality (IAQ) controls, design of the IAQ control retrofits, and preliminary simulations of contaminant levels with the IAQ control retrofits. In Phase II.B of the study, all of the baseline cases will be modified to incorporate the IAQ control retrofits. The retrofit results will then be compared to the baseline results to evaluate the effectiveness of the retrofits.

The pollutant concentrations in a building depend on many factors including the configuration of the building zones, the air leakage of the building envelope and of interior partitions, wind pressure profile on the building envelope, pollutant source strengths and temporal profiles, heating and cooling system airflow rates, furnace filter efficiency, characteristics of reversible pollutant sinks in the building, individual pollutant decay or deposition rates, and ambient weather and pollutant concentrations. This report describes the input data used to model the baseline houses with CONTAM93 and presents the results of the baseline simulations in the form of the transient pollutant concentrations for selected simulations and a summary of peak and average concentrations for all baseline simulations. Three indoor air quality control technologies were then selected for incorporation into the baseline house models to determine their effectiveness in controlling the modeled pollutant sources. The technologies include the following: electrostatic particulate filtration, heat recovery ventilation, and an outdoor air intake damper on the forced-air system return. Selected baseline cases were then modified to implement these indoor air quality control retrofits, and preliminary simulations were performed to demonstrate the ability of the program to model the control technologies.
\end{abstract}

Key Words: airflow modeling, building technology, computer simulation, filtration, heat recovery ventilator, HVAC system, indoor air quality, infiltration, residential buildings, ventilation 


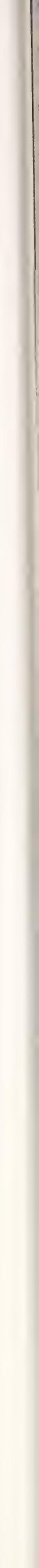




\section{Acknowledgements}

This work was sponsored by the U.S. Consumer Product Safety Commission under Interagency Agreement No. CPSC-IAG-93-1124. The authors wish to acknowledge the efforts of Roy Deppa and Lori Saltzman of CPSC in support of this project. The authors also express appreciation to Cherie Bulala for her assistance in performing simulations for the project. 


\section{Table of Contents}

Abstract iii

Acknowledgements $\mathrm{V}$

Introduction 1

Contents of Report

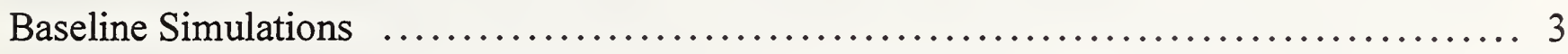

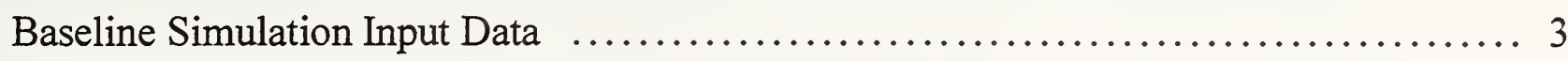

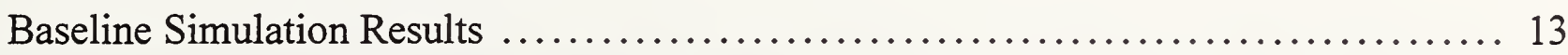

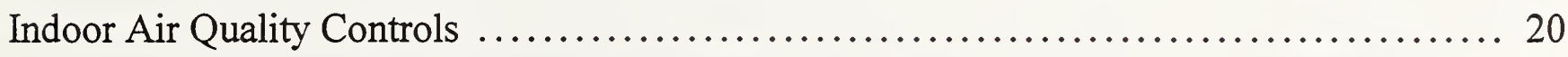

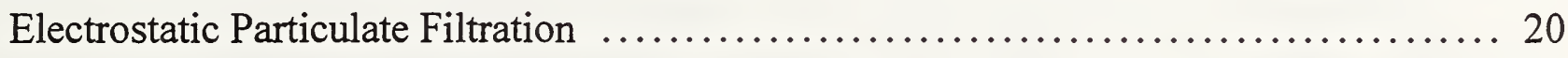

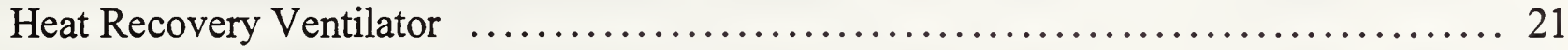

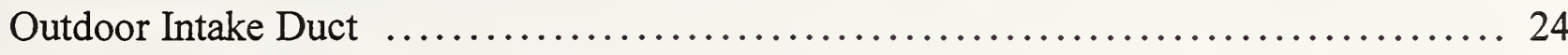

Preliminary Simulation of IAQ Control Retrofits $\ldots \ldots \ldots \ldots \ldots \ldots \ldots \ldots \ldots \ldots \ldots$

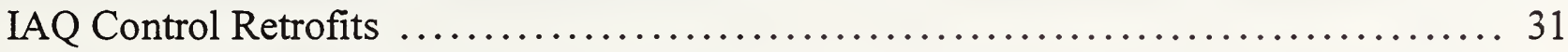

Results of Preliminary Simulation of IAQ Control Retrofits $\ldots \ldots \ldots \ldots \ldots \ldots \ldots \ldots . \ldots . \ldots$

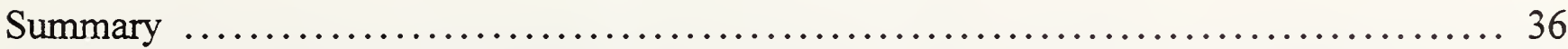

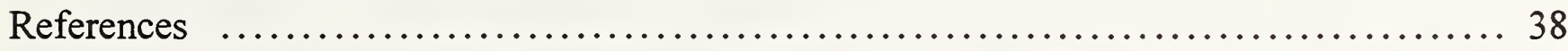

\section{Appendices}

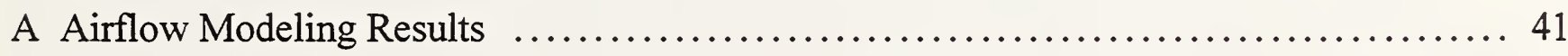

B Baseline and Preliminary Simulation Results $\ldots \ldots \ldots \ldots \ldots \ldots \ldots \ldots \ldots \ldots \ldots \ldots \ldots$ 


\section{Introduction}

Despite the increasing interest in residential indoor air quality (IAQ) problems, only limited research has been conducted which integrates the analysis of pollutant sources, residential heating and cooling system operation, and building characteristics. While central forced-air heating and cooling systems may provide solutions to some IAQ problems, such an integrated approach is required to analyze these options. Because large quantities of indoor air circulate through these systems, they offer the potential for treating the indoor air and then distributing this treated air through the system ductwork to the building. Also, outdoor air brought into the building by the forced-air system can be distributed throughout the building by this ductwork. Most modeling studies of IAQ in residential buildings have employed very simple models of the building and its systems, ignoring the multizone nature of the airflows involved. The use of such simple analytical procedures has limited our understanding of the impact of central forced-air heating and cooling systems on residential IAQ and the possibility of using these and other systems to mitigate IAQ problems.

The National Institute of Standards and Technology (NIST) is conducting a study for the U.S. Consumer Product Safety Commission (CPSC) to assess the potential effectiveness of existing heating, ventilating, and air conditioning (HVAC) technology to reduce the levels of selected pollutants in single-family residential buildings. This effort is employing a new multizone airflow and contaminant dispersal modeling program, CONTAM93 (1). In this effort, NIST is performing whole building airflow and contaminant dispersal computer simulations to assess the ability of modifications of central forced-air heating and cooling systems to control pollutant sources relevant to the residential environment. Phase I of the project included conducting a literature review, developing a detailed simulation plan, and hosting a workshop to discuss the project, and was described in a previous report (2). This report summarizes the results of Phase II.A which consisted of three major tasks: baseline simulations of contaminant levels without IAQ controls, design of the IAQ control retrofits, and preliminary simulations of contaminant levels with the IAQ control retrofits in place.

In Phase II.B of the study, the baseline HVAC systems will be modified to incorporate the IAQ control technologies described in this report and simulations will be performed for all conditions under which baseline simulations were performed. The Phase II.B simulation results will be compared with the results presented here to determine the effectiveness of the IAQ modifications at controlling the selected pollutant sources.

\section{Contents of Report}

The first section of the report describes the baseline simulations performed. The program CONTAM93 (1) was used to calculate airflows and pollutant distributions for the houses and pollutant sources described in the report on Phase I of the project (2). The houses modeled are not based on real buildings but are intended to be representative of typical buildings. This first section presents the input data used to describe the houses, HVAC systems, pollutants, sources, and boundary conditions in the baseline simulations. In addition, this section summarizes the 
results of the baseline simulations including transient pollutant concentrations for selected simulations and a summary of peak and average concentrations for all baseline simulations.

The second section describes the indoor air quality control technologies that will be evaluated in the computer simulations during Phase II.B. These technologies will be incorporated into the baseline house models to determine their effectiveness in controlling the selected pollutant sources. The three technologies described in this section include electrostatic particulate filtration, heat recovery ventilation, and an outdoor air intake damper on the forced-air system return. This section describes each of these technologies and includes revisions of the baseline house duct drawings. In addition, this section contains an estimate of the equipment and installation costs and a revision of the thermal load calculations based on the modifications. Finally, the impacts of each of these technologies on "other contaminants" are discussed qualitatively. These other contaminants, as described in the original project work statement, include contaminants that have typically been of concern to designers of residential ventilation systems including cooking odors, tobacco smoke, moisture, outdoor pollen, outdoor odors and ozone.

The third section presents the results of preliminary simulations of the IAQ control retrofits. These simulations involved modifying selected baseline simulation cases with the three IAQ control retrofits. The preliminary simulations were performed to demonstrate the ability of the program to model the IAQ control technologies.

The report includes two appendices. The first appendix describes modeling performed to characterize the airflow in the houses including the results of fan pressurization simulations and whole house infiltration simulations. The second appendix includes summary tables of the baseline and preliminary simulation results. 


\section{Baseline Simulations}

This section of the report describes the baseline simulations performed in Phase II.A. This section presents the input data describing the houses, HVAC systems, pollutants, sources, and boundary conditions modeled in the baseline simulations. In addition, this section summarizes the results of the baseline simulations including transient pollutant concentrations for selected simulations and a summary of peak and average concentrations for all baseline simulations.

\section{Baseline Simulation Input Data}

Calculating airflow rates and contaminant concentrations with CONTAM93 or any other multizone model requires the following input: the configuration and volume of the building zones, the air leakage paths through the building envelope and interior walls, wind pressure profile on the building envelope, pollutant source strengths and temporal profiles, HVAC system flows, furnace filter efficiency, characteristics of reversible pollutant sinks, individual pollutant decay or deposition rates, and ambient weather and pollutant concentrations. This section describes the input data used in the baseline simulations.

The study included eight building models - a ranch and a two-story house, located in two sites (Miami and Minneapolis), with typical and low values of airtightness. The Phase I NISTIR (2) described the layout and dimensions of each house and contained floorplan drawings.

Simulations were performed under three sets of weather conditions (cold, mild, and hot) for each building. Each simulation was performed for a one-day cycle repeated until peak concentrations converged to a specified tolerance. Referring to all pollutant sources modeled for a single building as one simulation, there were a total of 24 baseline simulation cases. Table 1 lists the baseline simulations by house type, location, airtightness and weather condition. 
Table 1 - Baseline simulations

\begin{tabular}{|l|l|l|l|l|}
\hline Simulation & House type & Location & Airtightness & Weather \\
\hline SIM1FLC & ranch & Miami & typical & cold \\
\hline SIM1FLM & ranch & Miami & typical & mild \\
\hline SIM1FLH & ranch & Miami & typical & hot \\
\hline SIM1FTC & ranch & Miami & tight & cold \\
\hline SIM1FTM & ranch & Miami & tight & mild \\
\hline SIM1FTH & ranch & Miami & tight & hot \\
\hline SIM1MLC & ranch & Minneapolis & typical & cold \\
\hline SIM1MLM & ranch & Minneapolis & typical & mild \\
\hline SIM1MLH & ranch & Minneapolis & typical & hot \\
\hline SIM1MTC & ranch & Minneapolis & tight & cold \\
\hline SIM1MTM & ranch & Minneapolis & tight & mild \\
\hline SIM1MTH & ranch & Minneapolis & tight & hot \\
\hline SIM2FLC & two-story & Miami & typical & cold \\
\hline SIM2FLM & two-story & Miami & typical & mild \\
\hline SIM2FLH & two-story & Miami & typical & hot \\
\hline SIM2FTC & two-story & Miami & tight & cold \\
\hline SIM2FTM & two-story & Miami & tight & mild \\
\hline SIM2FTH & two-story & Miami & tight & hot \\
\hline SIM2MLC & two-story & Minneapolis & typical & cold \\
\hline SIM2MLM & two-story & Minneapolis & typical & mild \\
\hline SIM2MLH & two-story & Minneapolis & typical & hot \\
\hline SIM2MTC & two-story & Minneapolis & tight & cold \\
\hline SIM2MTM & two-story & Minneapolis & tight & mild \\
\hline SIM2MTH & two-story & Minneapolis & tight & hot \\
\hline
\end{tabular}

Detailed information on building component leakage of the houses is not available as the houses modeled were not based on real buildings. However, since there is no attempt to compare predictions with experimental data, the building leakage modeled needs only to be reasonable in magnitude and distribution. Table 2 shows all of the leakage paths between the zones of the Miami ranch house (see Figure 1 for the ranch house floorplan and zone labeling and Figure 2 for the two-story house floorplan and zone labeling). The Minneapolis houses have basements (zone label BMT) that are not shown in the figures. Table 3 lists the values for those leakage paths for both the typical and tight cases. The Table 3 leakage areas are for a reference pressure difference of $4 \mathrm{~Pa}$ and a discharge coefficient of 1.0 and are based on values listed in Table 23-3 of ASHRAE (3) unless otherwise noted. The typical values were generally based on "best estimate" and/or uncaulked entries in the ASHRAE table, while the tight values were based on minimum and/or caulked entries. All doors connecting zones other than closets were modeled as open. The same leakage values were used for the other houses, although the paths connecting the zones differed depending on the house configurations. 


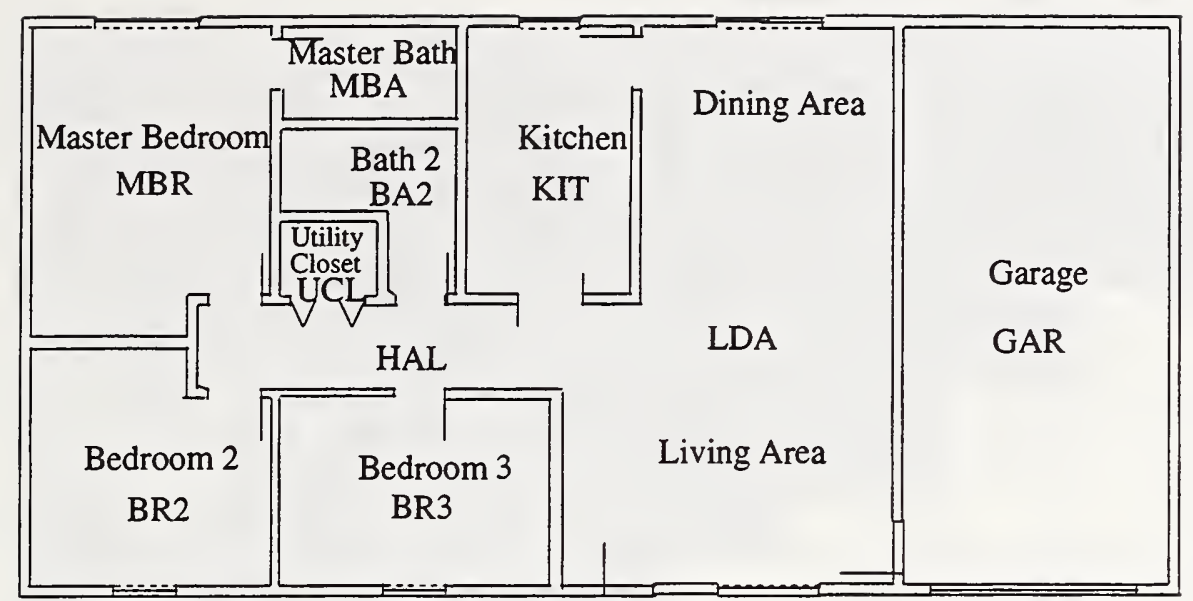

Figure 1 - Ranch house floorplan and zones
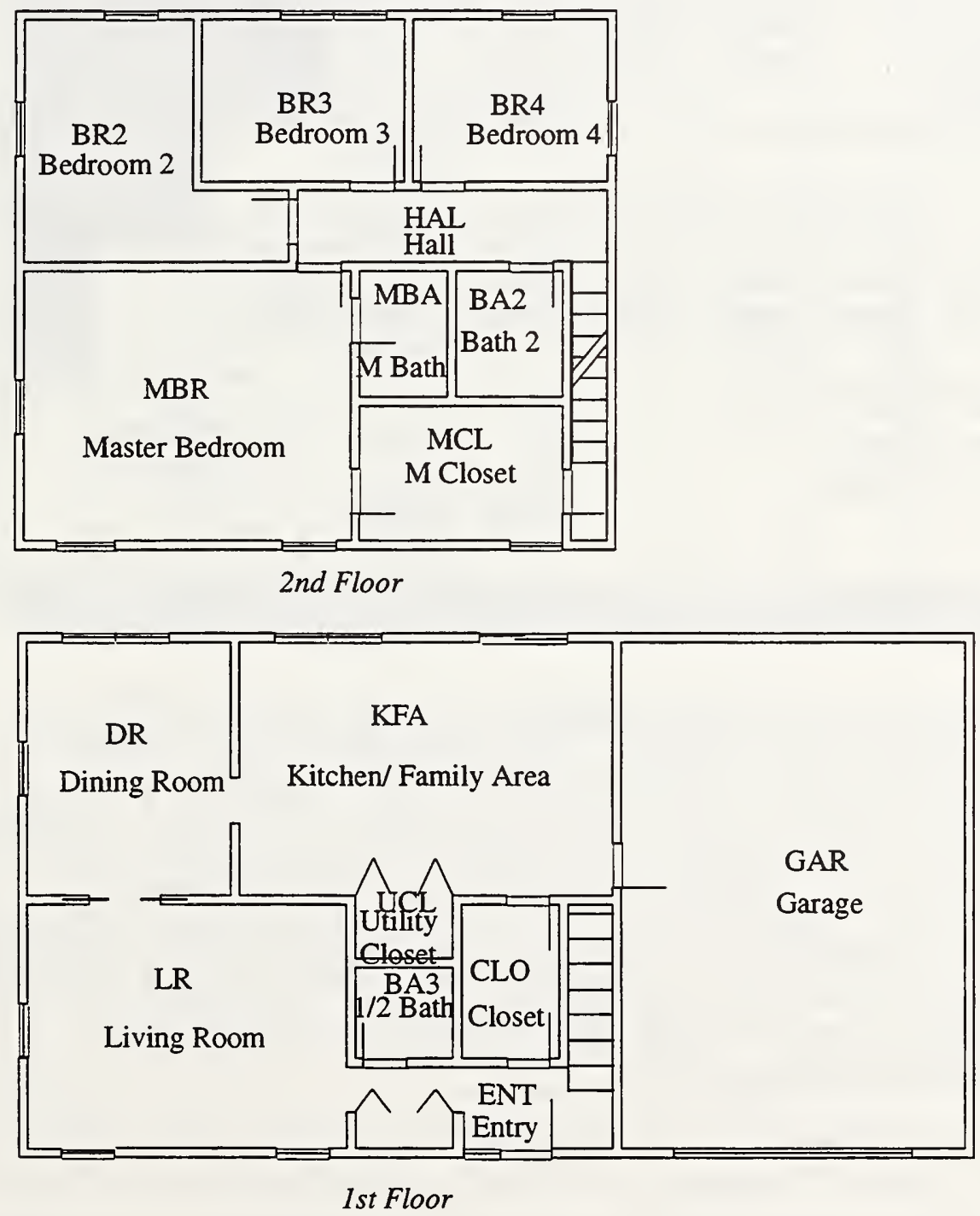

Figure 2 - Two-story house floorplan and zones 
Table 2 - Air leakage paths for Miami ranch house

\begin{tabular}{|c|c|c|c|c|c|c|c|c|c|c|c|}
\hline & MBR & $\mathrm{BR} 2$ & BR3 & MBA & $\mathrm{BA2}$ & UCL & $\mathrm{KIT}$ & LDA & HAL & GAR & ATC \\
\hline BR2 & $\begin{array}{l}\text { INTW } \\
\text { OUTL }\end{array}$ & & & & & & & & & & \\
\hline BR3 & & $\begin{array}{l}\text { INTW } \\
\text { OUTL }\end{array}$ & & & & & & & & & \\
\hline MBA & $\begin{array}{l}\text { INTD } \\
\text { INTW }\end{array}$ & & & & & & & & & & \\
\hline BA2 & $\begin{array}{l}\text { INTW } \\
\text { OUTL }\end{array}$ & & & $\begin{array}{l}\text { INTW } \\
\text { OUTL } \\
\end{array}$ & & & & & & & \\
\hline UCL & INTW & & & & INTW & & & & & & \\
\hline KIT & & & & $\begin{array}{l}\text { INTW } \\
\text { OUTL }\end{array}$ & $\begin{array}{l}\text { INTW } \\
\text { OUTL }\end{array}$ & & & & & & \\
\hline $\mathrm{LDA}$ & & & $\begin{array}{l}\text { INTW } \\
\text { OUTL }\end{array}$ & & & & $\begin{array}{l}\text { INTW } \\
\text { INTD } \\
\text { OUTL }\end{array}$ & & & & \\
\hline HAL & $\begin{array}{l}\text { INTD } \\
\text { INTW }\end{array}$ & $\begin{array}{l}\text { INTD } \\
\text { INTW }\end{array}$ & $\begin{array}{l}\text { INTD } \\
\text { INTW } \\
\text { OUTL }\end{array}$ & & $\begin{array}{l}\text { INTD } \\
\text { INTW }\end{array}$ & $\begin{array}{l}\text { CLD } \\
\text { INTW }\end{array}$ & \begin{tabular}{|l|} 
INTD \\
INTW \\
OUTL \\
\end{tabular} & HAD & & & \\
\hline GAR & & & & & & & & $\begin{array}{l}\text { EXTD } \\
\text { EXW } \\
\text { OUTL }\end{array}$ & & & \\
\hline ATC & $\begin{array}{l}\text { CEIL } \\
\text { CPEN }\end{array}$ & $\begin{array}{l}\text { CEIL } \\
\text { CPEN }\end{array}$ & $\begin{array}{l}\text { CEIL } \\
\text { CPEN }\end{array}$ & $\begin{array}{l}\text { CEIL } \\
\text { CPEN } \\
\text { PIP } \\
\end{array}$ & $\begin{array}{l}\text { CEIL } \\
\text { CPEN } \\
\text { PIP }\end{array}$ & \begin{tabular}{|l|} 
CEIL \\
CPEN
\end{tabular} & $\begin{array}{l}\text { CEIL } \\
\text { CPEN }\end{array}$ & $\begin{array}{l}\text { CEIL } \\
\text { CPEN } \\
\text { CPEN } \\
\end{array}$ & $\begin{array}{l}\text { CEIL } \\
\text { ATD }\end{array}$ & & \\
\hline AMB & $\begin{array}{l}\text { WIN } \\
\text { EXW } \\
\text { OUTL }\end{array}$ & $\begin{array}{l}\text { WIN } \\
\text { EXW } \\
\text { OUTL }\end{array}$ & $\begin{array}{l}\text { WIN } \\
\text { EXW } \\
\text { OUTL }\end{array}$ & \begin{tabular}{|l} 
EXV \\
EXW \\
OUTL
\end{tabular} & EXV & & \begin{tabular}{|l} 
WIN \\
EXV \\
EXW \\
OUTL
\end{tabular} & $\begin{array}{l}\text { SGD } \\
\text { EXTD } \\
\text { WIN } \\
\text { EXW } \\
\text { OUTL }\end{array}$ & & $\begin{array}{l}\text { GAD } \\
\text { GARF } \\
\text { EXW }\end{array}$ & VNT \\
\hline & MBR & BR2 & BR3 & MBA & $\mathrm{BA} 2$ & UCL & KIT & LDA & HAL & GAR & ATC \\
\hline
\end{tabular}

The infiltration through a building's envelope also depends on the static pressure distribution created by the wind on the building's exterior surfaces. The relationship between wind and surface pressures are characterized by wind pressure coefficients which depend on the wind direction, the building shape, the position on the building surface, and the presence of shielding near the building. The surface pressure coefficients for the building walls were based on Equation 23-8 of ASHRAE (3). The coefficient for the flat garage roof was based on Figure 14-6 of ASHRAE (3). The ASHRAE wind pressure coefficients do not include shielding effects and no modifier for shielding effects was used, however, recent studies have reported on the shielding effects of trees (4) and rows of houses (5). 
Table 3 - Air leakage values

\begin{tabular}{|c|c|c|c|}
\hline Name & Description & Typical & Tight \\
\hline ATD & Attic door & $30 \mathrm{~cm}^{2} / \mathrm{ea}$ & $18 \mathrm{~cm}^{2} / \mathrm{ea}$ \\
\hline CEIL & Ceiling [Based on general ceiling] & $1.8 \mathrm{~cm}^{2} / \mathrm{m}^{2}$ & $0.79 \mathrm{~cm}^{2} / \mathrm{m}^{2}$ \\
\hline \multirow[t]{2}{*}{ CLD } & Closet door (closed) [Based on interior door] & $0.9 \mathrm{~cm}^{2} / \mathrm{m}$ & $0.25 \mathrm{~cm}^{2} / \mathrm{m}$ \\
\hline & Closet door frame [Based on general door frame] & $25 \mathrm{~cm}^{2} / \mathrm{ea}$ & $12 \mathrm{~cm}^{2} / \mathrm{ea}$ \\
\hline CPEN & HVAC ceiling penetration [Based on kitchen vent with damper closed] & $5 \mathrm{~cm}^{2} / \mathrm{ea}$ & $1 \mathrm{~cm}^{2} / \mathrm{ea}$ \\
\hline \multirow[t]{2}{*}{ EXTD } & Exterior door [Single] & $21 \mathrm{~cm}^{2} / \mathrm{ea}$ & $12 \mathrm{~cm}^{2} / \mathrm{ea}$ \\
\hline & Door frame [Wood] & $1.7 \mathrm{~cm}^{2} / \mathrm{m}^{2}$ & $0.3 \mathrm{~cm}^{2} / \mathrm{m}^{2}$ \\
\hline \multirow[t]{2}{*}{ EXV } & Bathroom exhaust vent & $20 \mathrm{~cm}^{2} / \mathrm{ea}$ & $10 \mathrm{~cm}^{2} / \mathrm{ea}$ \\
\hline & Kitchen exhaust vent & $40 \mathrm{~cm}^{2} / \mathrm{ea}$ & $5 \mathrm{~cm}^{2} / \mathrm{ea}$ \\
\hline \multirow[t]{3}{*}{ EXW } & Ceiling-wall joint & $1.5 \mathrm{~m}^{2} / \mathrm{m}$ & $0.5 \mathrm{~m}^{2} / \mathrm{m}$ \\
\hline & Floor-wall joint & $4 \mathrm{~cm}^{2} / \mathrm{m}$ & $0.8 \mathrm{~cm}^{2} / \mathrm{m}$ \\
\hline & Wall-wall joint [Based on ceiling-wall joint] & $1.5 \mathrm{~m}^{2} / \mathrm{m}$ & $0.5 \mathrm{~m}^{2} / \mathrm{m}$ \\
\hline \multirow[t]{2}{*}{ GAD } & Garage door [Based on general door $(2 \mathrm{~m} \mathrm{x} 4 \mathrm{~m})$ ] & $0.45 \mathrm{~cm}^{2} / \mathrm{m}$ & $0.31 \mathrm{~cm}^{2} / \mathrm{m}$ \\
\hline & Garage door frame [Wood] & $1.7 \mathrm{~cm}^{2} / \mathrm{m}^{2}$ & $0.3 \mathrm{~cm}^{2} / \mathrm{m}^{2}$ \\
\hline GARF & Garage roof [Based on general ceiling] & $1.8 \mathrm{~cm}^{2} / \mathrm{m}^{2}$ & $0.79 \mathrm{~cm}^{2} / \mathrm{m}^{2}$ \\
\hline $\mathrm{HAD}$ & Hall doorway & $2.4 \mathrm{~m}^{2} / \mathrm{ea}$ & $2.4 \mathrm{~m}^{2} / \mathrm{ea}$ \\
\hline \multirow[t]{2}{*}{ INTD } & Interior door (closed) [Based on Table 4.2 of Klote and Milke (6)] & $140 \mathrm{~cm}^{2} / \mathrm{ea}$ & $75 \mathrm{~cm}^{2} / \mathrm{ea}$ \\
\hline & Interior door (open) & $2.1 \mathrm{~m}^{2} / \mathrm{ea}$ & $2.1 \mathrm{~m}^{2} / \mathrm{ea}$ \\
\hline INTW & Interior wall [Based on gypsum board on stud wall (Shaw et al. 7)] & $2.0 \mathrm{~cm}^{2} / \mathrm{m}^{2}$ & $2.0 \mathrm{~cm}^{2} / \mathrm{m}^{2}$ \\
\hline OUTL & Electric outlet & $2.5 \mathrm{~cm}^{2} / \mathrm{ea}$ & $0.5 \mathrm{~cm}^{2} / \mathrm{ea}$ \\
\hline PIP & Piping penetrations & $6 \mathrm{~cm}^{2} / \mathrm{ea}$ & $2 \mathrm{~cm}^{2} / \mathrm{ea}$ \\
\hline SGD & Sliding glass door & $22 \mathrm{~cm}^{2} / \mathrm{ea}$ & $3 \mathrm{~cm}^{2} / \mathrm{ea}$ \\
\hline VNT & Attic vent [Based on Table 21-1 of 3 ] & $1 \mathrm{~cm}^{2} / 300 \mathrm{~cm}^{2}$ & $1 \mathrm{~cm}^{2} / 300 \mathrm{~cm}^{2}$ \\
\hline \multirow[t]{2}{*}{ WIN } & Double hung window & $2.5 \mathrm{~cm}^{2} / \mathrm{m}$ & $0.65 \mathrm{~cm}^{2} / \mathrm{m}$ \\
\hline & Window framing [Wood] & $1.7 \mathrm{~cm}^{2} / \mathrm{m}^{2}$ & $0.3 \mathrm{~cm}^{2} / \mathrm{m}^{2}$ \\
\hline
\end{tabular}

The building HVAC systems were designed in Phase I of the study and are described in the Phase I report (2). This earlier report contains the heating and cooling equipment types and descriptions, overall and individual supply and return airflow rate design values for both heating and cooling, and drawings showing the system equipment and duct locations and duct sizes. In addition to this information, CONTAM93 requires information on the system operation, specifically, an on-off schedule. The schedule was determined by calculating the fractional on-time required to meet the cooling or heating load for each 3-hour period of the day. A control profile incorporating this schedule was then input for each simulation. For the baseline simulations, the HVAC systems included standard furnace filters with constant efficiencies of $5 \%$ for fine particles and $90 \%$ for coarse particles. Fine particles are defined as having a diameter less than $2.5 \mu \mathrm{m}$ (the efficiency is based on a diameter of $0.6 \mu \mathrm{m}$ ); coarse particles are defined as having a diameter greater than $2.5 \mu \mathrm{m}$ (the efficiency is based on a diameter of $6 \mu \mathrm{m}$ ). These 
efficiency values are based on assumed arrestance for these filters of about $90 \%$ and a review of manufacturers' test data. No outdoor air intake is included for the baseline HVAC systems.

Another important consideration for the HVAC systems is duct leakage. Since the duct system itself is not modeled in these simulations, duct leakage is modeled by including an additional system supply or return point and reducing the other supply and return flows by the corresponding amount rather than by an effective leakage area. Cummings et al. 1991 (8) tested duct leakage in 160 houses in Florida and found that return leaks were dominant in the majority of homes. They reported an average return leak fraction of $10.7 \%$ (based on ratio of leakage flow to total system flow). For the Minneapolis houses, a return leak of $10 \%$ was included in the basement. For the Miami ranch house, a supply leak of $10 \%$ was included in the attic because the system has a central return. For the Miami two-story house, no leaks were included because all ducts and equipment are internal. The air distribution system layouts were designed based on guidelines published by the National Association of Home Builders (9) and drawings are included in the Phase I report (2).

The ambient boundary conditions required by CONTAM93 include weather and outdoor pollutant concentrations. The weather conditions were chosen by selecting a hot, mild, and cold day for each location from Weather Year for Energy Calculation (WYEC) data (10). The WYEC data is presented in Tables 5 and 6 for Miami and Minneapolis, respectively, and includes temperature, wind speed, and wind direction from north. 
Table 5 - Miami weather data

\begin{tabular}{|c|c|c|c|c|c|c|c|c|c|}
\hline & \multicolumn{3}{|c|}{ Cold } & \multicolumn{3}{|c|}{ Mild } & \multicolumn{3}{|c|}{ Hot } \\
\hline Hour & $\begin{array}{c}\mathrm{T} \\
\left({ }^{\circ} \mathrm{C}\right)\end{array}$ & $\begin{array}{l}V_{\text {wind }} \\
(\mathrm{m} / \mathrm{s})\end{array}$ & $\begin{array}{l}\text { Dir } \\
\left(^{\circ}\right)\end{array}$ & $\begin{array}{c}\mathrm{T} \\
\left({ }^{\circ} \mathrm{C}\right)\end{array}$ & $\begin{array}{l}V_{\text {wind }} \\
(\mathrm{m} / \mathrm{s})\end{array}$ & $\begin{array}{l}\text { Dir } \\
\left({ }^{\circ}\right)\end{array}$ & $\begin{array}{c}\mathrm{T} \\
\left({ }^{\circ} \mathrm{C}\right)\end{array}$ & $\begin{array}{l}V_{\text {wind }} \\
(\mathrm{m} / \mathrm{s})\end{array}$ & $\begin{array}{l}\text { Dir } \\
\left({ }^{\circ}\right)\end{array}$ \\
\hline 0 & 2.8 & 2.3 & 320 & 13.3 & 3.9 & 360 & 26.7 & 0 & 0 \\
\hline 1 & 2.8 & 2.3 & 300 & 13.3 & 2.7 & 360 & 26.1 & 1.2 & 200 \\
\hline 2 & 2.8 & 3.5 & 310 & 13.3 & 3.5 & 360 & 26.1 & 1.2 & 200 \\
\hline 3 & 2.8 & 2.7 & 320 & 13.9 & 1.9 & 20 & 25.6 & 1.6 & 200 \\
\hline 4 & 2.2 & 2.3 & 310 & 13.3 & 2.7 & 20 & 25.6 & 1.9 & 200 \\
\hline 5 & 2.2 & 3.5 & 310 & 13.9 & 1.6 & 360 & 26.1 & 1.9 & 230 \\
\hline 6 & 2.8 & 2.7 & 320 & 13.3 & 2.3 & 340 & 25.6 & 1.9 & 200 \\
\hline 7 & 3.3 & 3.5 & 300 & 14.4 & 2.3 & 340 & 26.7 & 1.6 & 230 \\
\hline 8 & 4.4 & 2.3 & 290 & 16.1 & 2.7 & 340 & 27.2 & 1.9 & 200 \\
\hline 9 & 6.1 & 2.7 & 330 & 21.1 & 4.7 & 70 & 30.6 & 2.3 & 200 \\
\hline 10 & 8.9 & 3.1 & 320 & 23.3 & 4.7 & 70 & 31.7 & 2.3 & 230 \\
\hline 11 & 11.7 & 2.3 & 320 & 23.3 & 5.1 & 70 & 32.8 & 0 & 0 \\
\hline 12 & 13.9 & 2.7 & 330 & 23.3 & 5.4 & 70 & 33.3 & 2.3 & 200 \\
\hline 13 & 14.4 & 2.7 & 350 & 22.8 & 5.1 & 70 & 33.3 & 3.9 & 140 \\
\hline 14 & 16.1 & 2.3 & 360 & 22.8 & 5.4 & 70 & 32.8 & 4.3 & 180 \\
\hline 15 & 17.2 & 0.8 & 40 & 22.2 & 4.7 & 70 & 31.7 & 4.7 & 160 \\
\hline 16 & 17.8 & 2.7 & 40 & 21.7 & 3.9 & 90 & 30.6 & 1.9 & 290 \\
\hline 17 & 17.2 & 3.5 & 20 & 21.7 & 3.1 & 90 & 31.7 & 3.1 & 140 \\
\hline 18 & 16.7 & 1.9 & 340 & 21.7 & 4.3 & 70 & 30.6 & 2.3 & 160 \\
\hline 19 & 16.1 & 2.3 & 340 & 21.1 & 4.3 & 90 & 27.8 & 1.6 & 50 \\
\hline 20 & 15 & 1.6 & 350 & 21.1 & 2.7 & 90 & 27.8 & 1.2 & 50 \\
\hline 21 & 14.4 & 1.9 & 350 & 21.1 & 3.1 & 90 & 27.2 & 1.6 & 200 \\
\hline 22 & 16.1 & 2.3 & 30 & 21.7 & 1.2 & 90 & 26.1 & 2.3 & 230 \\
\hline 23 & 16.1 & 2.3 & 60 & 21.7 & 2.3 & 90 & 26.1 & 1.2 & 250 \\
\hline 24 & 17.2 & 3.5 & 60 & 20.6 & 3.1 & 50 & 26.1 & 0 & 0 \\
\hline
\end{tabular}


Table 6 - Minneapolis weather data

\begin{tabular}{|c|r|c|r|r|r|r|r|r|r|}
\hline & \multicolumn{3}{|c|}{ Cold } & \multicolumn{3}{|c|}{ Mild } & \multicolumn{3}{|c|}{ Hot } \\
\hline Hour & $\begin{array}{c}\mathrm{T} \\
\left({ }^{\circ} \mathrm{C}\right)\end{array}$ & $\begin{array}{c}\mathrm{V}_{\text {wind }} \\
(\mathrm{m} / \mathrm{s})\end{array}$ & $\begin{array}{c}\text { Dir } \\
\left({ }^{\circ}\right)\end{array}$ & $\begin{array}{c}\mathrm{T} \\
\left({ }^{\circ} \mathrm{C}\right)\end{array}$ & $\begin{array}{c}\mathrm{V}_{\text {wind }} \\
(\mathrm{m} / \mathrm{s})\end{array}$ & $\begin{array}{c}\text { Dir } \\
\left({ }^{\circ}\right)\end{array}$ & $\begin{array}{c}\mathrm{T} \\
\left({ }^{\circ} \mathrm{C}\right)\end{array}$ & $\begin{array}{c}\mathrm{V}_{\text {wind }} \\
(\mathrm{m} / \mathrm{s})\end{array}$ & $\begin{array}{c}\text { Dir } \\
\left({ }^{\circ}\right)\end{array}$ \\
\hline 0 & -21.1 & 1.6 & 330 & 7.8 & 1.9 & 60 & 21.1 & 3.1 & 180 \\
\hline 1 & -21.1 & 1.6 & 330 & 7.8 & 1.9 & 40 & 20 & 2.7 & 180 \\
\hline 2 & -21.1 & 3.1 & 350 & 7.8 & 3.1 & 90 & 18.9 & 2.7 & 180 \\
\hline 3 & -21.1 & 3.1 & 350 & 7.2 & 1.9 & 100 & 17.8 & 1.9 & 180 \\
\hline 4 & -21.1 & 3.1 & 350 & 7.2 & 4.7 & 130 & 18.3 & 1.6 & 158 \\
\hline 5 & -21.1 & 3.1 & 350 & 7.2 & 3.9 & 130 & 17.2 & 2.7 & 135 \\
\hline 6 & -21.7 & 3.5 & 350 & 7.2 & 3.1 & 120 & 17.8 & 3.5 & 158 \\
\hline 7 & -21.7 & 2.7 & 340 & 7.2 & 3.9 & 140 & 20 & 1.9 & 158 \\
\hline 8 & -21.7 & 2.7 & 350 & 7.8 & 2.7 & 120 & 24.4 & 4.7 & 180 \\
\hline 9 & -21.1 & 3.9 & 340 & 8.9 & 3.1 & 130 & 26.1 & 5.8 & 180 \\
\hline 10 & -20.6 & 3.9 & 310 & 7.8 & 4.3 & 130 & 28.3 & 6.6 & 203 \\
\hline 11 & -20.6 & 4.7 & 310 & 8.3 & 4.7 & 130 & 30 & 6.2 & 203 \\
\hline 12 & -20.6 & 3.9 & 320 & 8.9 & 4.3 & 140 & 30.6 & 6.2 & 203 \\
\hline 13 & -20.6 & 4.3 & 320 & 8.9 & 4.7 & 140 & 31.1 & 7 & 203 \\
\hline 14 & -20 & 5.1 & 300 & 8.3 & 6.2 & 120 & 31.1 & 7.4 & 203 \\
\hline 15 & -20 & 4.7 & 290 & 8.9 & 6.2 & 110 & 31.1 & 6.6 & 203 \\
\hline 16 & -20.6 & 4.3 & 310 & 8.9 & 5.8 & 130 & 31.1 & 6.6 & 203 \\
\hline 17 & -21.1 & 3.5 & 290 & 9.4 & 5.1 & 130 & 28.9 & 4.7 & 203 \\
\hline 18 & -22.8 & 3.1 & 280 & 9.4 & 5.4 & 130 & 29.4 & 4.7 & 180 \\
\hline 19 & -23.3 & 2.7 & 280 & 11.1 & 5.4 & 160 & 27.8 & 4.7 & 180 \\
\hline 20 & -24.4 & 3.1 & 300 & 11.7 & 5.8 & 170 & 26.1 & 4.3 & 180 \\
\hline 21 & -25 & 3.1 & 280 & 11.1 & 6.2 & 180 & 24.4 & 3.9 & 180 \\
\hline 22 & -25.6 & 2.7 & 280 & 11.1 & 5.8 & 200 & 23.9 & 3.9 & 180 \\
\hline 24 & -27.2 & 2.3 & 240 & 10.6 & 6.2 & 220 & 23.3 & 4.7 & 158 \\
\hline & -28.9 & 2.3 & 240 & 7.8 & 2.7 & 240 & 22.8 & 4.3 & 180 \\
\hline
\end{tabular}

Outdoor pollutant concentrations vary by location and over time at any one location. The concentrations used as boundary conditions for the indoor sources in the simulations were selected as typical outdoor conditions and are not meant to represent the actual conditions at any specific location. The values used were specified per the schedules in Table 7. The $\mathrm{CO}$ and $\mathrm{NO}_{2}$ concentrations were chosen based on review of US EPA air quality documents $(11,12,13)$. They were chosen to have a diurnal pattern with morning and afternoon peaks. The selected $\mathrm{CO}$ and $\mathrm{NO}_{2}$ concentration schedules are very similar to values measured outside a research house in Chicago (Figure 3.2 of 14). Fine particles and TVOCs are not discussed in the EPA documents. The ambient fine particle concentration was chosen based on the average of reported average measurements for four US cities (Table 4 of 15). The TVOC concentration chosen is in the 
middle of the reported range of 10 to $211 \mu \mathrm{g} / \mathrm{m}^{3}$ measured at 68 sites in the US (16). The fine particle and TVOC concentrations were assumed to be constant throughout the day.

In addition to the ambient concentrations in Table 7 that served as the boundary conditions for the indoor sources, elevated levels of $\mathrm{CO}$, coarse particles, and $\mathrm{NO}_{2}$ were simulated in order to evaluate the effect of the IAQ control technologies on pollutants brought into residences from the outdoors. These elevated pollutant concentrations were selected based on review of US EPA air quality documents $(11,12,13)$ and were specified per the schedules in Table 8.

Table 7 - Outdoor pollutant concentration schedules

\begin{tabular}{|l|c|c|c|c|c|}
\hline Hour of day & $0-7$ & $7-9$ & $9-17$ & $17-19$ & $19-24$ \\
\hline $\mathrm{CO}(\mathrm{ppm})$ & 1 & 2 & 1.5 & 3 & 1.5 \\
\hline $\mathrm{NO}_{2}(\mathrm{ppm})$ & 0.02 & 0.04 & 0.02 & 0.04 & 0.02 \\
\hline Fine particles $\left(\mu \mathrm{g} / \mathrm{m}^{3}\right)$ & 13 & 13 & 13 & 13 & 13 \\
\hline TVOCs $\left(\mu \mathrm{g} / \mathrm{m}^{3}\right)$ & 100 & 100 & 100 & 100 & 100 \\
\hline
\end{tabular}

Table 8 - Elevated outdoor pollutant concentrations schedule

\begin{tabular}{|l|c|c|c|c|c|}
\hline Hour of day & $0-7$ & $7-9$ & $9-17$ & $17-19$ & $19-24$ \\
\hline $\mathrm{CO}(\mathrm{ppm})$ & 4 & 8 & 7 & 12 & 6 \\
\hline $\mathrm{NO}_{2}(\mathrm{ppm})$ & 0.2 & 0.4 & 0.2 & 0.4 & 0.2 \\
\hline Coarse particles $\left(\mu \mathrm{g} / \mathrm{m}^{3}\right)$ & 75 & 75 & 75 & 75 & 75 \\
\hline
\end{tabular}

The Phase I report (2) described the pollutant sources considered for inclusion in the study. The pollutant sources used in the baseline simulations included several VOC burst sources (medium strength source based on a polish and high strength source based on a spray carpet cleanser (17)), a constant VOC area source (based on a PVC flooring material with high emissions (18)), and combustion sources (based on medium source strengths for ovens and space heaters (19)) of CO, $\mathrm{NO}_{2}$, and fine particles. While the source strength used for the flooring material isbased on a material with high emissions, it is only moderately higher than the range of 0.17 to $2.11 \mathrm{mg} / \mathrm{m}^{2} \mathrm{~h}$ recently reported in 5 day emission tests of finished particleboard (20). Table 9 lists detailed information on these sources including the zones (see Figures 1 and 2 for zone labels, also BMT is the basement zone) in which they are located, source strengths, and schedules. 
Table 9 - Pollutant sources

\begin{tabular}{|l|l|l|l|l|}
\hline Source name & Pollutant & Zone(s) & Source strength & Schedule \\
\hline Burst (medium) & TVOCs & Several & $300 \mathrm{mg} / \mathrm{h}$ & $\begin{array}{l}9-9: 30 \mathrm{am} \\
7-7: 30 \mathrm{p} . \mathrm{m} .\end{array}$ \\
\hline Burst (high) & TVOCs & GAR and BMT & $1100 \mathrm{mg} / \mathrm{h}$ & $\begin{array}{l}9-10 \mathrm{~mm} \\
7-8 \mathrm{p} . \mathrm{m} .\end{array}$ \\
\hline Flooring material & TVOCs & All but GAR, ATC & $7.0 \mathrm{mg} / \mathrm{h} \mathrm{m}{ }^{2}$ & constant \\
\hline Oven & CO & $\begin{array}{l}\text { KIT (ranch house) } \\
\text { KFA (two-story house) }\end{array}$ & $1900 \mathrm{mg} / \mathrm{h}$ & $\begin{array}{l}7-7: 30 \mathrm{am} \\
6-7 \mathrm{p} . \mathrm{m} .\end{array}$ \\
\hline Oven & NO 2 & $\begin{array}{l}\text { KIT (ranch house) } \\
\text { KFA (two-story house) }\end{array}$ & $160 \mathrm{mg} / \mathrm{h}$ & $\begin{array}{l}7-7: 30 \mathrm{am} \\
6-7 \mathrm{p} . \mathrm{m} .\end{array}$ \\
\hline Oven & Fine particles & $\begin{array}{l}\text { KIT (ranch house) } \\
\text { KFA (two-story house) }\end{array}$ & $0.2 \mathrm{mg} / \mathrm{h}$ & $\begin{array}{l}7-7: 30 \mathrm{am} \\
6-7 \mathrm{p} . \mathrm{m} .\end{array}$ \\
\hline Heater & CO & GAR and BMT & $1000 \mathrm{mg} / \mathrm{h}$ & $\begin{array}{l}7-10 \mathrm{am} \text { (GAR) } \\
7-9 \mathrm{p} . \mathrm{m} . \text { (BMT) }\end{array}$ \\
\hline Heater & NO 2 & GAR and BMT & $250 \mathrm{mg} / \mathrm{h}$ & $\begin{array}{l}7-10 \mathrm{am} \text { (GAR) } \\
7-9 \mathrm{p} . \mathrm{m} . \text { (BMT) }\end{array}$ \\
\hline Heater & Fine particles & GAR and BMT & $2 \mathrm{mg} / \mathrm{h}$ & $\begin{array}{l}7-10 \mathrm{am} \text { (GAR) } \\
7-9 \mathrm{p} . \mathrm{m} . \text { (BMT) }\end{array}$ \\
\hline
\end{tabular}

In addition to the sources listed in Table 9, the simulation plan in the Phase I report (2) included a newly-finished floor as a floor-area based decaying source of VOCs. A test simulation with a medium strength source, modeled as a first order exponential decay source with initial emission rate of $17400 \mathrm{mg} / \mathrm{m}^{2} \mathrm{~h}$ and decay constant of $1.24 \mathrm{~h}^{-1}$ (based on a stain product (21)) was performed for the Miami ranch house. This source resulted in extremely high concentrations of TVOCs with a peak concentration of over $2 \mathrm{~g} / \mathrm{m}^{3}$ and a concentration of $37 \mathrm{mg} / \mathrm{m}^{3}$ at the end of the day. None of the IAQ control retrofits being evaluated can be expected to have a significant impact on the extremely high concentrations from this source during the one-day simulation period. Therefore, this source was not included in the remaining baseline simulations. Decaying high-strength sources such as this one are of interest and may be studied in the future with simulations of longer duration.

Reversible sink effects for the VOCs were modeled with sink elements based on a boundary layer diffusion controlled (BLDC) model with a linear adsorption isotherm. The BLDC adsorption model is described by Axley (22). The parameters required for this sink model are the film mass transfer coefficient, the adsorbent mass, and the isotherm partition coefficient, and these parameters would vary over time and by location within a house. However, since little real data is available for these parameters (which depend on factors such as gas diffusion properties, airflow rates, and adsorbent material) and because the goal was to obtain a reasonable estimate of the reversible sink effects, constant values were used for all of the parameters and only the adsorbent mass was varied by zone. The film mass transfer coefficient used was $35 \mu \mathrm{m} / \mathrm{s}$ and was calculated from equation 3.17a of Axley (22) with an assumed air velocity of $0.001 \mathrm{~m} / \mathrm{s}$, effective length of $4 \mathrm{~m}$, Schmidt number of 1.0 , and binary diffusion coefficient of $1.0 \times 10^{-5} \mathrm{~m}^{2} / \mathrm{s}$. The partition coefficient used was $0.5 \mathrm{~g}$-air/g-sorbent and was estimated from parameters reported for 
an empirical sink model for an experimental case of alkanes emitted by a wood stain in a test house (23). The adsorbent mass used was based on a mass of $6 \mathrm{~kg} \mathrm{per}^{2}$ of adsorbent surface area which was assumed to be equal to half of the zone interior surface area.

Nitrogen dioxide decay and particle deposition were modeled as single-reactant first order reactions with a single, constant value in all rooms of the houses. Nitrogen dioxide decay depends strongly on the materials present in a house (e.g., floor and wall coverings, furnishings, etc.) and a wide range of measured values have been reported including a range of $0.09-13.74$ $\mathrm{h}^{-1}$ by Lee et al. (24). Other studies have reported average $\mathrm{NO}_{2}$ decay rates of $0.17,0.29,0.65$, $0.8,0.82$, and $2.07 \mathrm{~h}^{-1}(25,26,27,28,29,24)$. The kinetic rate coefficient used for $\mathrm{NO}_{2}$ decay was $0.87 \mathrm{~h}^{-1}$ and is based on the average of measurements in a contemporary research house reported by Leslie et al. (14).

Particle deposition depends on the size and type of particles, particle concentration, airflow conditions, and surfaces available for deposition. The particle decay rate used for fine particles was $0.08 \mathrm{~h}^{-1}$ and was reported by Traynor et al. (30) for combustion products from a wood-burning stove in a test house. Offerman et al. (31) reported a similar mass-averaged value of $0.1 \mathrm{~h}^{-1}$ for tobacco smoke particles in a research house. The decay rate can be calculated as the product of an average deposition velocity and a room surface-to-volume ratio. Assuming a room surface-to-volume ratio of $2 \mathrm{~m}^{-1}$ (the actual value will depend on room geometry, furnishings, and surface finishes), a decay rate of $0.08 \mathrm{~h}^{-1}$ corresponds to a deposition velocity of approximately $0.001 \mathrm{~cm} / \mathrm{s}$. Sinclair et al. $(32,33)$ reported higher average deposition velocities of $0.005 \mathrm{~cm} / \mathrm{s}$ for fine-mode sulfate in telephone equipment buildings. However, the nature of the indoor environment, and especially the airflow conditions, in a detached single-family home and a commercial building are very different. Nazaroff et al. (34) discusses the use of deposition velocity and warns that "Deposition velocities determined for one indoor environment can only be applied to another to the extent that the air flow conditions are similar."

In the only report of coarse particle deposition rates in a test house found in the literature, Byrne et al. (35) reported values of 1.51 and $2.10 \mathrm{~h}^{-1}$ for $4 \mu \mathrm{m}$ particles in an unfurnished and furnished room, respectively. The reported mean deposition velocities of 0.027 to $0.038 \mathrm{~cm} / \mathrm{s}$ fall within the range of approximately .01 to $0.1 \mathrm{~cm} / \mathrm{s}$ calculated from a natural convection deposition model by Nazaroff and Cass (36). The actual decay rate for the coarse outdoor air particles modeled in the simulations would depend on the size distribution of the particles. Since no specific distribution has been assumed, a decay rate of $1.5 \mathrm{~h}^{-1}$ was chosen based on the lower value reported by Byrne.

\section{Baseline Simulation Results}

The results of each of the 24 simulations listed in Table 1 include pollutant concentrations for up to 18 pollutants in each of the building zones for each 15 -minute time step of the 24-hour simulation period. The complete transient simulation results are not presented here but are available in spreadsheet files. Instead, this section presents examples of the transient pollutant concentrations for selected simulations. Figures 3 through 6 show the pollutant concentrations in Zone LDA resulting from selected pollutant sources for simulation SIM1FLC (the typical Miami 
ranch house in cold weather). Figures 7 through 10 show the corresponding results for SIM1FTC (the tight Miami ranch house in cold weather). Although these figures are only examples of transient results, some observations can be made into trends and factors affecting the predicted contaminant concentrations. A complete summary of peak and 24-hour, 4-hour, and 1-hour average concentrations for all baseline simulations are included in Tables 1a through $24 \mathrm{e}$ of Appendix B.

Figures 3 and 7 show the $\mathrm{CO}$ concentrations in Zone LDA resulting from the oven and heater sources (CO.1 and CO.2 in Tables 1 and 4 of Appendix B) for SIM1FLC and SIM1FTC, respectively. Both graphs show two daily peaks due to the operation of the oven. For the tight house, the peaks are shifted to a slightly later time due to reduced outdoor airflow into the house which resulted in less mixing of $\mathrm{CO}$ from the kitchen into the rest of the house. The heater source causes much lower concentrations than the oven source due to the low airflow rate from the garage into the house and the lower source emission rate. The resulting $\mathrm{CO}$ concentrations for the heater source are influenced primarily by the outdoor level. There is more damping of the outdoor variations in the tight house than the typical house due to the reduced air infiltration rate.

Figures 4 and 8 show the $\mathrm{NO}_{2}$ concentrations (NO2.1 and NO2.2 in Tables 1 and 4 of Appendix B) in Zone LDA resulting from the oven and heater sources for SIM1FLC and SIM1FTC. The $\mathrm{NO}_{2}$ concentrations show some of the same characteristics as the $\mathrm{CO}$ concentrations, with two peaks from the oven and a damped dependence on the outdoor concentration for the heater. However, the $\mathrm{NO}_{2}$ peaks in the tight house are significantly less than in the typical house despite the reduced outdoor airflow into the house. In fact, the whole-house average $\mathrm{NO}_{2}$ concentrations are lower in the tight house than in the typical house $(0.025 \mathrm{ppm}$ vs. $0.026 \mathrm{ppm}$ for the oven source, and $0.003 \mathrm{ppm}$ vs. $0.008 \mathrm{ppm}$ for the heater source). These results may seem surprising as one might expect the reduced infiltration to result in higher $\mathrm{NO}_{2}$ concentrations in the tight house. However, these results may be explained by the impact of $\mathrm{NO}_{2}$ decay. The $\mathrm{NO}_{2}$ in the house is either generated by the indoor sources or brought in from outside. During much of the day, when the combustion appliances are not operated, the outdoor air is the source of indoor $\mathrm{NO}_{2}$ and, due to $\mathrm{NO}_{2}$ decay, the indoor concentrations are lower than the outdoor concentration. Therefore, reducing the infiltration actually results in lower indoor $\mathrm{NO}_{2}$ concentrations. When there is an indoor source of $\mathrm{NO}_{2}$, a lower infiltration rate may still result in lower $\mathrm{NO}_{2}$ concentrations in the zones without the source. However, the source-zone will have higher $\mathrm{NO}_{2}$ concentrations when the infiltration rate is lower (the peak kitchen concentration from the oven is $1.686 \mathrm{ppm}$ for the tight house and $1.434 \mathrm{ppm}$ for the typical house). It is important to note that this result of lower $\mathrm{NO}_{2}$ concentrations in tighter houses cannot be generalized to all cases. If the $\mathrm{NO}_{2}$ decay rate was lower, the indoor $\mathrm{NO}_{2}$ generation rate was higher, or the outdoor $\mathrm{NO}_{2}$ concentration was lower, the tighter house could have higher concentrations. See Tables $1 \mathrm{~b}$ and $4 \mathrm{~b}$ of Appendix $\mathrm{B}$ for the peak and average $\mathrm{NO}_{2}$ concentrations results for these simulations.

The TVOC concentrations in Zone LDA resulting from the burst source located in the LDA Zone (VOC4 in Tables 1 and 4 of Appendix B) are shown in Figures 5 and 9 for SIM1FLC and SIM1FTC. As expected, this source results in two daily peaks due to the source schedule and higher concentrations in the tight house due to the reduced airflow into the house. 
Figures 6 and 10 show the $\mathrm{CO}$ and coarse particle concentrations (CO.3 and PART.3 of Tables 1 and 4 in Appendix B) for SIM1FLC and SIM1FTC, respectively, due to the elevated outdoor pollutant concentrations of Table 8 . The $\mathrm{CO}$ concentration in the typical house tracks the outdoor concentration with a time lag based on the building time constant (related to the inverse of the building air change rate). The particle concentration shows the effect of the HVAC system cycling which changes the air change rate of the house and filters particles from the air. When the furnace is on, the concentration of coarse particles decreases due to the impact of the furnace filter. The tight house results exhibit damped $\mathrm{CO}$ peaks and valleys due to the longer time constants. Because the particles come from outdoors, the lower air change rates result in lower particle concentrations. 

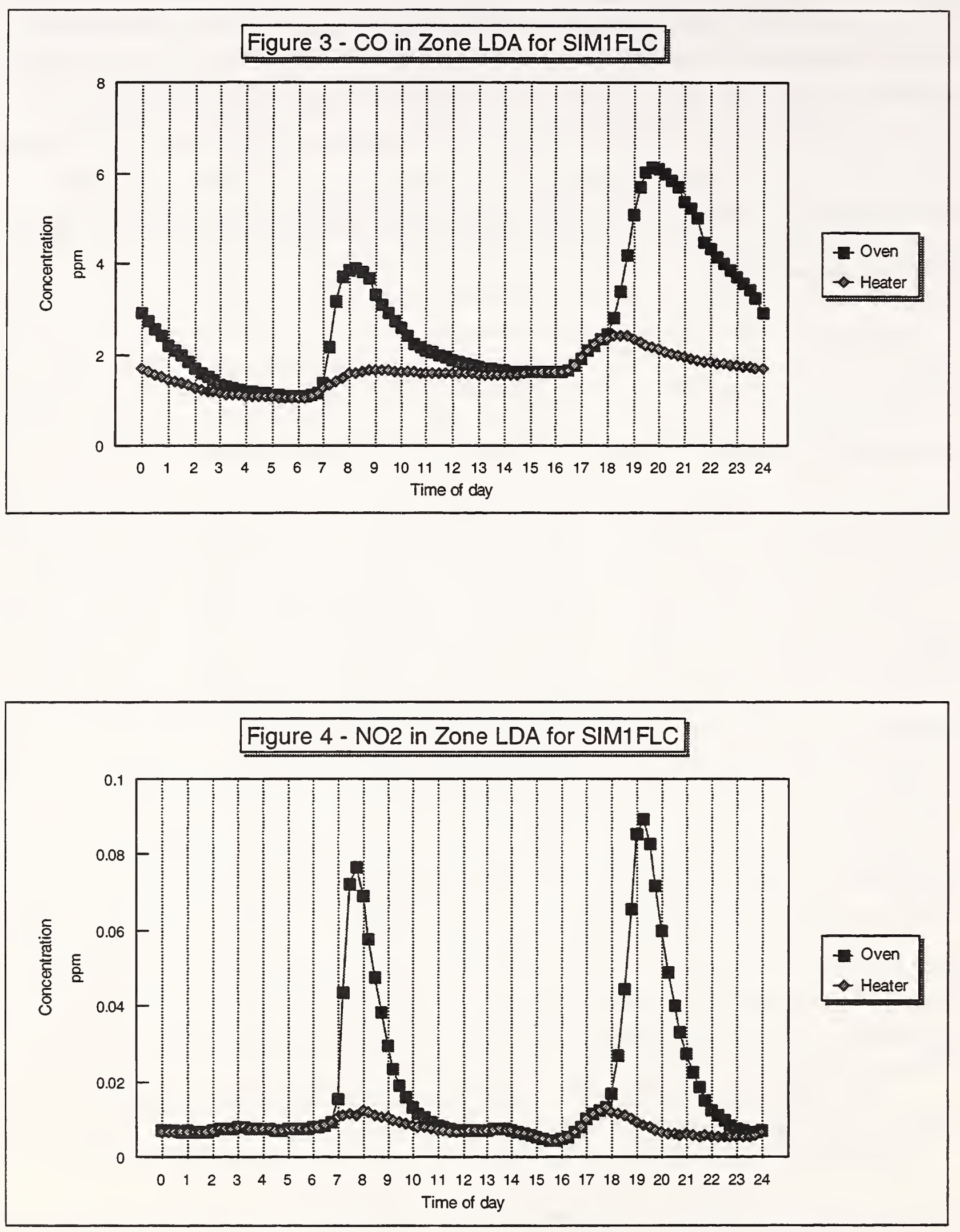

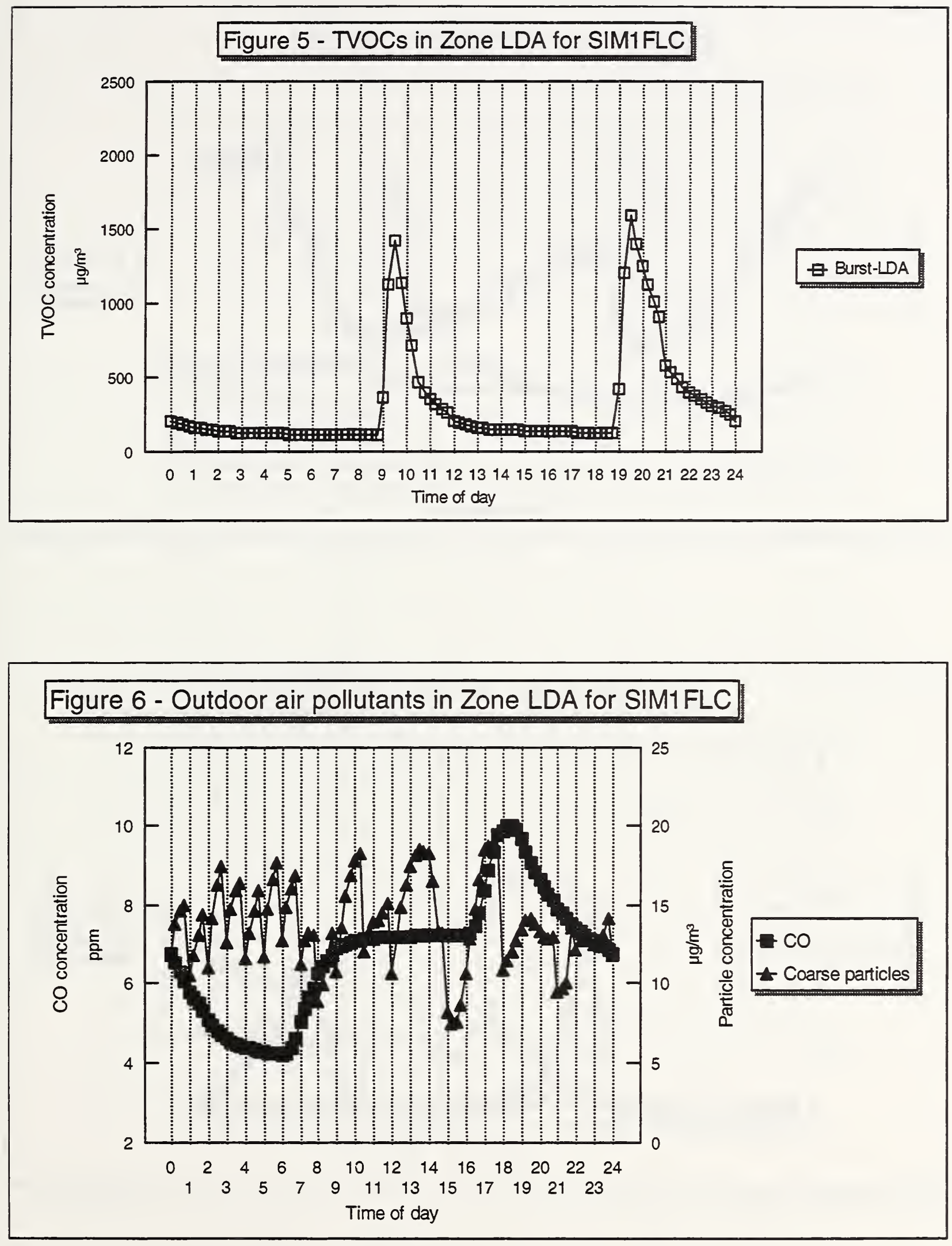

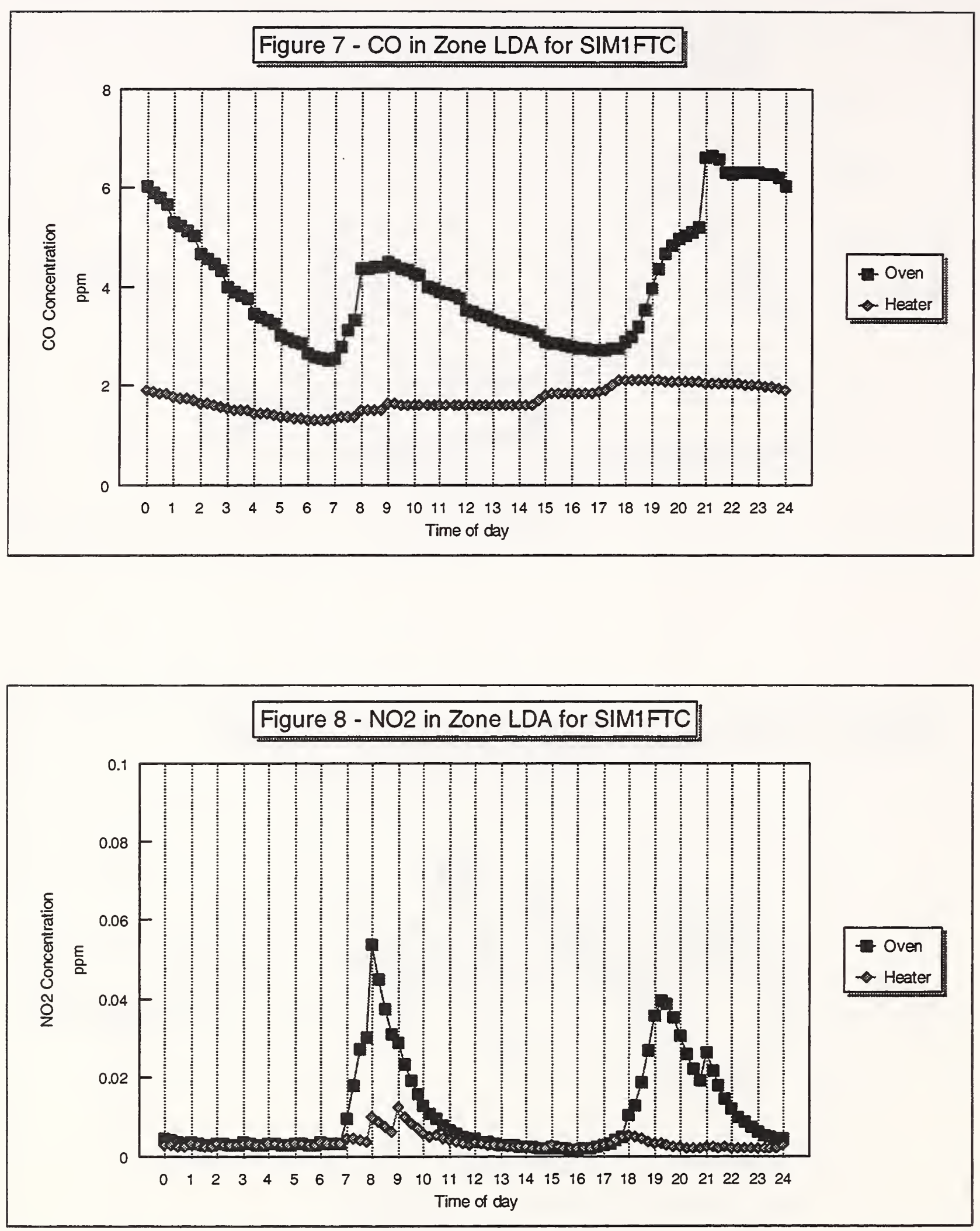

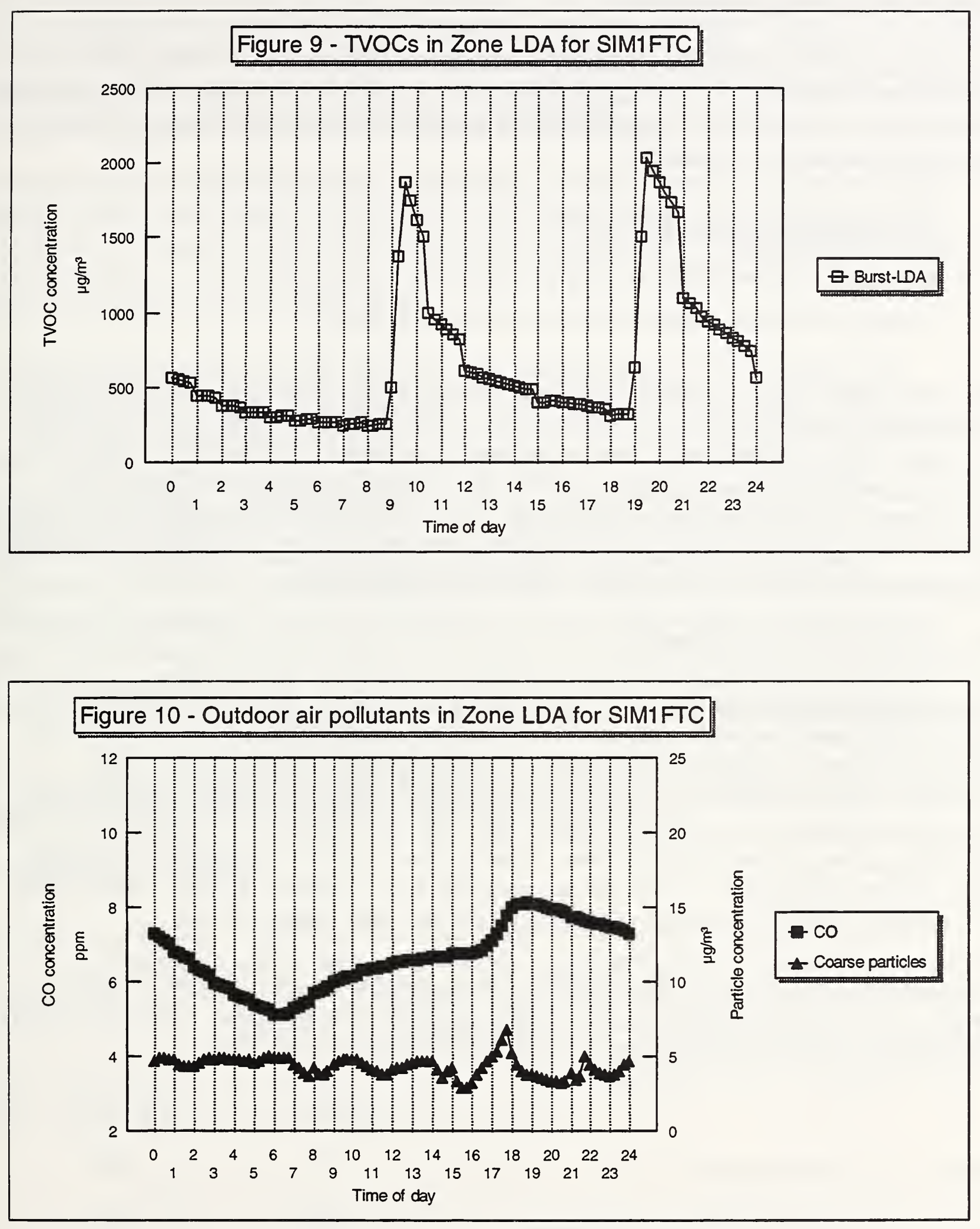


\section{Indoor Air Quality Controls}

This section describes the indoor air quality control technologies that will be evaluated in the study. These technologies will be incorporated into the baseline house models to determine their effectiveness in controlling the selected pollutant sources. The three technologies described in this section include the following:

\section{Electrostatic particulate filtration \\ Heat recovery ventilation}

Outdoor air intake damper on the forced-air system return

This section describes each of these technologies and includes revisions of the baseline house duct drawings. In addition, this section contains an estimate of the equipment and installation costs and a revision of the thermal load calculations based on the modifications. Finally, the impacts of each of these technologies on "other contaminants" are discussed. These other contaminants, as described in the original project work statement, include contaminants that have typically been of concern to designers of residential ventilation systems including cooking odors, tobacco smoke, moisture, outdoor pollen, outdoor odors, and ozone.

\section{Electrostatic Particulate Filtration}

The first IAQ control technology is increased particulate filtration through the installation of passive, electrostatic particulate filters. These filters were chosen based on the availability of performance data. In addition, the low pressure drop through these filters enables their installation without modification of the existing forced-air distribution system. The baseline houses are assumed to have standard furnace filters with an ASHRAE dust spot efficiency of less than $20 \%$ and an arrestance of $90 \%$. These values are based on tests conducted in accordance with ASHRAE Standard 52.1 (37). The increased filtration is based on the use of electrostatic filters with an ASHRAE dust spot efficiency of $30 \%$ and an arrestance of $95 \%$.

Although the efficiencies of particulate filters change over time as they become loaded, the computer simulations in this project will employ a constant filter efficiency. The efficiencies of the baseline and improved filters used in the simulations will be as follows:

$$
\text { Baseline Control \#1 }
$$

Particles $<2.5 \mu \mathrm{m}$ in diameter $\quad 5 \% \quad 30 \%$

Particles between 2.5 and $10 \mu \mathrm{m}$ in diameter $\quad 90 \% \quad 95 \%$

The improved filters are installed in place of the regular furnace filters. Their location is indicated in the revised duct drawings showing all of the IAQ control technologies, Figures 13 through 16. 
The installation of the improved filters are assumed not to affect the thermal loads of the houses. Due to a higher pressure drop through the filters, they may cause a slight reduction in the airflow rate through the system, which could affect the pressures across the building envelope and the resultant building infiltration rates. However, this effect is expected to be small, and the thermal load calculations were not modified for this control technology.

The cost of this first control technology includes the cost of the filters themselves and their installation. For comparison, the furnace filters in the baseline houses are assumed to cost $\$ 2$ each and to be changed every month. Therefore, the annual cost of the baseline filters is $\$ 24$. The improved filters are assumed to cost $\$ 15$ each and to be changed every 2 months. Therefore, the annual cost of the improved filters is $\$ 90$.

The installation of improved filters will reduce the concentrations of the so-called "other contaminants" in the houses to the degree that the filtration of each contaminant is increased. The concentrations of particulate contaminants with outdoor sources (pollen) will be reduced due to the increased particulate filtration. The concentrations of VOCs associated with outdoor odors will not be decreased. The increased filtration will not affect indoor ozone levels due to outdoor sources, since ozone removal rates will be unaffected by the new filters. In addition, these electrostatic filters are not sources of ozone themselves. The concentrations of other contaminants with indoor sources will also be affected to the degree that the filtration of each contaminant is increased. The levels of cooking odors and tobacco smoke will be decreased based on the increased filter efficiency for both fine and coarse particulates. Indoor moisture levels will be unaffected by the new filters because the outdoor air change rates will not be affected and because the improved filters have no humidification or dehumidification impacts.

Electronic air cleaners are also of interest and may be investigated in follow-up work. The existence of reliable performance data is being investigated.

\section{Heat Recovery Ventilator}

The second IAQ control technology is the installation of a heat recovery ventilator (HRV) in conjunction with the forced-air distribution system. As seen in Figure 11, the device brings outdoor air into the building where it exchanges heat with an airstream leaving the return side of the forced air system. Under heating conditions, the outdoor air is warmed by the outgoing airstream, and under cooling the outdoor air is cooled. The outgoing airstream is exhausted to the outdoors after leaving the heat recovery ventilator. The airstream from outdoors flows into the return side of the forced-air system after leaving the HRV. 


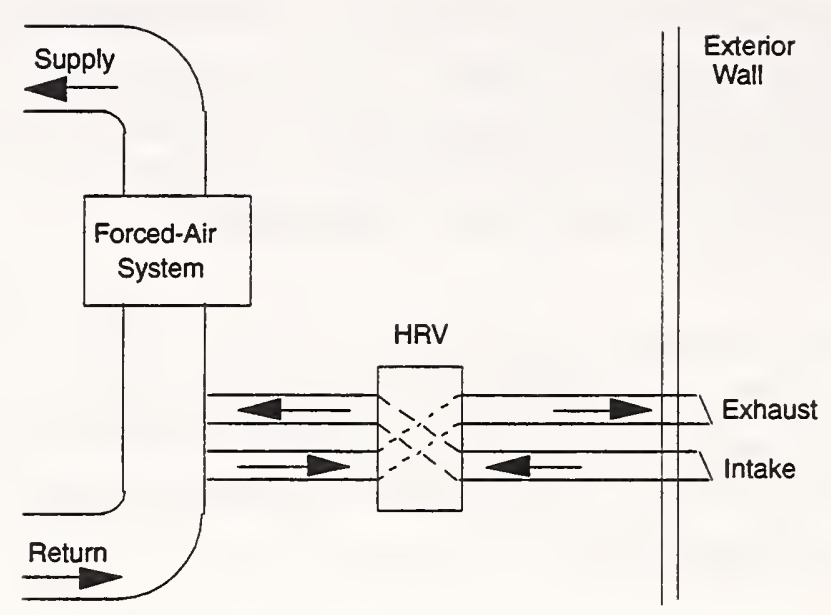

Figure 11 - Schematic of Heat Recovery Ventilator

The HRV specifications are based on a commercially-available model designed for residential use and installation in conjunction with forced-air systems. The airflow rate capacity of the device was selected to obtain an air change rate of at least 0.5 air changes per hour (ach) at full flow. The actual outdoor airflow rate during operation was selected to provide 0.35 ach through the HRV. The actual whole building air change rate will also include envelope infiltration, which in turn depends on the airtightness of the house, weather conditions and ventilation equipment operation. The HRV specifications for the four houses are as follows:

Miami, 2-story

Airflow capacity: 30 to $60 \mathrm{~L} / \mathrm{s}$ ( 65 to $127 \mathrm{cfm}$ ), roughly 0.25 to $0.5 \mathrm{ach}$ Airflow rate during operation: $44 \mathrm{~L} / \mathrm{s}(93 \mathrm{cfm})$

Efficiency: $69 \%$ at $0^{\circ} \mathrm{C}\left(32^{\circ} \mathrm{F}\right), 60 \%$ at $-25^{\circ} \mathrm{C}\left(-13^{\circ} \mathrm{F}\right)$

Maximum power consumption: $115 \mathrm{~W}$

No defrost

Miami, Ranch

Airflow capacity: 30 to $60 \mathrm{~L} / \mathrm{s}$ ( 65 to $127 \mathrm{~cm}$ ), roughly 0.4 to $0.8 \mathrm{ach}$

Airflow rate during operation: $26 \mathrm{~L} / \mathrm{s}(55 \mathrm{cfm})$

Efficiency: $69 \%$ at $0{ }^{\circ} \mathrm{C}\left(32^{\circ} \mathrm{F}\right), 60 \%$ at $-25^{\circ} \mathrm{C}\left(-13^{\circ} \mathrm{F}\right)$

Maximum power consumption: $115 \mathrm{~W}$

No defrost

Minneapolis, 2-story

Airflow capacity: 55 to $95 \mathrm{~L} / \mathrm{s}(115$ to $200 \mathrm{cfm})$, roughly 0.3 to 0.5 ach

Airflow rate during operation: $66 \mathrm{~L} / \mathrm{s}(140 \mathrm{cfm})$

Efficiency: $68 \%$ at $0{ }^{\circ} \mathrm{C}\left(32^{\circ} \mathrm{F}\right), 61 \%$ at $-25^{\circ} \mathrm{C}\left(-13^{\circ} \mathrm{F}\right)$

Maximum power consumption: $216 \mathrm{~W}$

Defrost cycle 
Minneapolis, Ranch

Airflow capacity: 30 to $70 \mathrm{~L} / \mathrm{s}$ ( 65 to $150 \mathrm{cfm}$ ), roughly 0.2 to $0.5 \mathrm{ach}$

Airflow rate during operation: $52 \mathrm{~L} / \mathrm{s}(110 \mathrm{cfm})$

Efficiency: $76 \%$ at $0{ }^{\circ} \mathrm{C}\left(32{ }^{\circ} \mathrm{F}\right), 56 \%$ at $-25^{\circ} \mathrm{C}\left(-13^{\circ} \mathrm{F}\right)$

Maximum power consumption: $105 \mathrm{~W}$

Defrost cycle

The defrost cycle involves closing the outdoor air dampers for 5 minutes when the outdoor temperature is below $-5^{\circ} \mathrm{C}\left(23^{\circ} \mathrm{F}\right)$. For outdoor temperatures between -5 and $-30^{\circ} \mathrm{C}(23$ and -22 ${ }^{\circ} \mathrm{F}$ ), each 5 -minute defrost cycle is followed by a 35 minute period of air exchange before the next defrost cycle. For outdoor temperatures below $-30^{\circ} \mathrm{C}\left(-22^{\circ} \mathrm{F}\right)$, each 5 -minute defrost cycle is followed by 20 minutes of air exchange.

The HRV can be operated in several different control modes. The operation of the device and the fan speed (high or low) can be controlled by a timer, manually by the occupant or by a dehumidistat.

The installation of the HRV in each of the four houses is indicated in the revised duct drawings in Figures 13 through 16.

The thermal loads of the houses are affected by the installation and operation of the HRV due to the increased outdoor air change rate of the house when the devices are in operation. The air change rate due to the HRV operation is assumed to be additive to the baseline infiltration rate of 0.75 ach assumed for the design thermal load calculations. The thermal loads are increased by only a fraction of the increased outdoor air change rate based on the heat exchange efficiencies of the devices. For an additional air change rate of 0.35 ach and the rated heat exchange efficiencies of the HRVs, the revised design thermal loads for the four houses are given below. The baseline design thermal loads are described in detail in the Phase I report (2).

$\begin{array}{ccc}\text { Miami, 2-story } & \text { Baseline } & \text { With HRV } \\ \text { Heating } & 2.87 \mathrm{~kW} & 3.14 \mathrm{~kW} \\ \text { Cooling } & 6.43 \mathrm{~kW} & 6.60 \mathrm{~kW} \\ & & \\ \text { Miami, Ranch } & \text { Baseline } & \text { With HRV } \\ \text { Heating } & 1.83 \mathrm{~kW} & 1.99 \mathrm{~kW} \\ \text { Cooling } & 5.76 \mathrm{~kW} & 5.88 \mathrm{~kW} \\ \text { Minneapolis, 2-story } & \text { Baseline } & \text { With HRV } \\ \text { Heating } & 12.64 \mathrm{~kW} & 13.59 \mathrm{~kW} \\ \text { Cooling } & 6.21 \mathrm{~kW} & 6.36 \mathrm{~kW} \\ \text { Minneapolis, Ranch } & & \\ \text { Heating } & \text { Baseline } & \text { With HRV } \\ \text { Cooling } & 9.25 \mathrm{~kW} & 9.86 \mathrm{~kW} \\ & 4.89 \mathrm{~kW} & 4.97 \mathrm{~kW}\end{array}$


The cost of the HRVs includes the cost of the equipment and installation, the operating costs for the fans in the devices and the increased energy consumption due to the additional outdoor air change of the building. The cost of the equipment is $\$ 500$ for both of the Miami houses, $\$ 600$ for the Minneapolis ranch house and $\$ 700$ for the Minneapolis two-story house. These are list prices from the manufacturer of the HRV on which the specifications are based. The installation costs are more variable, based on the layout of the house and local labor rates, and they can range from $\$ 200$ to $\$ 500$. The cost of the energy consumed by the device and by the additional outdoor air change rate requires detailed thermal modeling of the building and system. As discussed in the Phase I report of the project, such modeling is beyond the scope of this project.

The installation of the HRV will impact the so-called "other contaminants" in the houses due to the increased outdoor air change rate. Due to the additional outdoor airflow into the houses, the concentrations of contaminants with outdoor sources (pollen, outdoor odors and ozone) will increase. For a simple, nonreactive and unfiltered contaminant, there will be an increased contaminant load equal to the outdoor concentration multiplied by the outdoor airflow rate. The impact of particulates will be reduced based on the efficiency of the filters in the HRV and of the furnace filter. The impact of outdoor ozone will be reduced somewhat by losses on the interior surfaces of the HRV ductwork. The concentrations of other contaminants with indoor sources (cooking odors and tobacco smoke) will be reduced based on the increased air change rate of the building. The impact of the additional ventilation on moisture will depend on the building location, indoor moisture sources, and season. Indoor humidity levels will be reduced when there are large indoor sources and low relative humidity outdoors, but will be increased when the outdoor humidity is higher than the indoor level. Detailed modeling of moisture transport is required to assess these impacts and is beyond the scope of the current project.

\section{Outdoor Intake Duct}

The third IAQ control technology is the installation of an outdoor air intake duct on the return side of the forced air distribution system. As seen in Figure 12, the system consists of an intake, a duct, a motorized damper, and a volume damper for adjusting the airflow rate, and is connected to the return side of the return duct. The maximum airflow rate capacity of the intake is $78 \mathrm{~L} / \mathrm{s}$ $(165 \mathrm{cfm})$, which corresponds to the following air change rates for the four houses:

Miami, 2-story: $0.62 \mathrm{ach}$

Miami, Ranch: 1.05 ach

Minneapolis, 2-story: 0.41 ach

Minneapolis, Ranch: 0.53 ach 


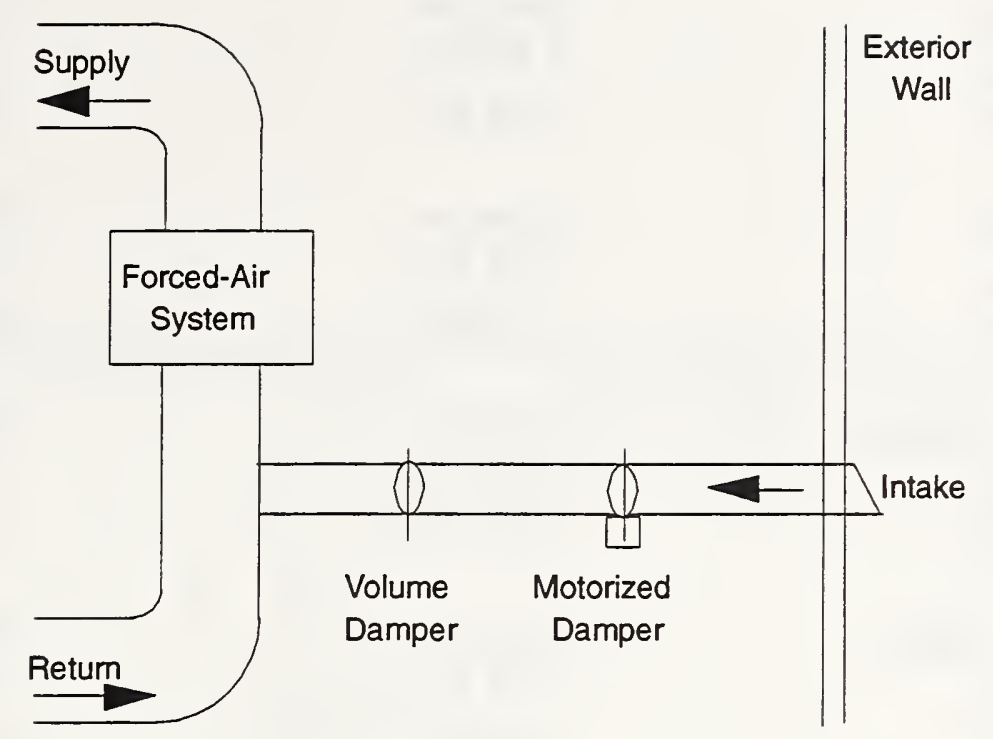

Figure 12 - Schematic of Outdoor Air Intake Duct

The actual airflow rate through the intake depends on the position of the volume damper, the overall airflow resistance of the intake system, and the pressure developed by the forced-air fan. In the computer simulations, it is assumed that the volume damper is adjusted such that the intake system provides 0.35 ach to the building when the furnace fan is in operation. This air change rate corresponds to the following outdoor air intake rates for the four buildings:
Miami, 2-story: $44 \mathrm{~L} / \mathrm{s}(93 \mathrm{cfm})$
Miami, Ranch: $26 \mathrm{~L} / \mathrm{s}(55 \mathrm{cfm})$
Minneapolis, 2-story: $66 \mathrm{~L} / \mathrm{s}(140 \mathrm{cfm})$
Minneapolis, Ranch: $52 \mathrm{~L} / \mathrm{s}(110 \mathrm{cfm})$

The motorized damper can be controlled in several different ways. It is generally interlocked with the forced-air system fan so that it opens only when the forced-air fan is operating. The motorized damper can also be controlled to open based on a timer, dehumidistat or pollutant (e.g. carbon monoxide or carbon dioxide) sensor.

The installation of the outdoor air intake duct in each of the four houses is indicated in the revised duct drawings in Figures 13 through 16.

The thermal loads of the houses are affected by the installation and operation of the outdoor air intake duct due to the increased outdoor air change rate of the house when the devices are in operation. The air change rate due to the HRV operation is assumed to be additive to the baseline infiltration rate of 0.75 ach assumed for the design thermal load calculations. Based on an additional air change rate of 0.35 ach and no heat exchange, the design thermal loads for the four houses are given below. The baseline thermal loads were described in detail in the Phase I report (2). 


$\begin{array}{ccc}\text { Miami, 2-story } & \text { Baseline } & \text { With OAID } \\ \text { Heating } & 2.87 \mathrm{~kW} & 3.54 \mathrm{~kW} \\ \text { Cooling } & 6.43 \mathrm{~kW} & 6.96 \mathrm{~kW} \\ & & \\ \text { Miami, Ranch } & \text { Baseline } & \text { With OAID } \\ \text { Heating } & 1.83 \mathrm{~kW} & 2.23 \mathrm{~kW} \\ \text { Cooling } & 5.76 \mathrm{~kW} & 6.09 \mathrm{~kW} \\ \text { Minneapolis, 2-story } & \text { Baseline } & \text { With OAID } \\ \text { Heating } & 12.64 \mathrm{~kW} & 15.00 \mathrm{~kW} \\ \text { Cooling } & 6.21 \mathrm{~kW} & 6.71 \mathrm{~kW} \\ \text { Minneapolis, Ranch } & & \\ \text { Heating } & \text { Baseline } & \text { With OAID } \\ \text { Cooling } & 9.25 \mathrm{~kW} & 10.73 \mathrm{~kW} \\ & 4.89 \mathrm{~kW} & 5.18 \mathrm{~kW}\end{array}$

The cost of the outdoor air intake duct includes the cost of the equipment and installation and the increased energy consumption due to the additional outdoor air change of the building. The cost of the equipment, including the controls and the motorized dampers, is $\$ 750$ based on list prices from the manufacturer of the outdoor air intake duct on which the specifications are based. The installation costs are more variable, based on the layout of the house and local labor rates, and they can range from $\$ 100$ to $\$ 300$. The cost of the energy consumed by the device and by the additional outdoor air change rate requires detailed thermal modeling of the building and system. As discussed in the Phase I report of the project (2), such modeling is beyond the scope of this project.

The installation of the outdoor air intake duct will impact the so-called "other contaminants" in the houses. Due to the additional outdoor airflow into the houses, the concentrations of contaminants with outdoor sources (pollen, outdoor odors and ozone) will increase. For a simple, nonreactive and unfiltered contaminant, the impact will be an increased contaminant load equal to the outdoor concentration multiplied by the outdoor airflow rate. The impact of particulates will be lessened based on the removal efficiency of the furnace filter. The impact of ozone will be lessened by losses on the interior surfaces of the ductwork. The concentrations of other contaminants with indoor sources (cooking odors and tobacco smoke) will be reduced based on the increased air change rate of the building. As in the case of the HRV, the impact of the additional ventilation on moisture will depend on the building location, indoor moisture sources, and season. 


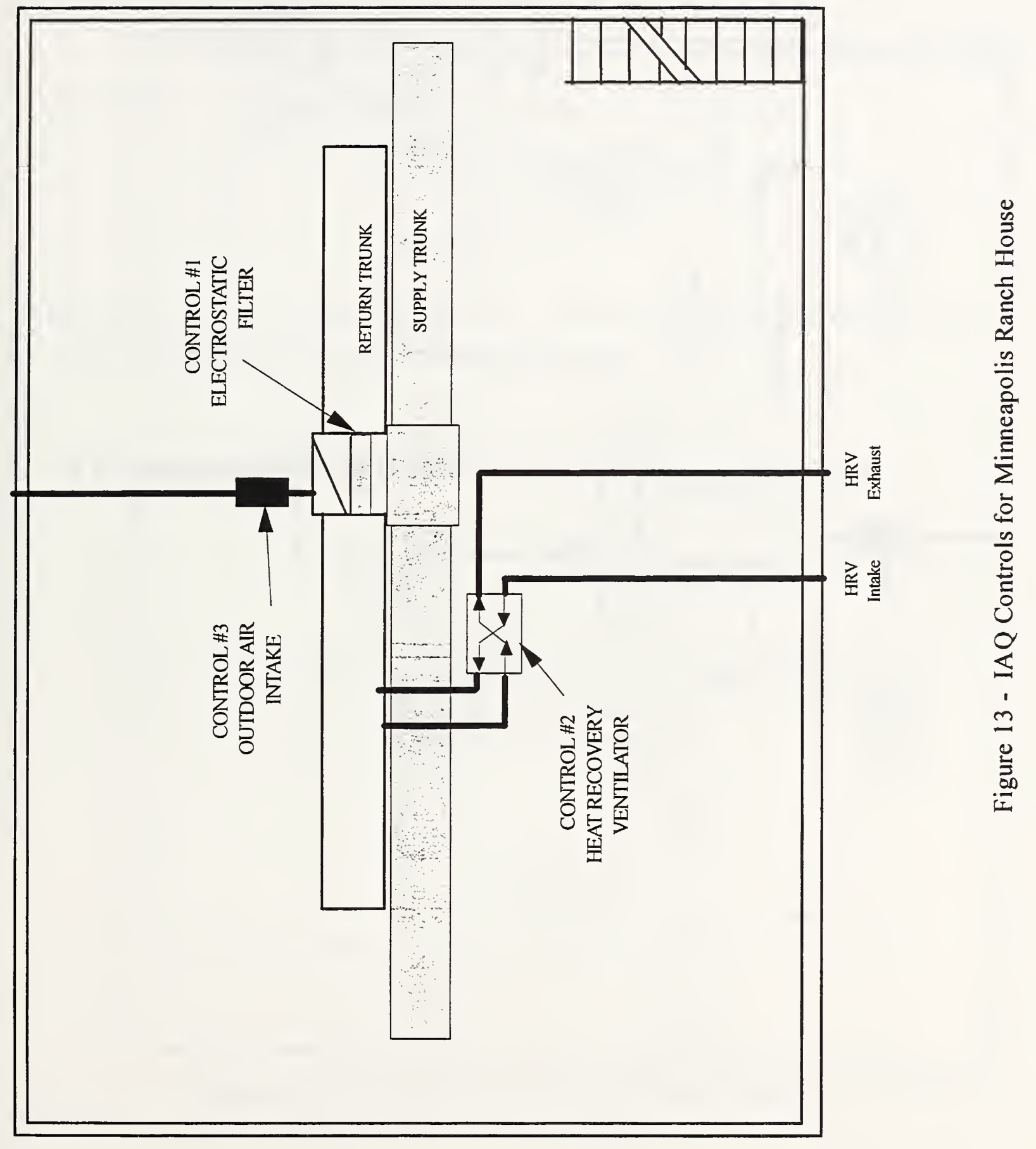




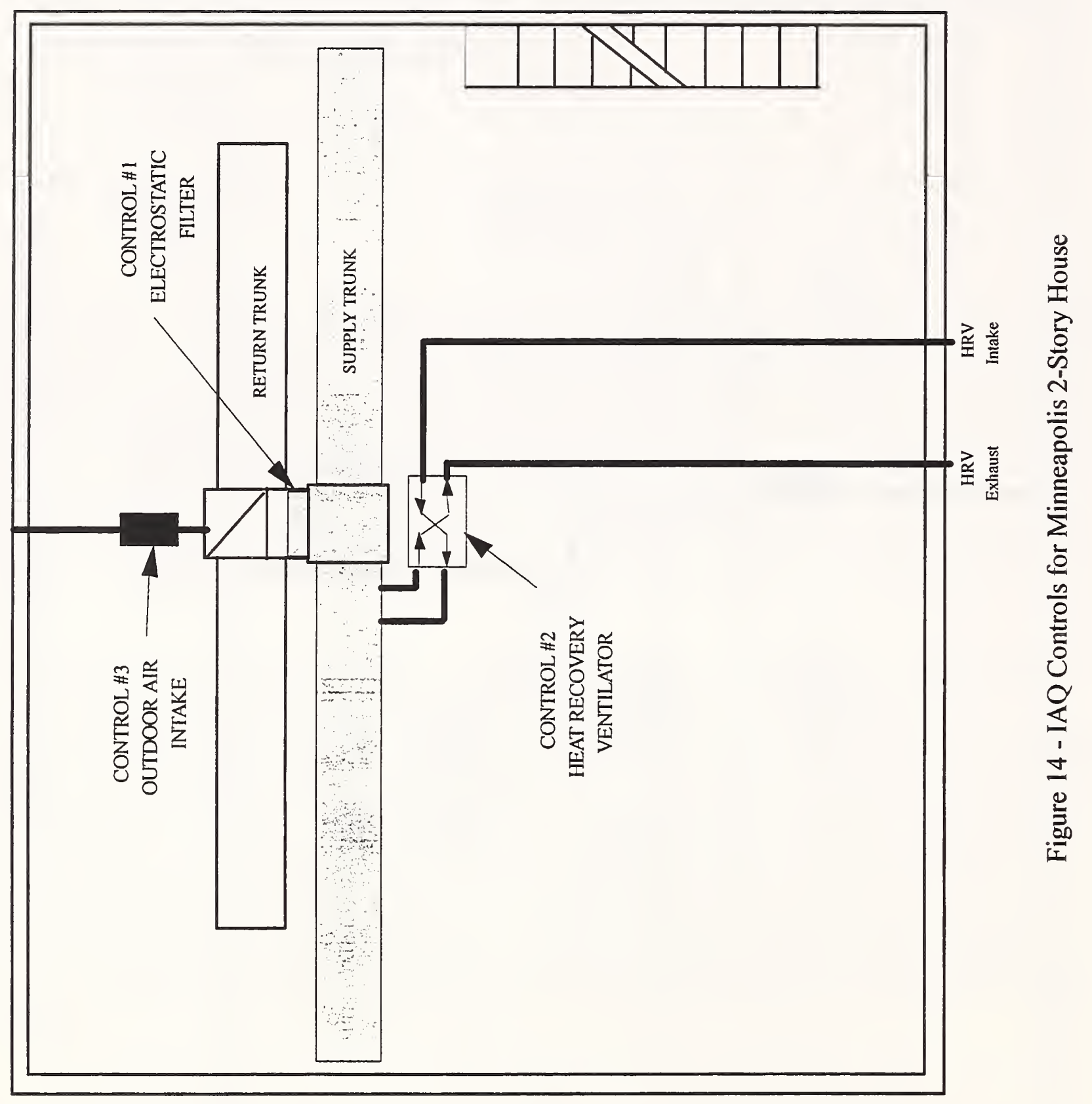



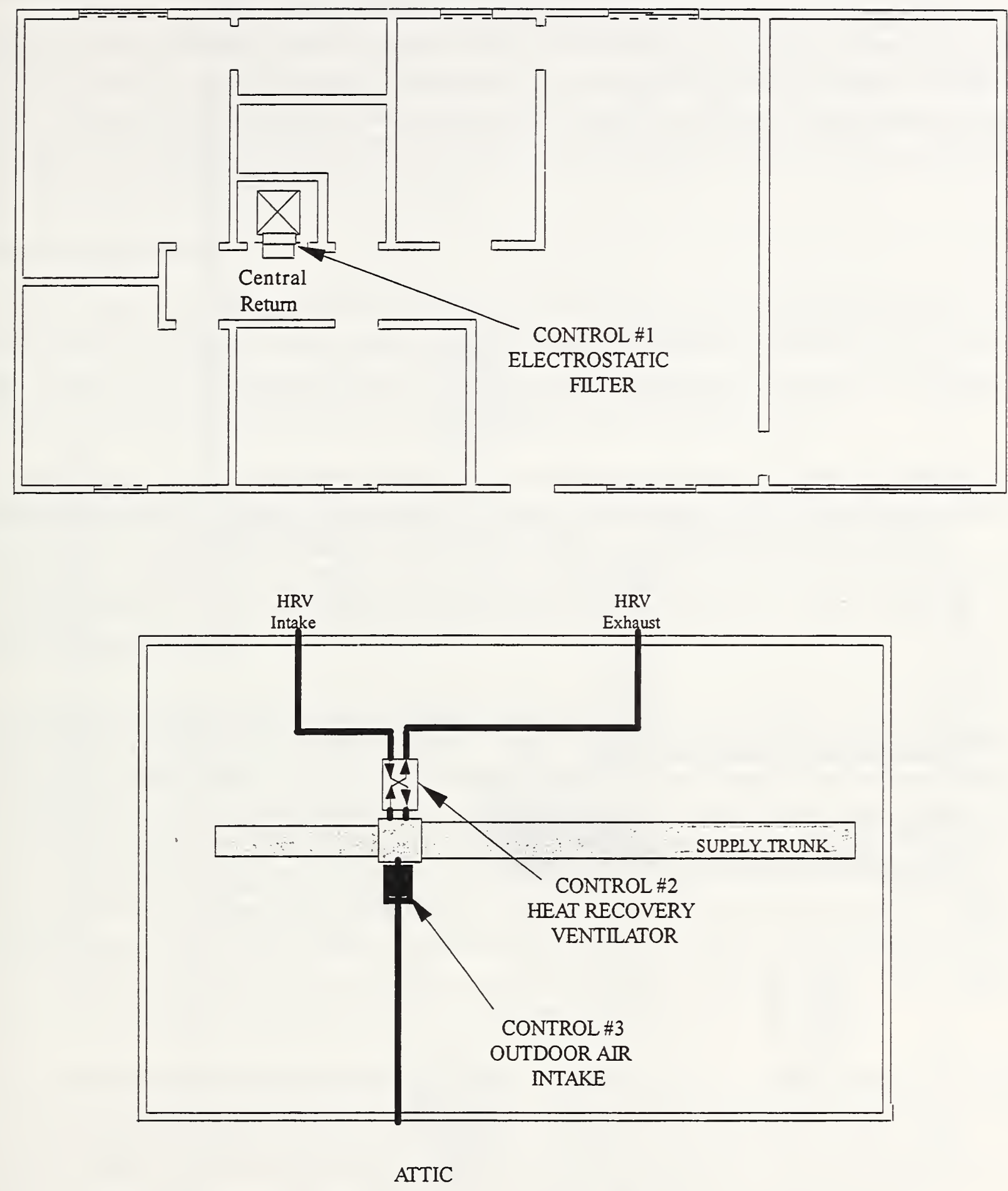

Figure 15 - IAQ Controls for Miami Ranch House 


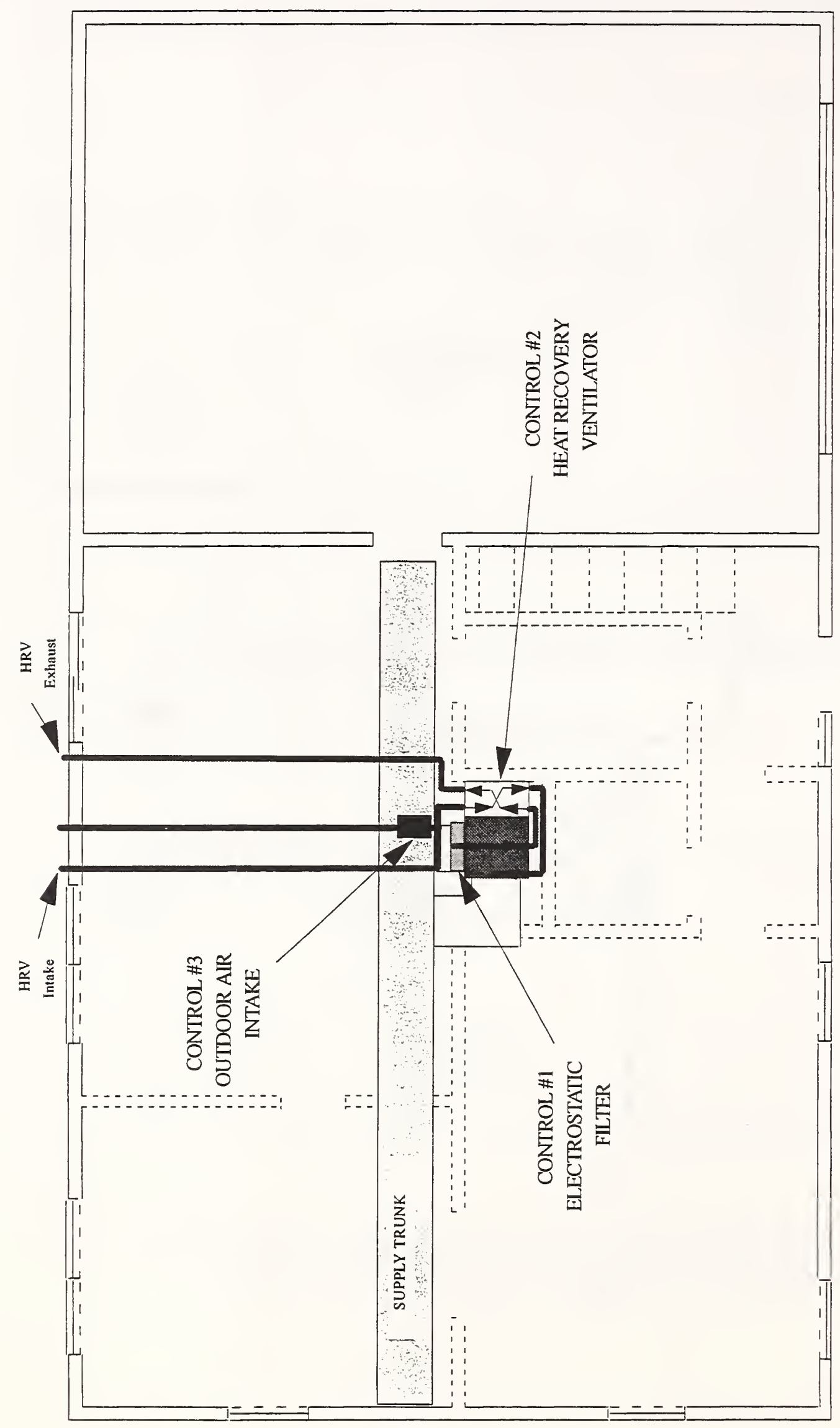

 


\section{Preliminary Simulation of IAQ Control Retrofits}

This section describes the preliminary simulations of the IAQ control retrofits. These simulations involved modifying selected baseline simulation cases with the IAQ control retrofits described above. The preliminary simulations were performed to verify the ability of the program to model the control technologies. In Phase II.B of the study, all of the baseline cases will be modified to incorporate each of the IAQ control retrofits.

\section{IAQ Control Retrofits}

The IAQ control retrofits selected for modeling in this study are an electrostatic particulate filter, a heat recovery ventilator, and an outdoor air intake damper installed on the forced-air system return. These three technologies were described in detail in the previous section. This section discusses only the details important to modeling them with CONTAM93 (1).

The electrostatic particulate filters selected for the study have a filter efficiency of $30 \%$ for fine particles (emitted by the combustion sources in these simulations) and $95 \%$ for coarse particles (associated with the elevated outdoor air concentrations). The filters will be modeled by replacing the standard furnace filters in the baseline HVAC systems with the electrostatic filters. The filter efficiency will be modeled as constant over time and impacts on airflow through the system will be neglected.

The second IAQ control retrofit is the installation of a heat recovery ventilator (HRV) in conjunction with the HVAC system. The HRV draws air from the return side of the forced-air system and replaces it with outdoor air drawn through the heat exchanger. The outdoor airflow rate supplied will be $44 \mathrm{~L} / \mathrm{s}$ for the Miami 2-story house, $26 \mathrm{~L} / \mathrm{s}$ for the Miami ranch house, 66 $\mathrm{L} / \mathrm{s}$ for the Minneapolis 2-story house, and $52 \mathrm{~L} / \mathrm{s}$ for the Minneapolis ranch house. The HRV will be modeled by setting the outdoor airflow rate for each HVAC system to the appropriate fraction of the total system supply airflow rate. Thus, the desired amount of outdoor air will be supplied whenever the HVAC system is operating. The HVAC systems will be operated on the same schedules determined for the baseline simulations based on thermal loads. Other possible control options (such as constant operation or demand control) will not be studied.

Other considerations in modeling the HRV include filtration of the incoming outdoor air and the $\mathrm{HRV}$ defrost cycle. A standard furnace filter (with efficiencies of $5 \%$ for fine particles and $90 \%$ for coarse particles) will be included in the outdoor air intake path of the HRV. The HRV employs a defrost cycle in cold weather which involves periodically closing the outdoor air damper. However, operation of the defrost cycle will be neglected in the simulations.

The third IAQ control retrofit is the installation of an outdoor air intake duct on the return side of the HVAC system, which draws outdoor air into the return side of the forced-air system whenever it is operating. This retrofit will be modeled similar to the HRV. The baseline HVAC system will be modified to include a constant fraction of outdoor air whenever the HVAC system is operating. The outdoor air supply airflow rates will be the same as listed above for the HRV, and a standard furnace filter will be included in the outdoor air intake path. The primary 
difference between the outdoor air intake damper and the HRV is that the outdoor air intake damper does not include an exhaust duct. Therefore, the outdoor airflow will tend to pressurize the house. This effect will be modeled by reducing the HVAC return flows by an amount equal to the outdoor air supplied to the system.

\section{Results of Preliminary Simulation of IAQ Control Retrofits}

The baseline case selected for modification with the IAQ control retrofits was SIM1FLC, the Miami ranch house with typical airtightness in cold weather. The simulations with the electrostatic particulate filtration, the HRV, and the outdoor air intake damper are referred to as SIM1FLCF, SIM1FLCH, and SIM1FLCO, respectively.

The results of each simulation includes pollutant concentrations for up to 18 pollutants in each of the building zones for each 15 minute time step of the 24 hour simulation period. As was the case for the baseline simulations, the complete transient simulation results are not presented here but are available in spreadsheet files. Figures 17 through 20 show examples of the transient pollutant concentrations and Tables 25a through 27e of Appendix B present a complete summary of peak and 24-hour, 4-hour, and 1-hour average concentrations for the preliminary IAQ control retrofit simulations as described for the baseline simulations.

Figure 17 shows total volatile organic compound (TVOC) concentrations in Zone LDA resulting from the constant floor source (VOC2 of Tables 1, 26, and 27 of Appendix B) for SIM1FLC, SIM1FLCH, and SIM1FLCO. Since SIM1FLCF differs from SIM1FLC by improved particle filtration efficiency, all VOC concentrations in SIM1FLCF are identical to SIM1FLC and are not shown. Both outdoor air intake devices result in modest reductions in the TVOC concentrations in the zone, with the HRV having a slightly greater effect. The HRV may have a greater effect because it has a neutral effect on indoor pressure (compared to the outdoor air intake damper which pressurizes the building) resulting in a greater average air change rate. The 24-hour average TVOC concentration in Zone LDA is $6040 \mu \mathrm{g} / \mathrm{m}^{3}, 5545 \mu \mathrm{g} / \mathrm{m}^{3}$, and $5720 \mu \mathrm{g} / \mathrm{m}^{3}$ for SIM1FLC, SIM1FLCH, and SIM1FLCO, respectively (see Tables 1c, 26c, and 27c of Appendix B).

Figure 18 shows TVOC concentrations in Zone LDA resulting from a burst VOC source in the garage (VOC5 of Tables 1, 26, and 27 of Appendix B). The VOC concentrations for SIM1FLC and SIM1FLCH are nearly identical while the concentrations for SIM1FLCO are somewhat lower. The 24 hour average TVOC concentration in Zone LDA for this source is $141 \mu \mathrm{g} / \mathrm{m}^{3}, 140$ $\mu \mathrm{g} / \mathrm{m}^{3}$, and $132 \mu \mathrm{g} / \mathrm{m}^{3}$ for SIM1FLC, SIM1FLCH, and SIM1FLCO, respectively (see Tables $1 \mathrm{c}$, $26 \mathrm{c}$, and 27c of Appendix B). The slightly reduced concentrations for SIM1FLCO is due to the effect of the outdoor air pressurizing the interior of the house which reduces the transport of the contaminant from the garage.

Figure 19 shows fine particle concentrations in the kitchen resulting from the oven source (PART.1 of Tables 1, 25, 26, and 27 of Appendix B). The improved filtration in case SIM1FLCF resulted in lower concentrations while the outdoor air intake devices had very little impact, possibly because the outdoor air particle concentration of $13 \mu \mathrm{g} / \mathrm{m}^{3}$ is close to the 24 hour 
average baseline concentration. The 24 hour average fine particle concentration in Zone KIT is $11.4 \mu \mathrm{g} / \mathrm{m}^{3}, 9.8 \mu \mathrm{g} / \mathrm{m}^{3}, 11.6 \mu \mathrm{g} / \mathrm{m}^{3}$, and $11.6 \mu \mathrm{g} / \mathrm{m}^{3}$ for SIM1FLC, SIM1FLCF, SIM1FLCH, and SIM1FLCO, respectively (see Tables 1c, 25c, 26c, and 27c of Appendix B).

Figure 20 shows coarse particle concentrations in Zone LDA resulting from elevated outdoor levels (PART.3 of Tables 1, 25, 26, and 27 of Appendix B). None of the IAQ control retrofits resulted in a significant impact on the coarse particle concentrations. The 24 hour average coarse particle concentration in Zone LDA is $13.7 \mu \mathrm{g} / \mathrm{m}^{3}, 13.6 \mu \mathrm{g} / \mathrm{m}^{3}, 13.8 \mu \mathrm{g} / \mathrm{m}^{3}$, and $13.5 \mu \mathrm{g} / \mathrm{m}^{3}$ for SIM1FLC, SIM1FLCF, SIM1FLCH, and SIM1FLCO, respectively (see Tables 1c, 25c, 26c, and 27c of Appendix B). Possible explanations for the small changes include the relatively small increase in filtration efficiency for the electrostatic particulate filter (from $90 \%$ to $95 \%$ ) and the inclusion of a standard filter in the outdoor air intake path for both the HRV and the outdoor air intake damper. The outdoor air intake filter limits the number of particles brought in with the outdoor air. 

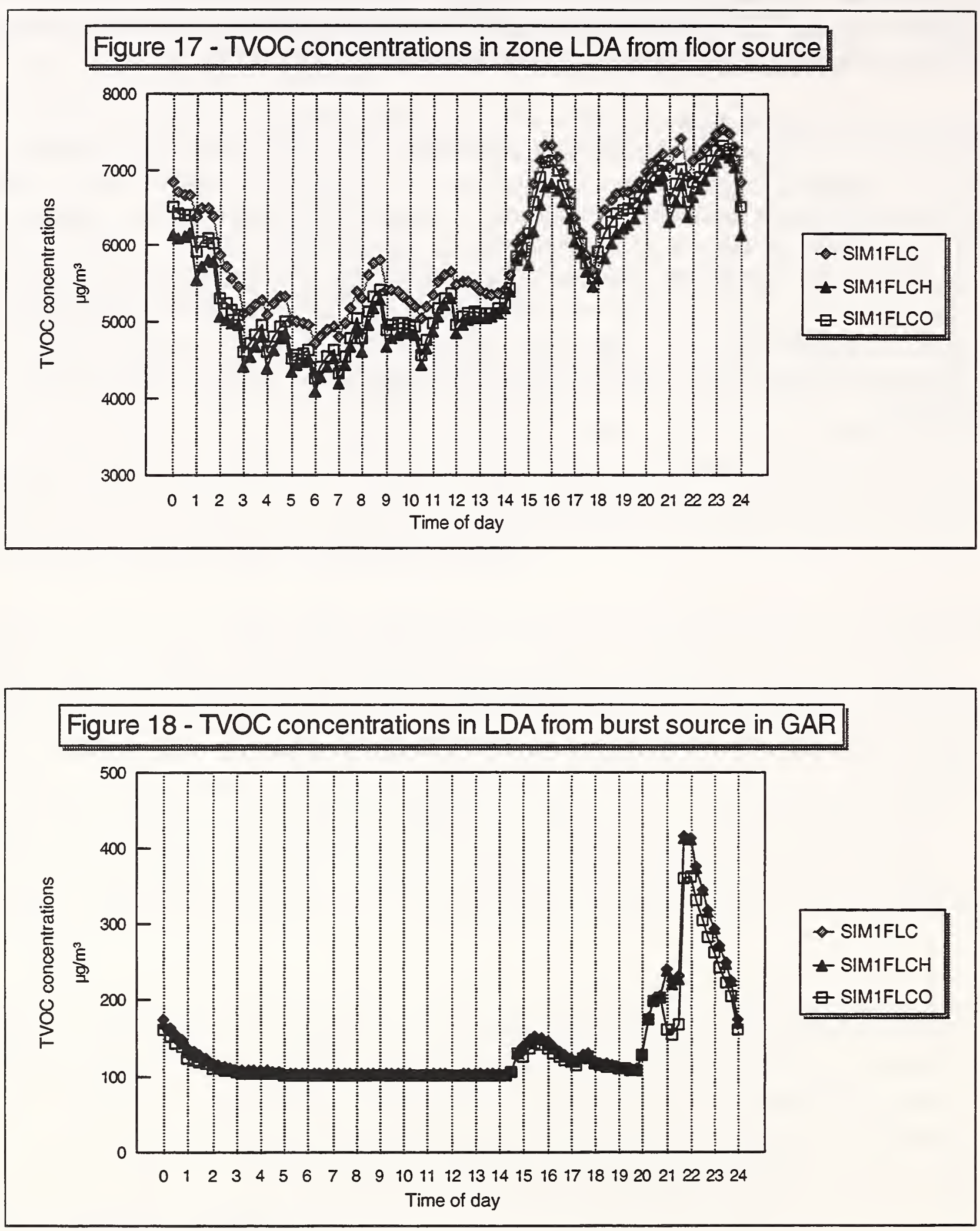


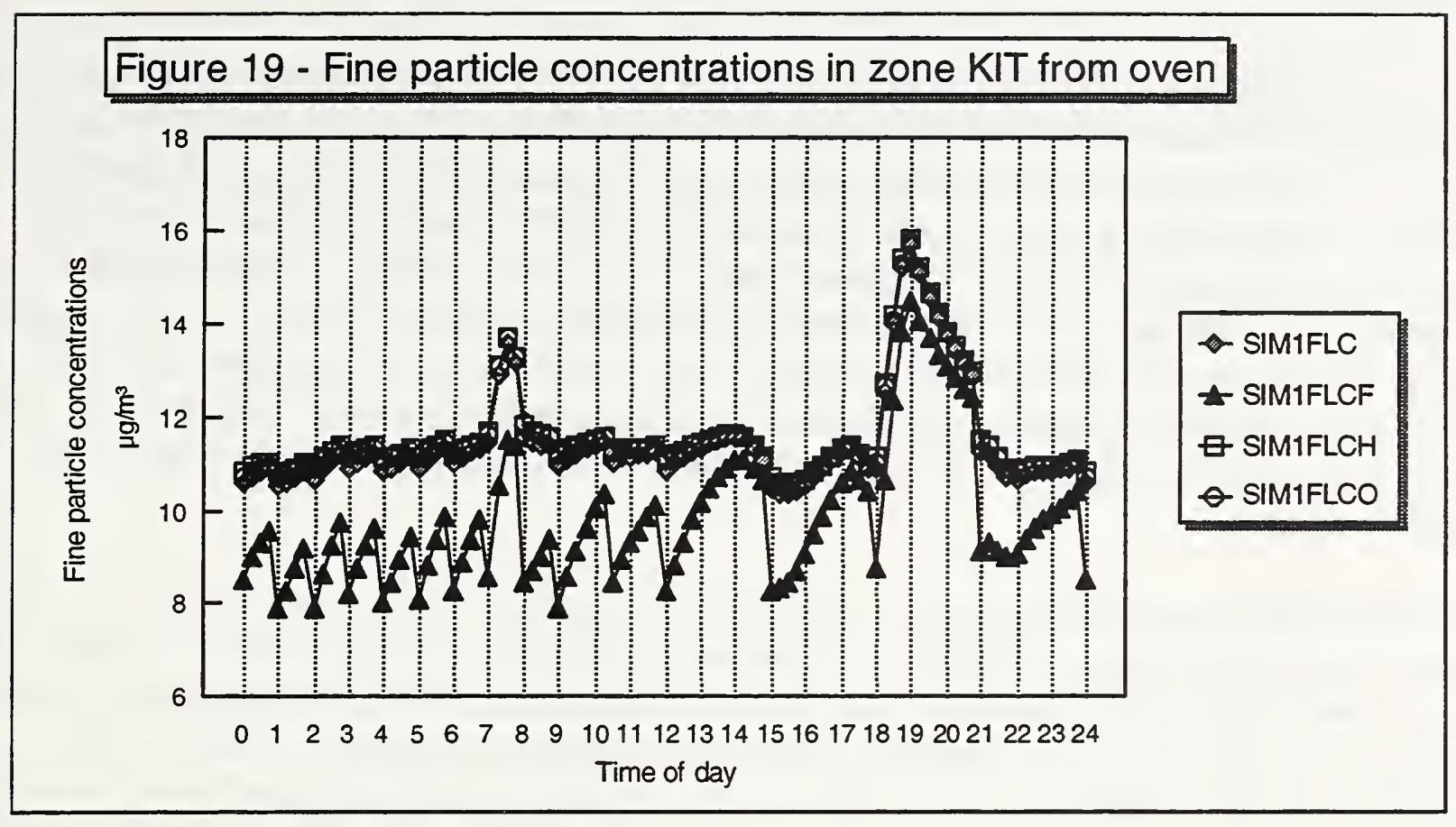

Figure 20 - Coarse particle concentrations in LDA from elevated outdoor levels

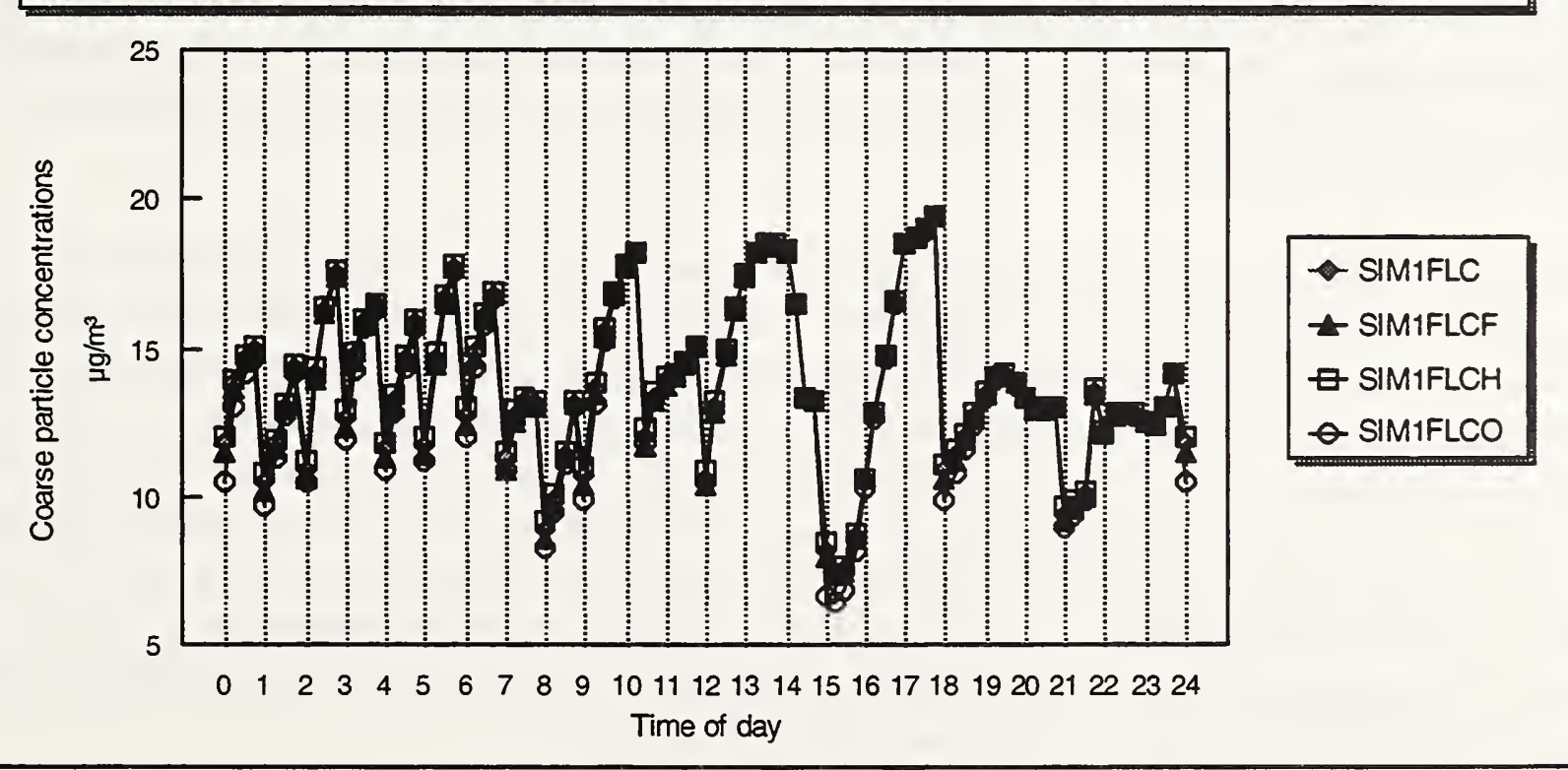




\section{Summary}

The National Institute of Standards and Technology (NIST) has completed Phase II.A of a project for the U.S. Consumer Product Safety Commission (CPSC) to study the impact of HVAC systems on residential indoor air quality and to assess the potential for using residential forced-air systems to control indoor pollutant levels. In this effort, NIST is performing whole building airflow and contaminant dispersal computer simulations with the program CONTAM93 to assess the ability of modifications of central forced-air heating and cooling systems to control pollutant sources relevant to the residential environment. During Phase II.A of this project, three major efforts were completed: baseline simulations of contaminant levels without IAQ controls, design of the IAQ control retrofits, and preliminary simulations of contaminant levels with the IAQ control retrofits.

It is important to note that the project is essentially a scoping study to conduct a preliminary assessment, using computer simulation, of the potential for using forced-air HVAC systems to improve residential IAQ. The project results are also limited by the lack of high quality input data for some simulation inputs and the lack of a thorough empirical evaluation of the model's predictive capability. Despite these limitations, the project is expected to identify key issues for further analysis and experimental work to meet the overall goal of cost-effective IAQ control in residential buildings.

This report described the input data used to model the baseline houses with CONTAM93 including the configuration of the building zones, the air leakage of the building envelopes and of interior partitions, wind pressure profile on the building envelope, pollutant source strengths and temporal profiles, heating and cooling system flows, furnace filter efficiency, pollutant sinks, pollutant decay or deposition, and ambient weather and pollutant concentrations. The results of the baseline simulations including transient pollutant concentrations for selected simulations and a summary of peak and average concentrations for all baseline simulations were also presented. It should be noted that the results for any one simulation may be counter-intuitive and should not be generalized to all cases.

Three indoor air quality control technologies were then selected for incorporation into the baseline house models to determine their effectiveness in controlling the modeled pollutant sources. The technologies selected include the following: an electrostatic particulate filter with efficiencies of $30 \%$ for fine particles and $95 \%$ for coarse particles, a heat recovery ventilator (HRV) providing an actual outdoor airflow of $0.35 \mathrm{ach}$, and an outdoor air intake damper on the forced-air system return also providing an actual outdoor airflow of 0.35 ach. The annual cost of the filters was estimated at $\$ 90$. The estimated installation and equipment costs of the HRV and of the outdoor air intake duct were $\$ 700$ to $\$ 1200$ and $\$ 850$ to $\$ 1050$, respectively. Detailed thermal modeling of the building and system would be required to determine the annual energy costs of these devices and is beyond the scope of this project.

Selected baseline cases were then modified to implement these IAQ control retrofits and preliminary simulations were performed to verify the ability of the program to model the control technologies. The results for the IAQ control retrofits are presented as examples only and are not 
intended to be used to evaluate the effectiveness of the controls. In Phase II.B of the study, all of the baseline cases will be modified to incorporate each of the IAQ control retrofits. The Phase II.B simulation results will be compared to the baseline simulation results to determine the effectiveness of the IAQ control technologies at reducing contaminant levels in single-family residential buildings. 


\section{References}

1. Walton GN. CONTAM93 - User Manual (1994) NISTIR 5385, National Institute of Standards and Technology.

2. Emmerich SJ and Persily AK. Indoor Air Quality Impacts of Residential HVAC Systems Phase I Report: Computer Simulation Plan (1994) NISTIR 5346, National Institute of Standards and Technology.

3. ASHRAE. 1993 Handbook of Fundamentals (1993) American Society of Heating, Refrigerating, and Air-Conditioning Engineers, Inc.

4. Strathopoulos T, Chiovitti D, and Dodaro L. "Wind Shielding Effects of Trees on Low Buildings" (1994) Building and Environment 29:141-150.

5. Walker IS and Wilson DJ. "Practical Methods for Improving Estimates of Natural Ventilation Rates" (1994) Proceedings of the 15th AIVC Conference.

6. Klote JH and Milke JA. Design of Smoke Management Systems (1992) American Society of Heating, Refrigerating, and Air-Conditioning Engineers, Inc. and Society of Fire Protection Engineers.

7. Shaw CY, Magee RJ, and Rousseau J. "Overall and Component Airtightness Values of a Five-story Apartment Building (1991) ASHRAE Transactions, Vol. 97, Pt. 2.

8. Cummings JB, Tooley, Jr. JJ, Moyer N. Investigation of Air Distribution System Leakage and Its Impact in Central Florida Homes - Final Report (1991) Report No. FSEC-CR-397-91, Florida Solar Energy Center.

9. Yingling RK, Luebs DF, and Johnson RJ. Residential Duct Systems - Selection and Design of Ducted HVAC Systems (1981) National Association of Home Builders of the United States.

10. Crow LW. Development of hourly data for weather year for energy calculations (WYEC), including solar data, at 29 stations throughout the United States and 5 stations in southern Canada (1983) ASHRAE RP 364, Bulletin.

11. EPA. National Air Quality and Emissions Trends Report, 1992 (October 1993) U.S. Environmental Protection Agency.

12. EPA. Air Quality Criteria for Carbon Monoxide (December 1991) U.S. Environmental Protection Agency.

13. EPA. Air Quality Criteria for Oxides of Nitrogen, Volume I of III (August 1993) U.S. Environmental Protection Agency. 
14. Leslie NP, Ghassan PG and Krug EK. Baseline Characterization of Combustion Products at the GRI Conventional Research House (1988) GRI-89/0210, Gas Research Institute.

15. Sinclair JD, Psota-Kelty LA, Weschler CJ and Shields HC. "Measurement and Modeling of Airborne Concentrations and Indoor Surface Accumulation Rates of Ionic Substances at Neenah, Wisconsin" (1990) Atmospheric Environment 24A:627-638.

16. Shields HC and Fleischer DM. VOC Survey: Sixty-eight Telecommunication Facilities (1993) Proceedings of Indoor Air '93, Vol. 2.

17. Colombo A, de Bortoli M, Pecchia E, Schauenburg H, Schlitt H and Vissers H. "Chamber Testing of Organic Emission from Building and Furnishing Materials" (1990) The Science of the Total Environment 91:237-249.

18. Saarela $\mathrm{K}$ and Sandell E. "Comparative Emission Studies of Flooring Materials with Reference to Nordic Guidelines" (1991) Proceedings of ASHRAE IAQ 91.

19. DOE. Indoor Air Quality Environmental Information Handbook: Combustion Sources (1990) DOE/EH/79079-H1, U.S. Department of Energy.

20. Hoag M and Cade D. "Particleboard and MDF VOC Emissions Testing" (1994) presented at the 28th International Particleboard/Composite Materials Symposium.

21. Tichenor BA and Guo Z. "The Effect of Ventilation on Emission Rates of Wood Finishing Materials" (1991) Environment International 17:317-323.

22. Axley JW. "Adsorption Modeling for Macroscopic Contaminant Dispersal Analysis" (1990) NIST-GCR-90-573, National Institute of Standards and Technology.

23. Chang JCS and Guo Z. "Modeling of Alkane Emissions from a Wood Stain" (1993) Proceedings of Indoor Air '93, Vol. 2.

24. Lee K, Yanagisawa Y, Spengler JD, and Billick IH. "Determination of Nitrogen Dioxide Generation and Decay Rates using Mass Balance Model" (1993) Proceedings of Indoor Air '93, Vol. 3.

25. Leslie NP and Billick IH. "Examination of Combustion Products in an Unoccupied Research House" (1990) Proceedings of Indoor Air '90.

26. Ozkaynak H, Ryan PB, Allen GA, and Turner WA. "Indoor Air Quality Modeling: Compartmental Approach with Reactive Chemistry" (1982) Environment International 8:461-471. 
27. Borrazzo JE, Osborn JF, Fortmann RC, Keefer RL, and Davidson CI. "Modeling and Monitoring of CO, $\mathrm{NO}$ and $\mathrm{NO}_{2}$ in a Modern Townhouse" (1987) Atmospheric Environment $21: 299-311$.

28. Spicer CW, Coutant RW, Ward GF, Joseph DW, Gaynor AJ, and Billick IH. "Rates and Mechanisms of NO2 Removal from Indoor Air by Residential Materials" (1989) Environment International 15:643-654.

29. Tamura GT. "Measurement of Combustion Products from Kerosene Space Heaters in a Two-Story House" (1987) ASHRAE Transactions V. 94, Pt. 1.

30. Traynor GW, Apte MG, Carruthers AR, Dillworth JF, Grimsrud DT, and Gundel LA. "Indoor Air Pollution due to Emissions from Wood-Burning Stoves" (1987) Environ. Sci. Technol. 21:691-697.

31. Offerman FJ, Sextro RG, Fisk WJ, Grimsrud DT, Nazaroff WW, Nero AV, Revzan KL, and Yater J. "Control of Respirable Particles in Indoor Air with Portable Air Cleaners" (1985) Atmospheric Environment 19:1761-1771.

32. Sinclair JD, Psota-Kelty LA, and Weschler CJ. "Indoor/outdoor Ratios and Indoor Surface Accumulations of Ionic Substances at Newark, New Jersey" (1988) Atmospheric Environment 22:461-469.

33. Sinclair JD, Psota-Kelty LA, and Weschler CJ. "Indoor/outdoor Concentrations and Indoor Surface Accumulations of Ionic Substances" (1985) Atmospheric Environment 19:315-323.

34. Nazaroff WW, Gadgil AJ, and Weschler CJ. "Critique of the Use of Deposition Velocity in Modeling Indoor Air Quality" (1993) Modeling of Indoor Air Quality and Exposure by American Society for Testing and Materials.

35. Byrne MA, Lange C, Goddard AJH, and Roed J. "Indoor Aerosol Deposition Measurements for Exposure Assessment Calculations" (1993) Proceedings of Indoor Air '93.

36. Nazaroff WW and Cass GR. "Mass-transport Aspects of Pollutant Removal at Indoor Surfaces" (1989) Environment International 15:567-584.

37. ASHRAE. Gravimetric and Dust Spot Procedures for Testing Air Cleaning Devices Used in General Ventilation for Removing Particulate Matter (1992) ASHRAE Standard 52.1-1992. 


\section{Appendix A Airflow Modeling Results}

CONTAM93 was used to analyze airflow in the houses using two approaches: simulated fan pressurization tests and directly calculated whole building air change rates under a range of wind speed and indoor - outdoor temperature differences.

Fan pressurization tests in the houses were simulated with CONTAM93 by including a constant flow element in the door of each house and adjusting the flow until a pressure differences of 4 and $50 \mathrm{~Pa}$ was achieved. The airflow rates at $50 \mathrm{~Pa}$ were divided by the interior volumes of the houses to determine the $50 \mathrm{~Pa}$ air change rates, and the $4 \mathrm{~Pa}$ flows were converted to effective leakage areas using Equation 27 in Chapter 23 of ASHRAE (3). The results of the fan pressurization simulations are shown in Table 1. The difference between the Miami and Minneapolis houses is due primarily to the existence of the basement in the Minneapolis houses. In terms of both measures of airtightness, the tight houses are about $66 \%$ tighter than the houses of typical leakage.

Table 1 - Fan pressurization simulation results

\begin{tabular}{|l|c|c|}
\hline \multicolumn{1}{|c|}{ House } & $\begin{array}{c}\mathrm{ach}_{50} \\
\left(\mathrm{hr}^{-1}\right)\end{array}$ & $\begin{array}{c}\text { Leakage area } \\
\left(\mathrm{cm}^{2}\right)\end{array}$ \\
\hline Typical Miami ranch & 13.2 & 680 \\
\hline Tight Miami ranch & 4.1 & 220 \\
\hline Typical Minneapolis ranch & 6.6 & 720 \\
\hline Tight Minneapolis ranch & 2.2 & 230 \\
\hline Typical Miami 2 story & 12.9 & 1,120 \\
\hline Tight Miami 2 story & 4.6 & 390 \\
\hline Typical Minneapolis 2 story & 8.8 & 1,170 \\
\hline Tight Minneapolis 2 story & 3.1 & 410 \\
\hline
\end{tabular}

CONTAM93 was used to calculate whole building air change rates for wind speeds from 0 to 10 $\mathrm{m} / \mathrm{s}$ and indoor-outdoor temperature differences from -10 to $30^{\circ} \mathrm{C}$. The wind direction was held constant throughout the simulations. These simulations were performed with the HVAC systems both on and off. Whole building air change rates were calculated by adding the airflow entering the conditioned space of the house through all leakage paths. The results of these airflow simulations are shown in Tables 2 through 9 for the system off.

Several general trends are shown by these tables. Using 'tight' values for the airflow elements vs. 'typical' or best estimate values reduced the whole building air change rate by up to a factor of four as compared to a factor of three for the fan pressurization results. Also, over the range considered here, the wind speed had a much greater impact on the whole building air change rate than the temperature difference. However, the tight airflow elements reduced the impact of the wind speed more than the impact of the temperature difference. 
Table 2 - Whole house a ir change rate for typical Miamiranch house (ach)

\begin{tabular}{|c|c|c|c|c|c|c|c|c|c|}
\hline \multirow{2}{*}{$\frac{\text { Tin - Tout }(\mathrm{K})}{\text { Wind speed }(\mathrm{m} / \mathrm{s})}$} & -10 & -5 & 0 & 5 & 10 & 15 & 20 & 25 & 30 \\
\hline & & & & & & & & & \\
\hline 0 & 0.33 & 0.21 & 0.00 & 0.22 & 0.35 & 0.46 & 0.57 & 0.67 & 0.76 \\
\hline 2 & 0.40 & 0.32 & 0.33 & 0.38 & 0.47 & 0.54 & 0.65 & 0.74 & 0.84 \\
\hline 4 & 0.75 & 0.78 & 0.82 & 0.85 & 0.89 & 0.94 & 1.00 & 1.08 & 1.15 \\
\hline 6 & 1.31 & 1.34 & 1.38 & 1.42 & 1.46 & 1.50 & 1.54 & 1.61 & 1.67 \\
\hline 8 & 1.92 & 1.96 & 2.01 & 2.06 & 2.11 & 2.16 & 2.21 & 2.27 & 2.33 \\
\hline 10 & 2.57 & 2.63 & 2.69 & 2.75 & 2.81 & 2.87 & 2.94 & 3.01 & 3.08 \\
\hline
\end{tabular}

Table 3 - Whole house air change rate for tight Miamiranch house (ach)

\begin{tabular}{|c|c|c|c|c|c|c|c|c|c|}
\hline Tin - Tout $(\mathrm{K})$ & -10 & -5 & 0 & 5 & 10 & 15 & 20 & 25 & 30 \\
\hline \multicolumn{10}{|l|}{ Wind speed $(\mathrm{m} / \mathrm{s})$} \\
\hline 0 & 0.10 & 0.07 & 0.00 & 0.07 & 0.11 & 0.14 & 0.17 & 0.20 & 0.23 \\
\hline 2 & 0.11 & 0.09 & 0.08 & 0.10 & 0.14 & 0.17 & 0.20 & 0.23 & 0.26 \\
\hline 4 & 0.18 & 0.18 & 0.19 & 0.21 & 0.22 & 0.24 & 0.26 & 0.28 & 0.31 \\
\hline 6 & 0.30 & 0.31 & 0.32 & 0.33 & 0.34 & 0.36 & 0.38 & 0.39 & 0.42 \\
\hline 8 & 0.44 & 0.46 & 0.47 & 0.48 & 0.49 & 0.51 & 0.53 & 0.54 & 0.57 \\
\hline 10 & 0.60 & 0.61 & 0.63 & 0.64 & 0.65 & 0.67 & 0.69 & 0.71 & 0.73 \\
\hline
\end{tabular}

Table 4 - Whole house a ir change rate for typical Minneapolis ranch house (ach)

\begin{tabular}{|c|ccccccccc|}
\hline \multicolumn{1}{|c}{ Tin - Tout (K) } & -10 & -5 & 0 & 5 & 10 & 15 & 20 & 25 & 30 \\
\hline Wind speed (m/s) & & & & & & & & & \\
0 & 0.25 & 0.16 & 0.00 & 0.16 & 0.26 & 0.34 & 0.42 & 0.49 & 0.56 \\
2 & 0.29 & 0.23 & 0.18 & 0.23 & 0.31 & 0.39 & 0.46 & 0.53 & 0.59 \\
4 & 0.45 & 0.41 & 0.44 & 0.47 & 0.50 & 0.54 & 0.59 & 0.64 & 0.69 \\
6 & 0.69 & 0.72 & 0.75 & 0.78 & 0.81 & 0.83 & 0.87 & 0.91 & 0.95 \\
8 & 1.03 & 1.06 & 1.09 & 1.12 & 1.16 & 1.19 & 1.22 & 1.26 & 1.29 \\
10 & 1.39 & 1.43 & 1.46 & 1.50 & 1.54 & 1.57 & 1.62 & 1.66 & 1.70 \\
\hline
\end{tabular}

Table 5 - Whole house a ir change rate for tight $\mathrm{M}$ inne apolis ranch house $(\mathrm{ach})$

\begin{tabular}{|c|c|c|c|c|c|c|c|c|c|}
\hline Tin - Tout (K) & -10 & -5 & 0 & 5 & 10 & 15 & 20 & 25 & 30 \\
\hline Wind speed $(\mathrm{m} / \mathrm{s})$ & & & & & & & & & \\
\hline 0 & 0.09 & 0.06 & 0.00 & 0.06 & 0.10 & 0.13 & 0.16 & 0.19 & 0.21 \\
\hline 2 & 0.09 & 0.07 & 0.04 & 0.07 & 0.11 & 0.14 & 0.17 & 0.20 & 0.22 \\
\hline 4 & 0.13 & 0.10 & 0.11 & 0.12 & 0.14 & 0.16 & 0.19 & 0.21 & 0.24 \\
\hline 6 & 0.17 & 0.18 & 0.19 & 0.19 & 0.21 & 0.22 & 0.23 & 0.25 & 0.27 \\
\hline 8 & 0.25 & 0.26 & 0.27 & 0.28 & 0.29 & 0.30 & 0.31 & 0.33 & 0.34 \\
\hline 10 & 0.34 & 0.35 & 0.36 & 0.37 & 0.38 & 0.39 & 0.41 & 0.42 & 0.44 \\
\hline
\end{tabular}


Table 6 - Whole house air change rate fortypical Miami2 story house (ach)

\begin{tabular}{|c|rrrrrrrrr|}
\hline Tin - Tout (K) & \multicolumn{1}{c}{-10} & -5 & 0 & 5 & 10 & 15 & 20 & 25 & 30 \\
\hline Wind speed (m/s) & & & & & & & & & \\
0 & 0.38 & 0.24 & 0.00 & 0.25 & 0.40 & 0.53 & 0.64 & 0.76 & 0.87 \\
2 & 0.44 & 0.34 & 0.36 & 0.42 & 0.51 & 0.62 & 0.72 & 0.81 & 0.91 \\
4 & 0.82 & 0.86 & 0.89 & 0.93 & 0.96 & 1.02 & 1.08 & 1.15 & 1.21 \\
6 & 1.43 & 1.47 & 1.51 & 1.55 & 1.60 & 1.64 & 1.68 & 1.74 & 1.80 \\
8 & 2.10 & 2.15 & 2.20 & 2.25 & 2.30 & 2.36 & 2.41 & 2.47 & 2.53 \\
10 & 2.82 & 2.88 & 2.94 & 3.01 & 3.07 & 3.14 & 3.21 & 3.28 & 3.35 \\
\hline
\end{tabular}

Table 7 - Whole house a ir change rate fortight Miami2 story house (ach)

\begin{tabular}{|c|ccccccccc|}
\hline Tin - Tout (K) & -10 & -5 & 0 & 5 & 10 & 15 & 20 & 25 & 30 \\
\hline Wind speed (m/s) & & & & & & & & & \\
0 & 0.13 & 0.08 & 0.00 & 0.09 & 0.14 & 0.18 & 0.22 & 0.26 & 0.30 \\
2 & 0.14 & 0.10 & 0.09 & 0.12 & 0.16 & 0.21 & 0.25 & 0.28 & 0.32 \\
4 & 0.20 & 0.22 & 0.23 & 0.24 & 0.26 & 0.28 & 0.30 & 0.34 & 0.38 \\
6 & 0.36 & 0.37 & 0.38 & 0.40 & 0.41 & 0.43 & 0.44 & 0.47 & 0.49 \\
8 & 0.53 & 0.54 & 0.56 & 0.57 & 0.59 & 0.60 & 0.62 & 0.64 & 0.66 \\
10 & 0.71 & 0.73 & 0.75 & 0.76 & 0.78 & 0.80 & 0.82 & 0.84 & 0.86 \\
\hline
\end{tabular}

Table 8 - Whole house air change rate for typicalMinneapolis 2 story house (ach)

\begin{tabular}{|c|c|c|c|c|c|c|c|c|c|}
\hline Tin - Tout $(\mathrm{K})$ & -10 & -5 & 0 & 5 & 10 & 15 & 20 & 25 & 30 \\
\hline Wind speed $(\mathrm{m} / \mathrm{s})$ & & & & & & & & & \\
\hline 0 & 0.25 & 0.15 & 0.00 & 0.17 & 0.27 & 0.35 & 0.43 & 0.50 & 0.58 \\
\hline 2 & 0.30 & 0.24 & 0.25 & 0.28 & 0.34 & 0.42 & 0.48 & 0.54 & 0.61 \\
\hline 4 & 0.57 & 0.60 & 0.62 & 0.64 & 0.66 & 0.70 & 0.74 & 0.78 & 0.83 \\
\hline 6 & 0.99 & 1.02 & 1.05 & 1.08 & 1.10 & 1.13 & 1.16 & 1.20 & 1.24 \\
\hline 8 & 1.46 & 1.49 & 1.52 & 1.56 & 1.60 & 1.63 & 1.67 & 1.71 & 1.75 \\
\hline 10 & 1.95 & 2.00 & 2.04 & 2.08 & 2.12 & 2.17 & 2.22 & 2.27 & 2.32 \\
\hline
\end{tabular}

Table 9 - Whole house air change rate for tight Minneapolis 2 story house (ach)

\begin{tabular}{|c|rrrrrrrrr|}
\hline Tin - Tout (K) & -10 & -5 & 0 & 5 & 10 & 15 & 20 & 25 & 30 \\
\hline Wind speed (m/s) & & & & & & & & & \\
0 & 0.09 & 0.06 & 0.00 & 0.06 & 0.09 & 0.12 & 0.15 & 0.18 & 0.20 \\
2 & 0.10 & 0.07 & 0.06 & 0.08 & 0.11 & 0.14 & 0.17 & 0.19 & 0.21 \\
4 & 0.14 & 0.15 & 0.16 & 0.17 & 0.18 & 0.19 & 0.21 & 0.23 & 0.26 \\
6 & 0.25 & 0.26 & 0.27 & 0.28 & 0.29 & 0.30 & 0.31 & 0.33 & 0.34 \\
8 & 0.37 & 0.38 & 0.39 & 0.40 & 0.41 & 0.42 & 0.44 & 0.45 & 0.47 \\
10 & 0.50 & 0.51 & 0.53 & 0.54 & 0.55 & 0.56 & 0.58 & 0.59 & 0.61 \\
\hline
\end{tabular}


Tables 10 through 17 present the results of the airflow simulations with the HVAC system on. Operation of the HVAC system increased the building air change rate as much as 0.31 ach at zero wind speed and temperature difference due to supply duct leakage in the attic. The effect of the system fan was less than 0.07 ach at high wind speeds $(>4 \mathrm{~m} / \mathrm{s})$ and temperature differences ( $>$ $\left.10^{\circ} \mathrm{C}\right)$.

Table 10 - Whole house air change rate for typical Miami ranch house with system on (ach)

\begin{tabular}{|c|ccccccccc|}
\hline Tin-Tout (K) & -10 & -5 & 0 & 5 & 10 & 15 & 20 & 25 & 30 \\
\hline Wind speed (m/s) & & & & & & & & & \\
0 & 0.45 & 0.38 & 0.31 & 0.39 & 0.52 & 0.63 & 0.73 & 0.83 & 0.93 \\
2 & 0.59 & 0.52 & 0.41 & 0.50 & 0.63 & 0.74 & 0.84 & 0.93 & 103 \\
4 & 0.86 & 0.81 & 0.85 & 0.89 & 0.95 & 102 & 1.10 & 1.17 & 1.24 \\
6 & 1.34 & 1.37 & 141 & 1.45 & 149 & 1.55 & 161 & 167 & 173 \\
8 & 1.95 & 1.99 & 2.04 & 2.09 & 2.14 & 2.19 & 2.25 & 2.30 & 2.38 \\
10 & 2.60 & 2.66 & 2.72 & 2.78 & 2.84 & 2.91 & 2.97 & 3.04 & 3.11 \\
\hline
\end{tabular}

Table 11- Whole house air change rate for tight Miami ranch house with system on (ach)

\begin{tabular}{|c|c|c|c|c|c|c|c|c|c|}
\hline Tin - Tout $(\mathrm{K})$ & -10 & -5 & 0 & 5 & 10 & 15 & 20 & 25 & 30 \\
\hline Wind speed $(\mathrm{m} / \mathrm{s}$ & & & & & & & & & \\
\hline 0 & 0.29 & 0.29 & 0.30 & 0.30 & 0.30 & 0.31 & 0.31 & 0.33 & 0.37 \\
\hline 2 & 0.30 & 0.30 & 0.30 & 0.30 & 0.30 & 0.31 & 0.32 & 0.36 & 0.39 \\
\hline 4 & 0.37 & 0.36 & 0.34 & 0.33 & 0.31 & 0.32 & 0.36 & 0.41 & 0.44 \\
\hline 6 & 0.46 & 0.45 & 0.44 & 0.43 & 0.41 & 0.40 & 0.42 & 0.46 & 0.49 \\
\hline 8 & 0.56 & 0.55 & 0.53 & 0.52 & 0.53 & 0.55 & 0.57 & 0.58 & 0.61 \\
\hline 10 & 0.65 & 0.64 & 0.64 & 0.66 & 0.69 & 0.71 & 0.73 & 0.75 & 0.77 \\
\hline
\end{tabular}

Table 12 - Whole house air change rate for typical Minneapolis ranch house with system on (ach)

\begin{tabular}{|cccccccccc|}
\hline Tin - Tout (K) & -10 & -5 & 0 & 5 & 10 & 15 & 20 & 25 & 30 \\
\hline Wind speed (m/s) & & & & & & & & & \\
0 & 0.24 & 0.16 & 0.00 & 0.15 & 0.25 & 0.33 & 0.41 & 0.48 & 0.55 \\
2 & 0.28 & 0.22 & 0.18 & 0.22 & 0.30 & 0.38 & 0.45 & 0.52 & 0.58 \\
4 & 0.44 & 0.41 & 0.44 & 0.47 & 0.50 & 0.53 & 0.59 & 0.64 & 0.68 \\
6 & 0.69 & 0.72 & 0.75 & 0.78 & 0.80 & 0.83 & 0.87 & 0.91 & 0.94 \\
8 & 1.03 & 1.06 & 1.09 & 1.12 & 1.16 & 1.19 & 1.22 & 1.26 & 1.29 \\
10 & 1.39 & 1.42 & 1.46 & 1.50 & 1.53 & 1.57 & 1.61 & 1.65 & 1.70 \\
\hline
\end{tabular}

Table $\mathbb{B}$ - Whole house air change rate for tight Minneapolis ranch house with system on (ach)

\begin{tabular}{|cccccccccc|}
\hline Tin - Tout $(\mathrm{K})$ & -10 & -5 & 0 & 5 & 10 & 15 & 20 & 25 & 30 \\
\hline Wind speed $(\mathrm{m} / \mathrm{s})$ & & & & & & & & & \\
0 & 0.09 & 0.05 & 0.00 & 0.05 & 0.09 & 0.12 & 0.15 & 0.18 & 0.21 \\
2 & 0.08 & 0.06 & 0.04 & 0.06 & 0.10 & 0.13 & 0.16 & 0.19 & 0.21 \\
4 & 0.12 & 0.10 & 0.11 & 0.12 & 0.13 & 0.15 & 0.18 & 0.21 & 0.23 \\
6 & 0.17 & 0.18 & 0.18 & 0.19 & 0.20 & 0.22 & 0.23 & 0.25 & 0.26 \\
8 & 0.25 & 0.26 & 0.27 & 0.28 & 0.29 & 0.30 & 0.31 & 0.32 & 0.34 \\
10 & 0.34 & 0.35 & 0.36 & 0.37 & 0.38 & 0.39 & 0.40 & 0.42 & 0.43 \\
\hline
\end{tabular}


Table 14 - Whole house air change rate for typical Miami 2 story house with system on $(\mathrm{ach})$

\begin{tabular}{|c|ccccccccc|}
\hline Tm - Tout $(\mathrm{K})$ & -10 & -5 & 0 & 5 & 10 & 15 & 20 & 25 & 30 \\
\hline Wind speed $(\mathrm{m} / \mathrm{s})$ & & & & & & & & & \\
0 & 0.38 & 0.24 & 0.00 & 0.25 & 0.40 & 0.53 & 0.64 & 0.76 & 0.87 \\
2 & 0.44 & 0.34 & 0.36 & 0.42 & 0.51 & 0.62 & 0.72 & 0.81 & 0.91 \\
4 & 0.82 & 0.86 & 0.89 & 0.93 & 0.96 & 102 & 108 & 1.15 & 1.21 \\
6 & 143 & 147 & 1.52 & 1.56 & 160 & 164 & 168 & 174 & 180 \\
8 & 2.10 & 2.15 & 2.20 & 2.25 & 2.31 & 2.36 & 2.41 & 2.47 & 2.53 \\
10 & 2.82 & 2.88 & 2.94 & 3.00 & 3.07 & 3.14 & 3.21 & 3.28 & 3.35 \\
\hline
\end{tabular}

Table 15 - Whole house air change rate for tight Miami2 story house with system on (ach)

\begin{tabular}{|cccccccccc|}
\hline Tin - Tout $(\mathrm{K})$ & -10 & -5 & 0 & 5 & 10 & 15 & 20 & 25 & 30 \\
\hline Wind speed $(\mathrm{m} / \mathrm{s})$ & & & & & & & & & \\
0 & 0.13 & 0.08 & 0.00 & 0.09 & 0.14 & 0.18 & 0.22 & 0.26 & 0.30 \\
2 & 0.14 & 0.10 & 0.09 & 0.12 & 0.16 & 0.21 & 0.25 & 0.28 & 0.32 \\
4 & 0.20 & 0.22 & 0.23 & 0.24 & 0.26 & 0.27 & 0.30 & 0.34 & 0.38 \\
6 & 0.36 & 0.37 & 0.38 & 0.39 & 0.41 & 0.43 & 0.44 & 0.47 & 0.49 \\
8 & 0.53 & 0.54 & 0.56 & 0.57 & 0.59 & 0.60 & 0.62 & 0.64 & 0.66 \\
10 & 0.71 & 0.73 & 0.75 & 0.76 & 0.78 & 0.80 & 0.82 & 0.84 & 0.87 \\
\hline
\end{tabular}

Table 16 - Whole house air change rate for typical Minneapolis 2 story house with system on (ach)

\begin{tabular}{|cccccccccc|}
\hline Tin - Tout (K) & -10 & -5 & 0 & 5 & 10 & 15 & 20 & 25 & 30 \\
\hline Wind speed (m/s) & & & & & & & & & \\
0 & 0.25 & 0.16 & 0.01 & 0.17 & 0.27 & 0.35 & 0.43 & 0.51 & 0.58 \\
2 & 0.31 & 0.24 & 0.25 & 0.29 & 0.35 & 0.42 & 0.48 & 0.55 & 0.61 \\
4 & 0.57 & 0.60 & 0.62 & 0.64 & 0.66 & 0.70 & 0.74 & 0.79 & 0.83 \\
6 & 0.99 & 102 & 105 & 108 & 111 & 113 & 116 & 1.20 & 1.24 \\
8 & 146 & 149 & 153 & 156 & 160 & 163 & 167 & 171 & 175 \\
10 & 195 & 2.00 & 2.04 & 2.08 & 2.13 & 2.17 & 2.22 & 2.27 & 2.32 \\
\hline
\end{tabular}

Table 17 - Whole house air change rate for tight Minneapolis 2 story house with system on (ach)

\begin{tabular}{|cccccccccc|}
\hline Tin - Tout (K) & -10 & -5 & 0 & 5 & 10 & 15 & 20 & 25 & 30 \\
\hline Wind speed (m/s) & & & & & & & & & \\
0 & 0.09 & 0.06 & 0.00 & 0.06 & 0.09 & 0.12 & 0.15 & 0.18 & 0.20 \\
2 & 0.10 & 0.07 & 0.06 & 0.08 & 0.11 & 0.14 & 0.17 & 0.19 & 0.21 \\
4 & 0.15 & 0.15 & 0.16 & 0.17 & 0.18 & 0.19 & 0.21 & 0.23 & 0.26 \\
6 & 0.26 & 0.26 & 0.27 & 0.28 & 0.29 & 0.30 & 0.31 & 0.33 & 0.34 \\
8 & 0.38 & 0.38 & 0.39 & 0.40 & 0.41 & 0.42 & 0.44 & 0.45 & 0.47 \\
10 & 0.50 & 0.51 & 0.53 & 0.54 & 0.55 & 0.56 & 0.58 & 0.59 & 0.61 \\
\hline
\end{tabular}




\section{Appendix B Baseline and Preliminary Simulation Results}

Tables 1a through 24e of Appendix B summarize the results of all 24 baseline simulations. Tables 25 a through 27 e summarize the results of the 3 preliminary simulations of the IAQ control retrofits. Tables 1a through 27a show the overall peak concentrations (excluding the basement, attic, garage and closet zones), the location of that overall peak, and the whole house 24-hour average concentrations (excluding the basement, garage, and attic zones). Tables $1 \mathrm{~b}$ through $27 \mathrm{~b}$ show the individual zone peak concentrations for the main living space zones. Tables $1 \mathrm{c}$ through $27 \mathrm{c}$ show the individual zone 24 -hour average concentrations. Tables $1 \mathrm{~d}$ through $27 \mathrm{~d}$ show the individual zone 4-hour average concentrations. The 4-hour average was calculated for the VOC burst sources from 7 p.m. to 11 p.m., for the oven from 6 p.m. to 10 p.m., and for the heater from $7 \mathrm{am}$ to $11 \mathrm{am}$. No 4-hour average was calculated for either the floor VOC source or the outdoor air pollutants. Tables 1e through $27 \mathrm{e}$ show the individual zone 1 -hour average $\mathrm{CO}$ concentrations. The 1 -hour average was calculated for the oven from $7 \mathrm{p} . \mathrm{m}$. to 8 p.m. and for the heater from 9 am to $10 \mathrm{am}$. 


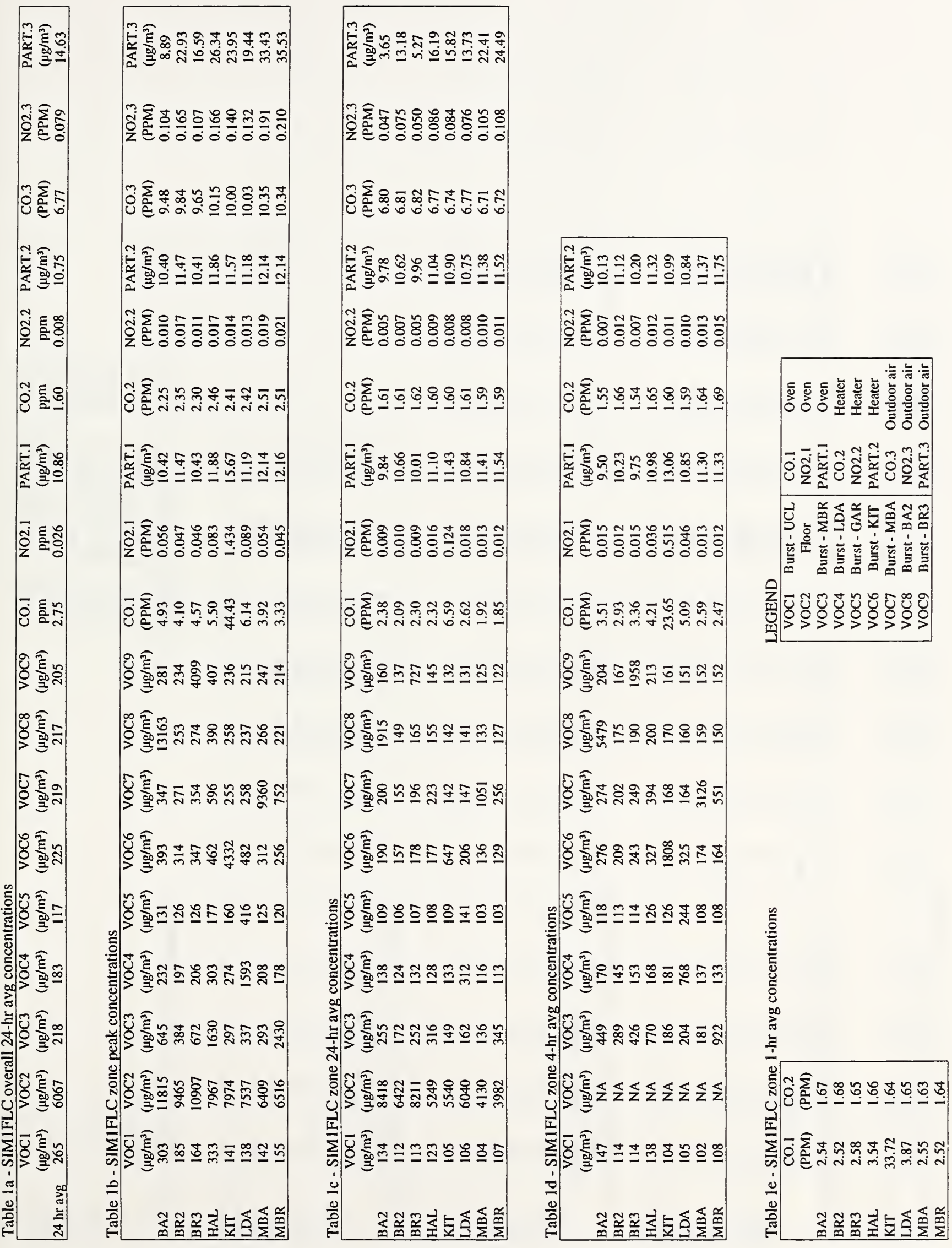




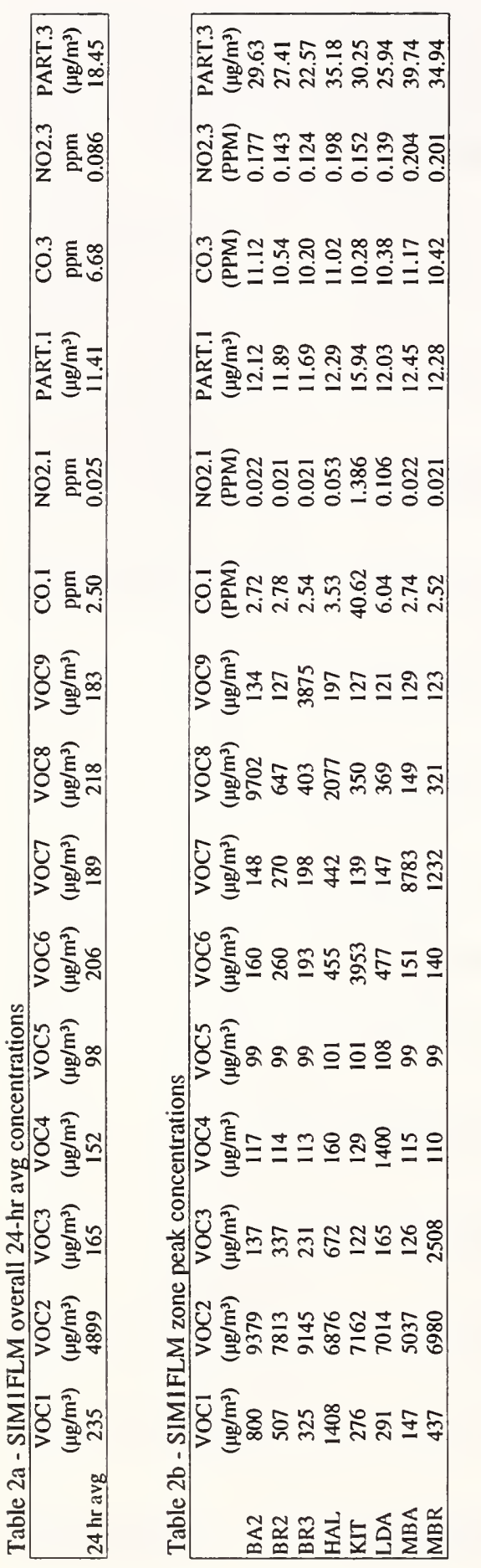

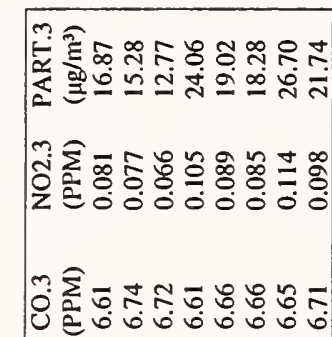

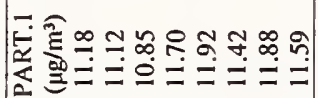

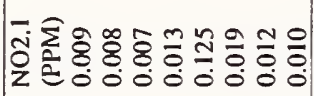

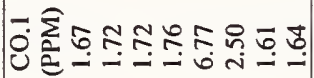

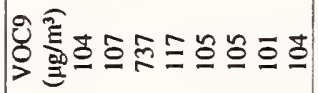

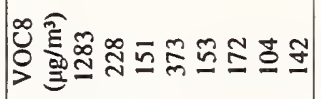

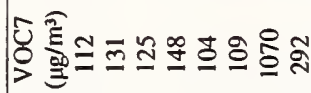

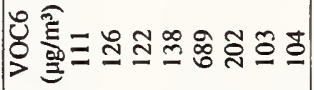

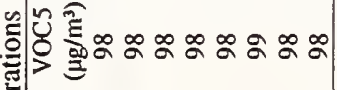

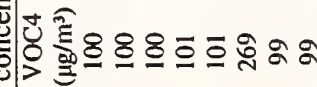

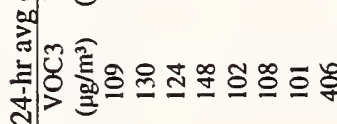

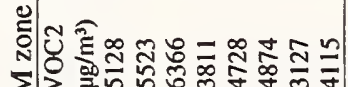

国

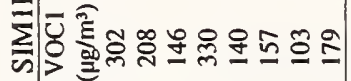
तै

흘

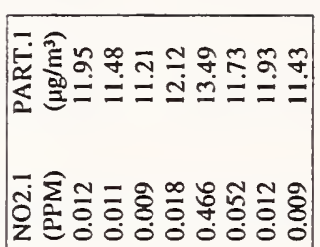

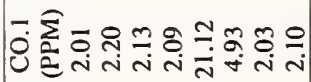

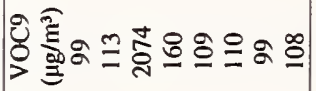

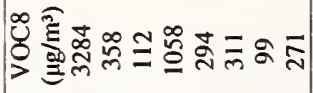

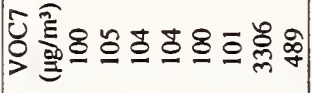

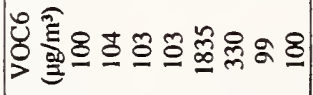

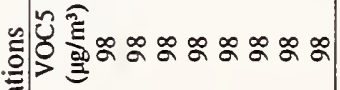

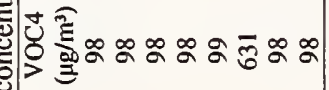

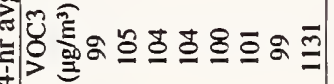

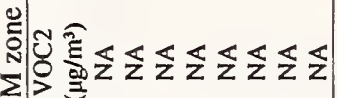

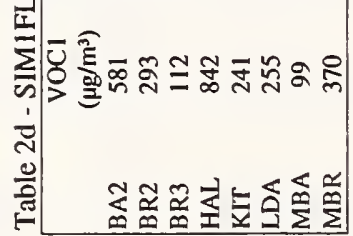
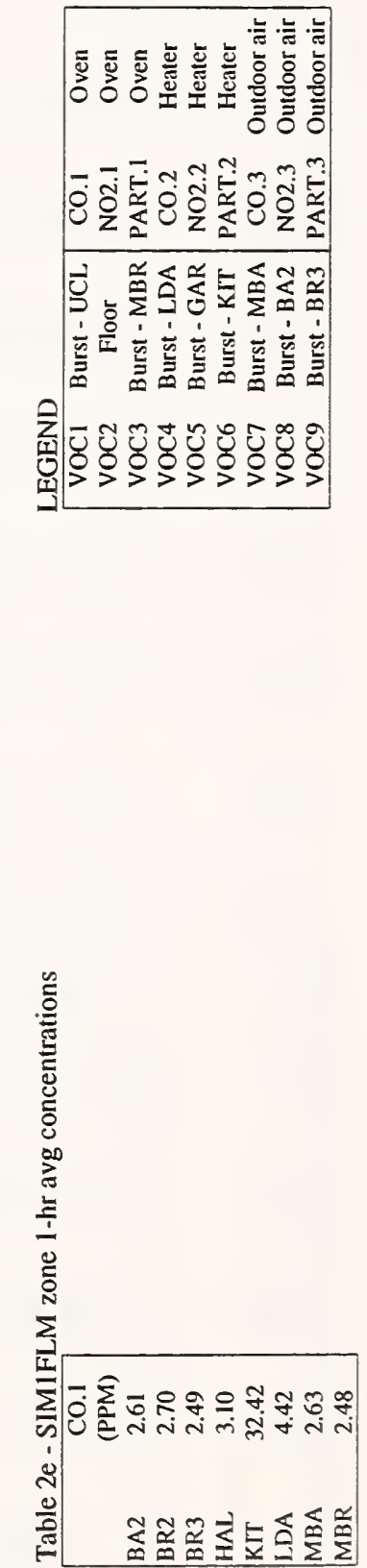


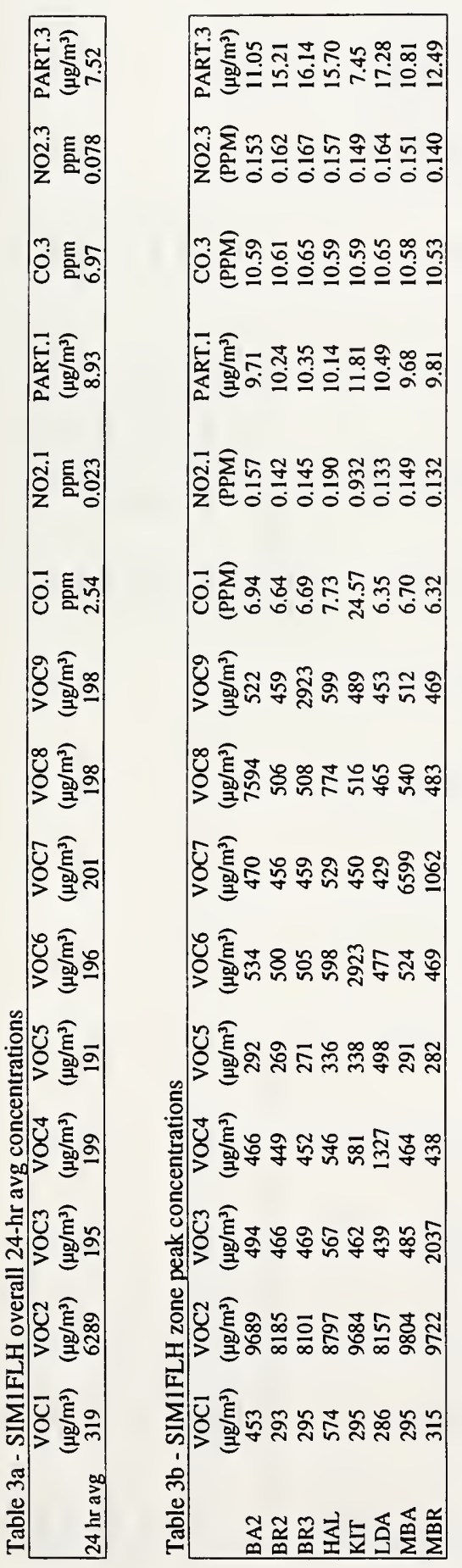

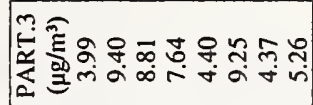

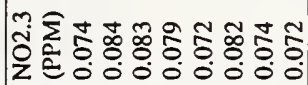

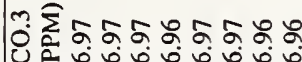

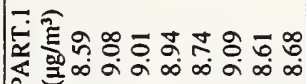

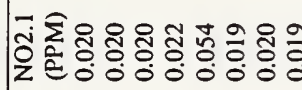

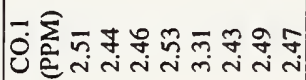

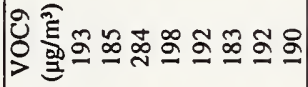

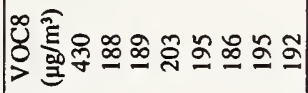

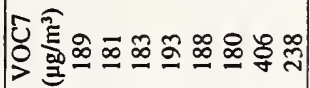

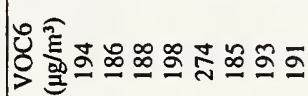

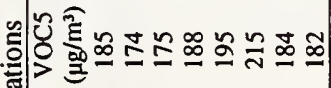

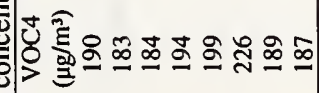
武行

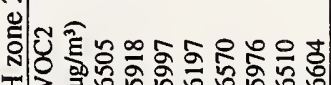
包 论 ले

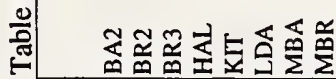

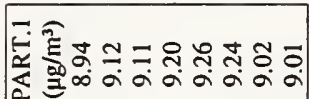

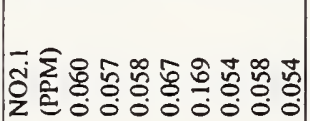

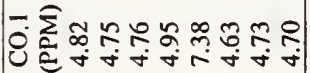

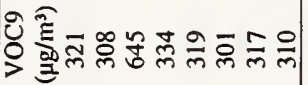

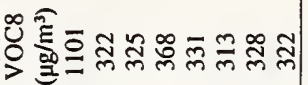

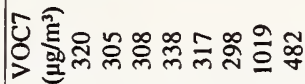

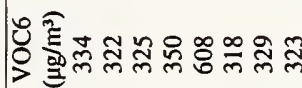

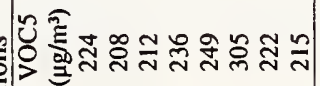

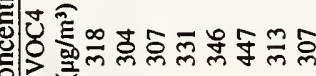

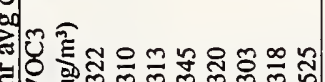

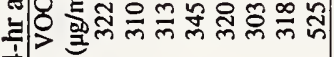

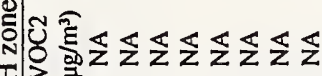

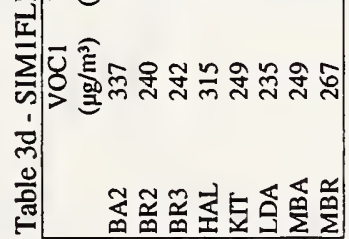

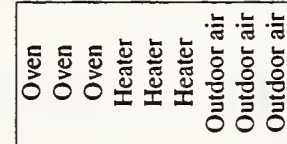

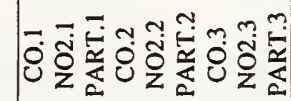

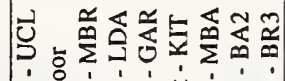

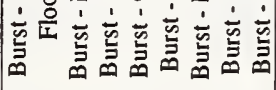

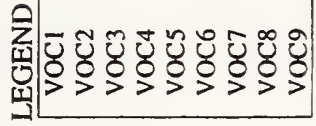

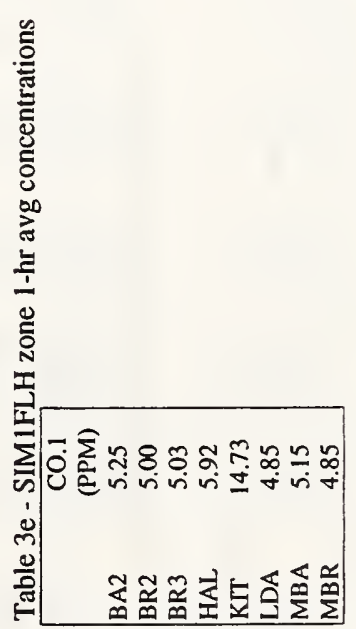




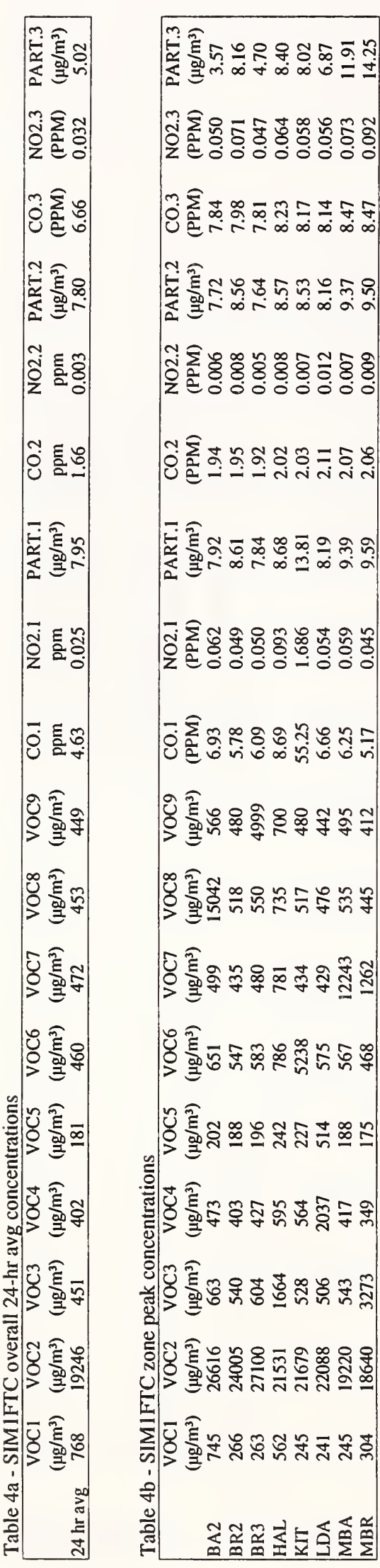

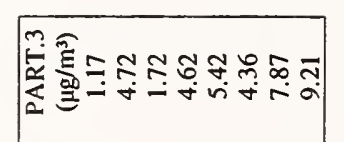

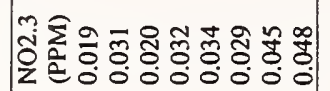

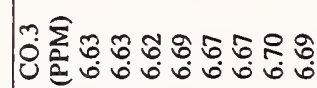

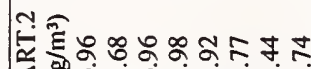

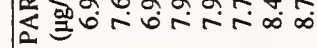

กิ๊

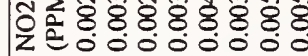

ชั

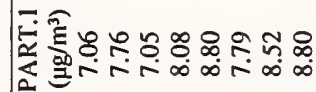

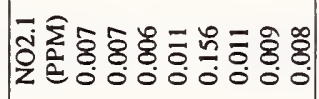

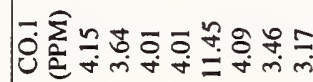

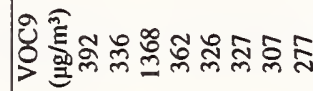

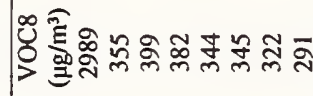

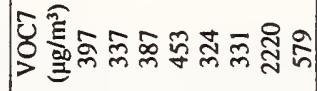

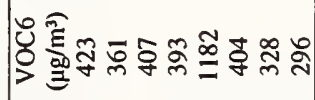

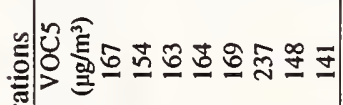

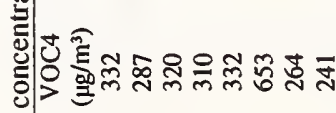

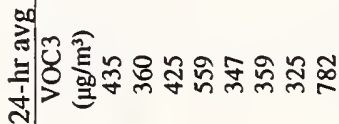

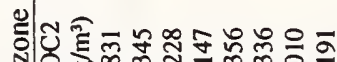

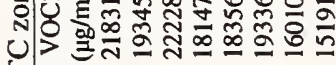

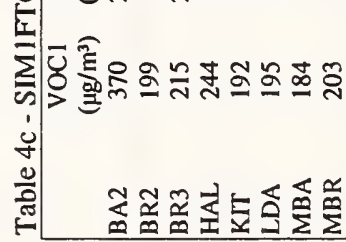

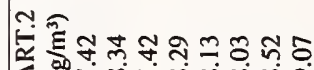

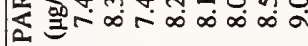

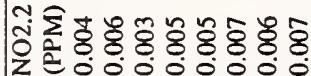

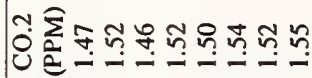

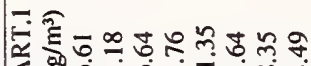

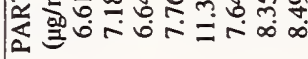

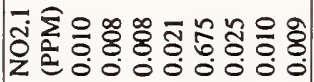

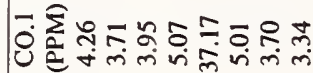

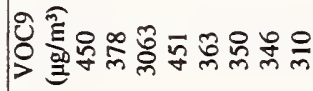

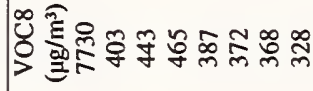

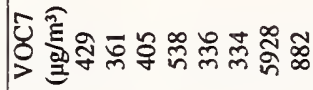

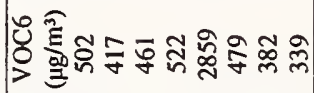

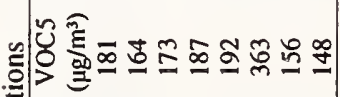

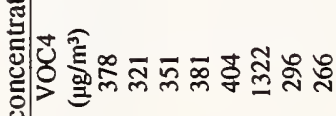

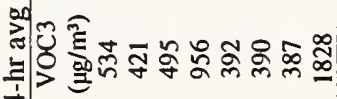

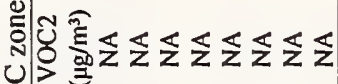

닌

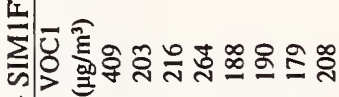

京

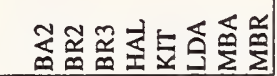

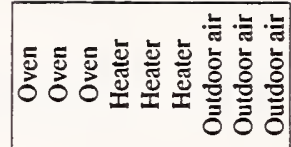

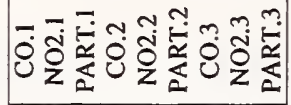

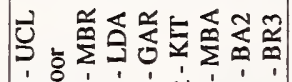

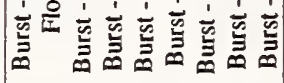

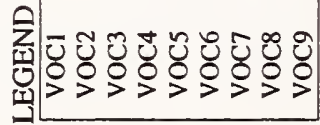

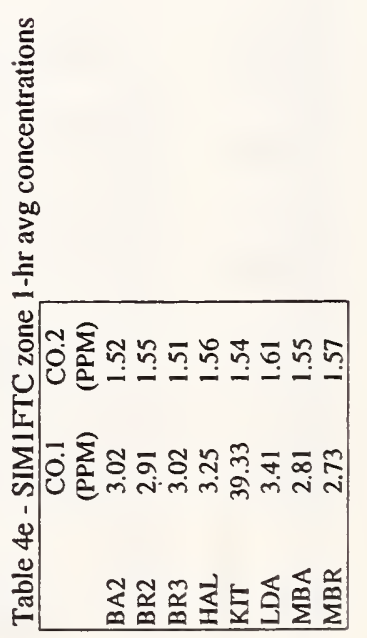




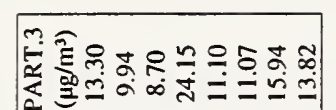

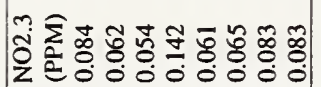

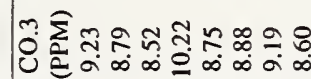

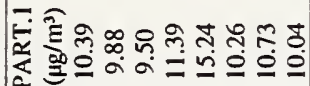

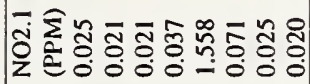

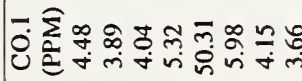

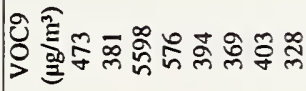

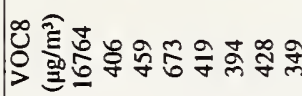

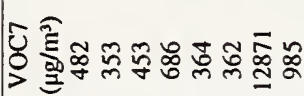

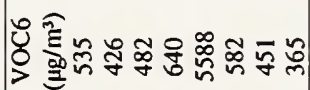

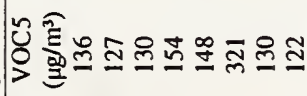

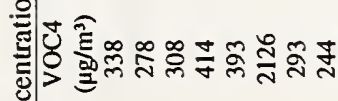

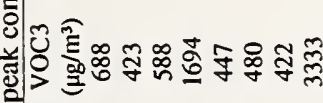

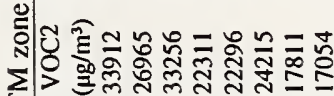

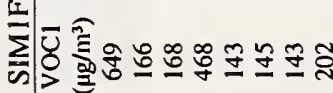
.

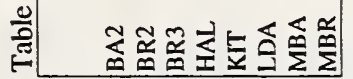

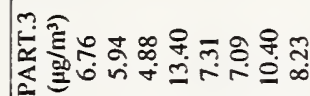

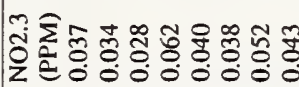

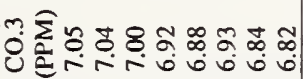

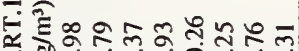
링

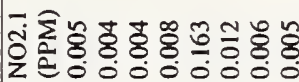

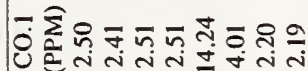

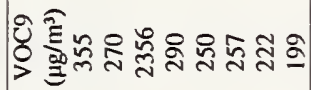

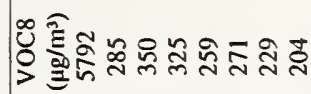

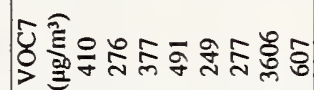

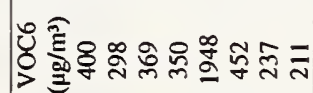

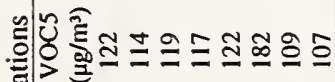

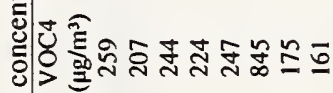

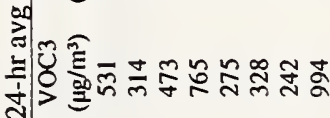

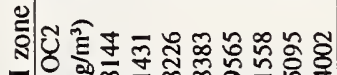

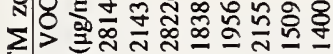

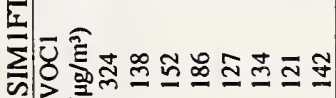

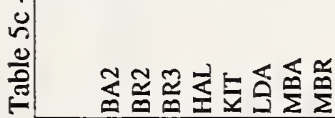

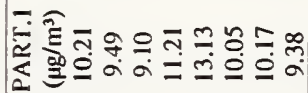

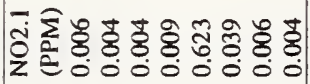

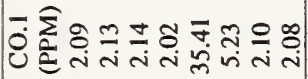

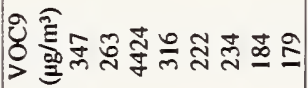

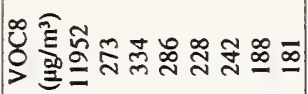

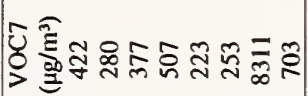

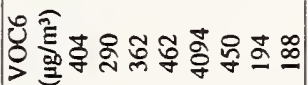

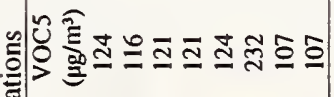

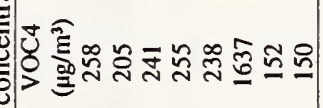

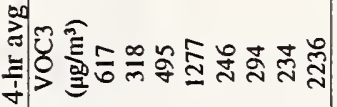

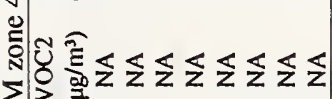

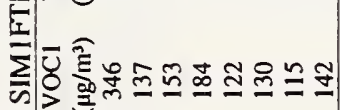
เั่

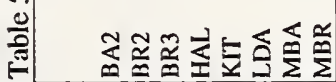

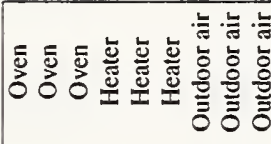

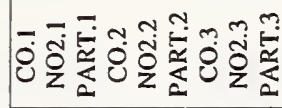

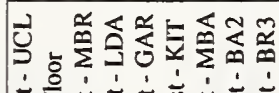

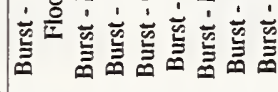

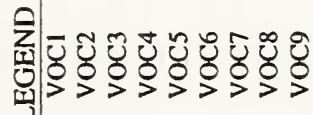



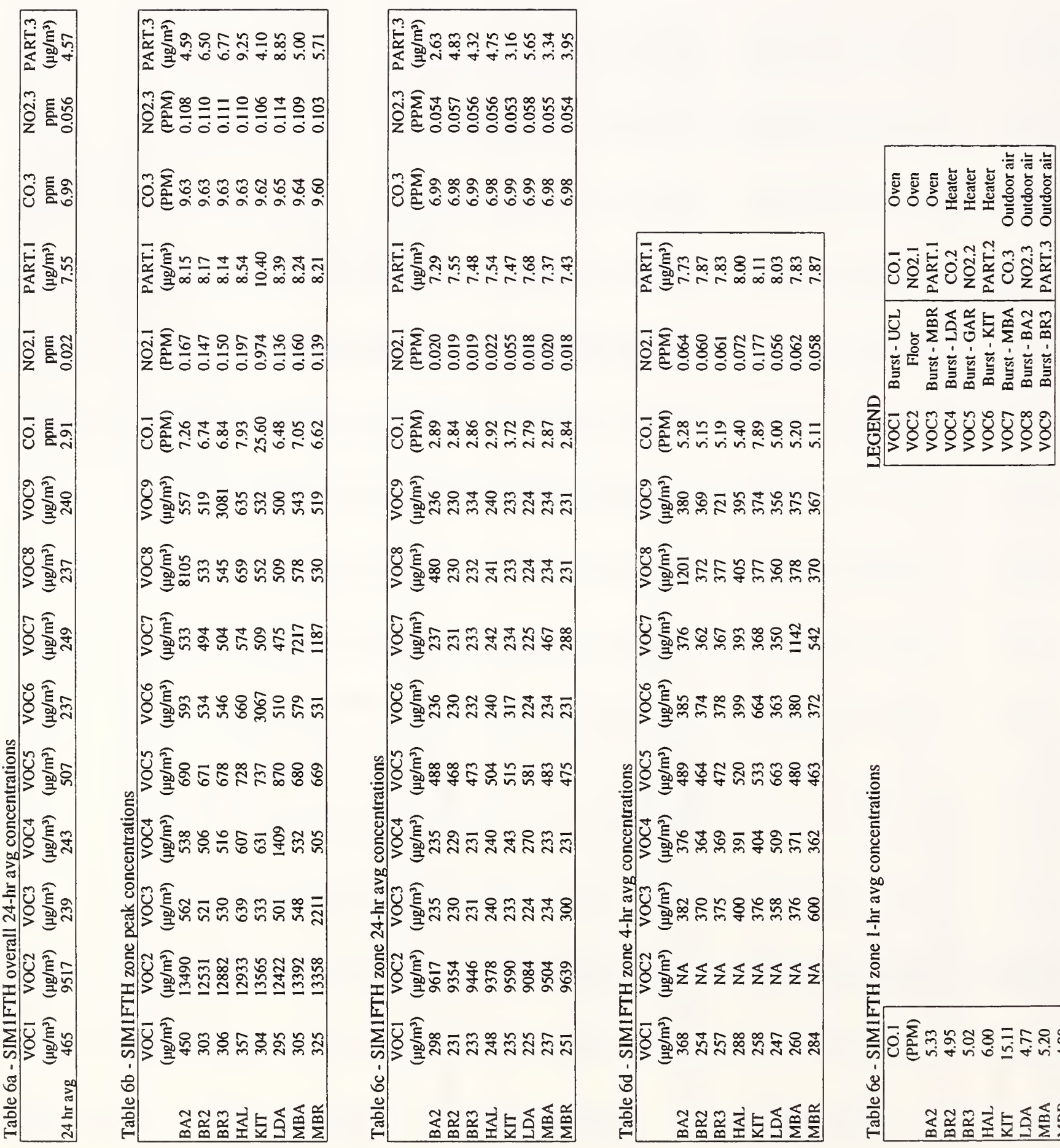

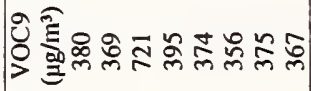

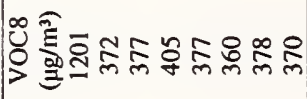

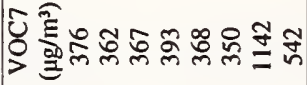

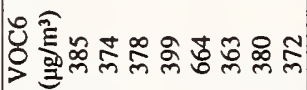

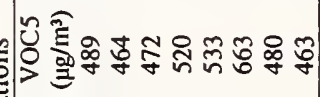
당

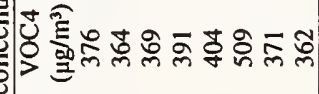

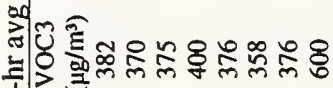

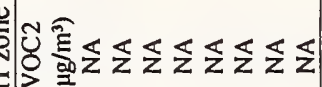

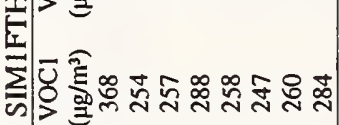
हु

管

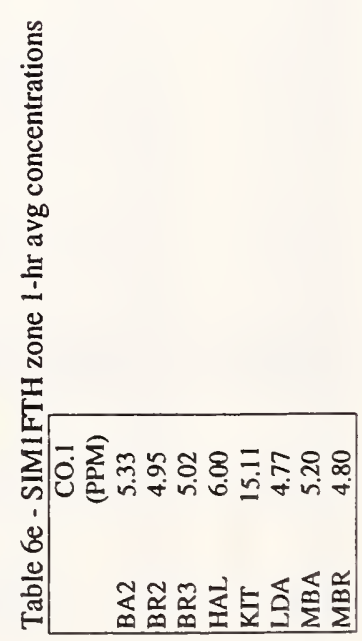




\begin{tabular}{|c|c|}
\hline 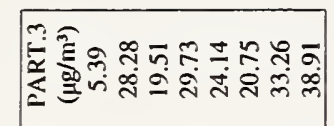 & 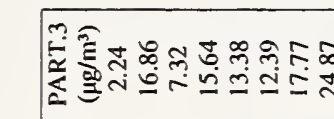 \\
\hline 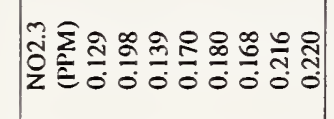 & 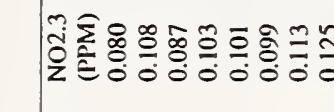 \\
\hline 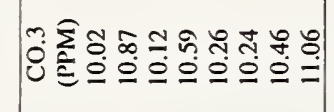 & 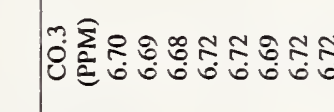 \\
\hline 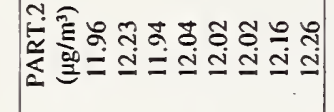 & 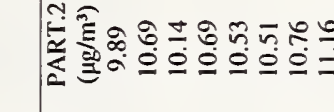 \\
\hline 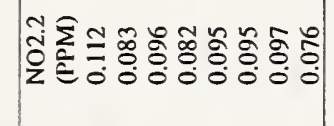 & $\frac{2}{20}$ \\
\hline 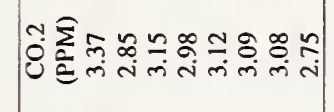 & 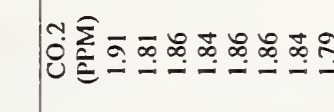 \\
\hline 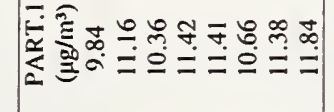 & 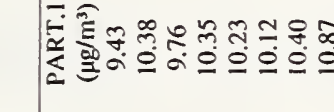 \\
\hline 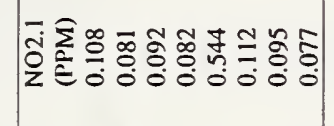 & : \\
\hline 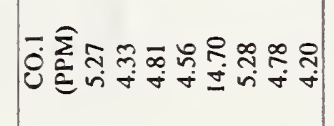 & 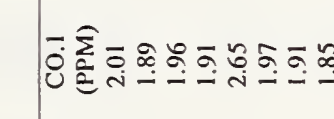 \\
\hline 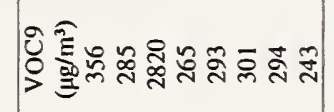 & 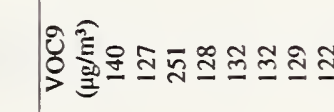 \\
\hline 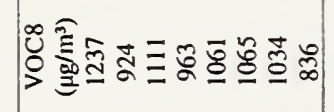 & 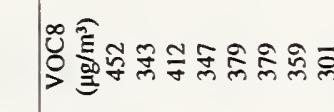 \\
\hline 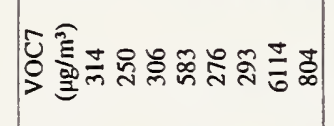 & 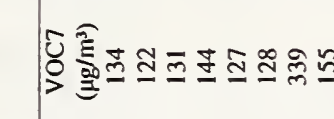 \\
\hline 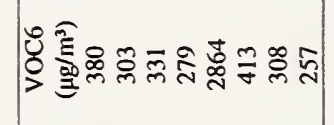 & 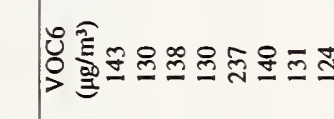 \\
\hline 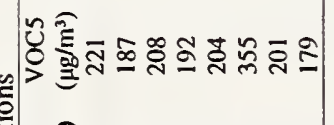 & 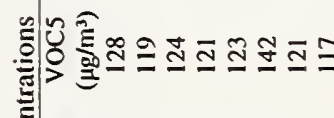 \\
\hline 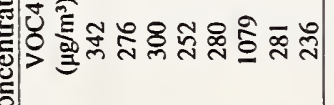 & 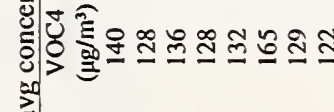 \\
\hline 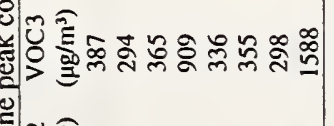 & 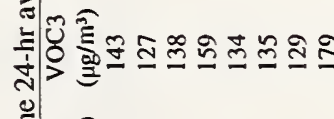 \\
\hline 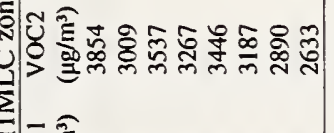 & 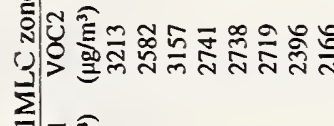 \\
\hline & ב \\
\hline
\end{tabular}

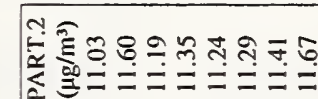

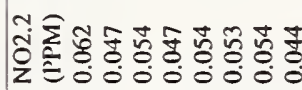

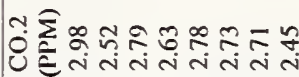

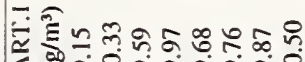

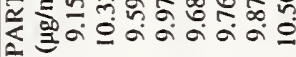

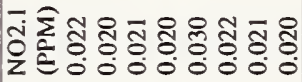

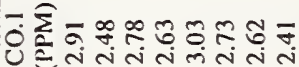

రิ

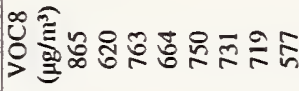

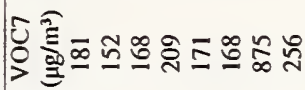

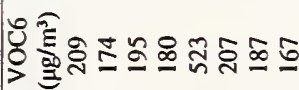

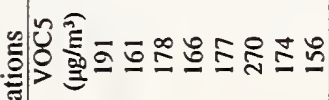

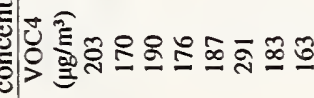

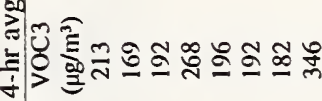

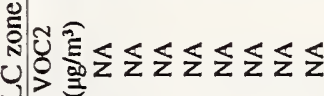

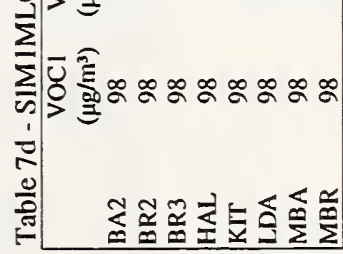

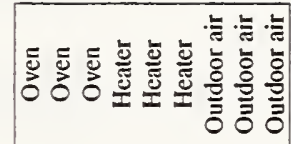

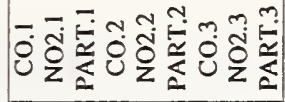

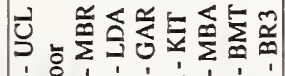

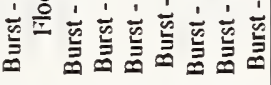

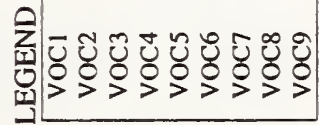

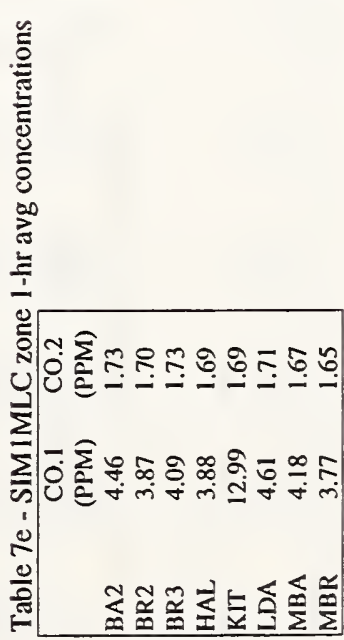




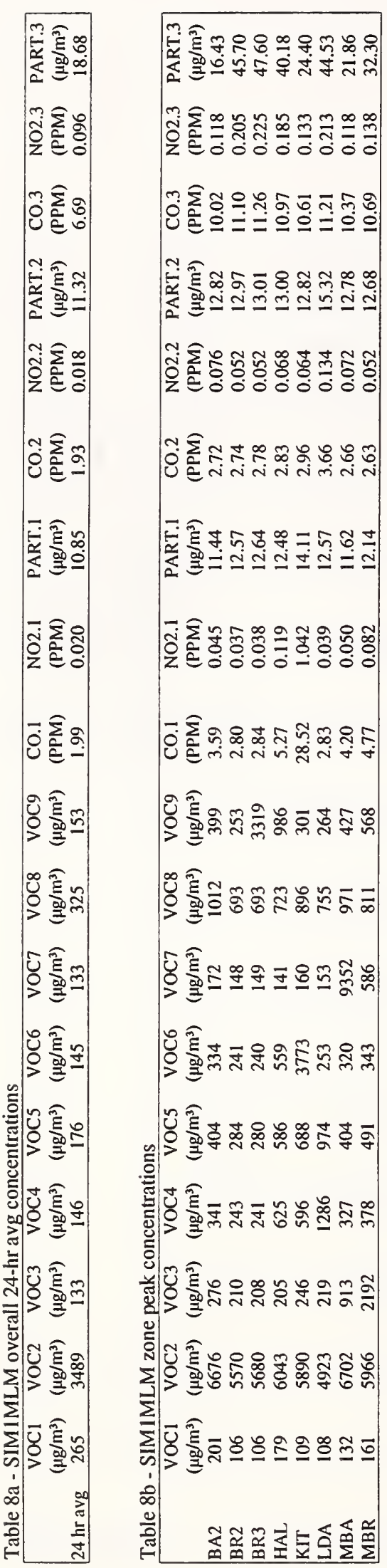

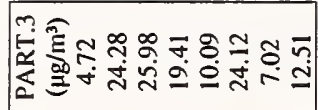

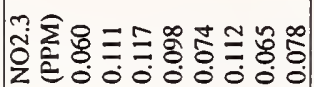

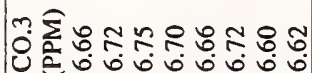
กิ๊

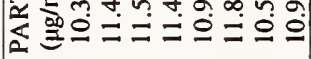

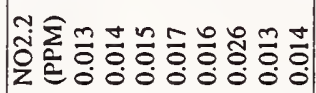

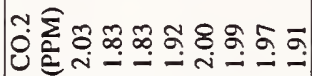

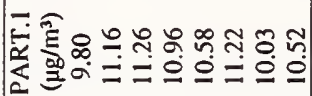

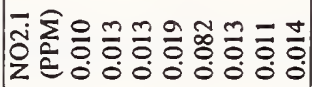

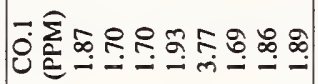
ర్రి

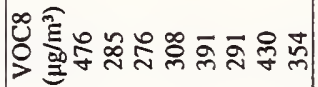

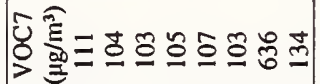

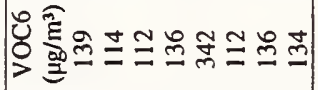

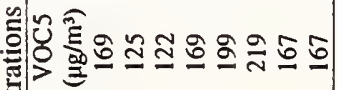

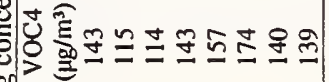

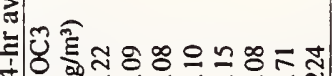

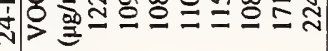

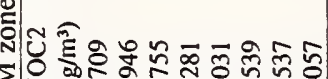

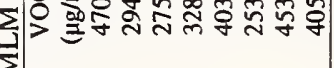

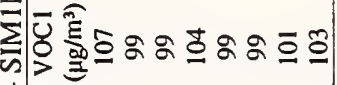
¿

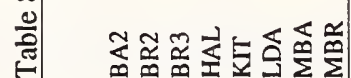

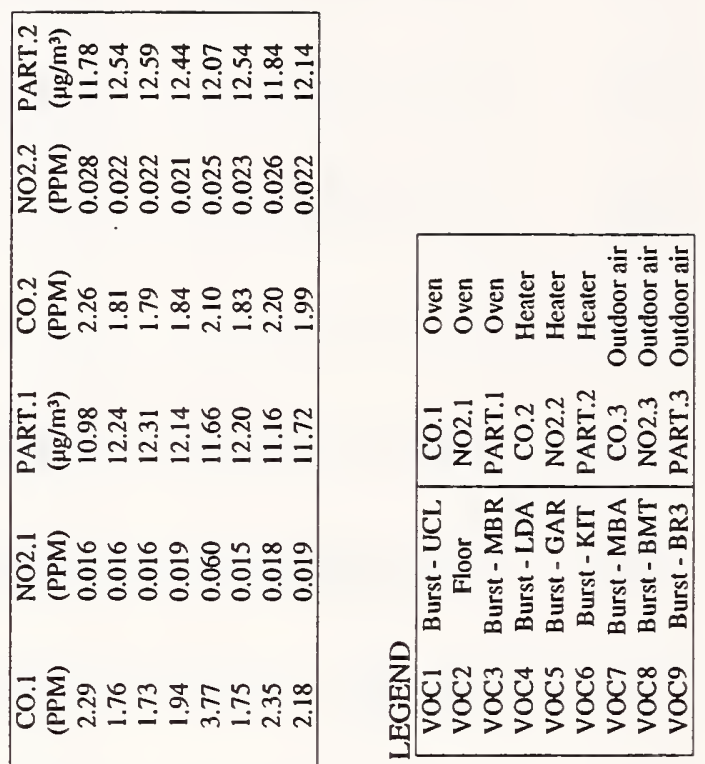

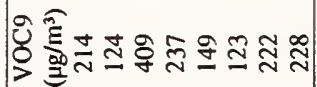

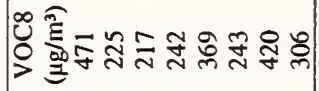

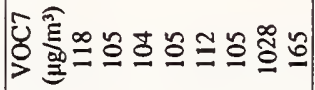

串

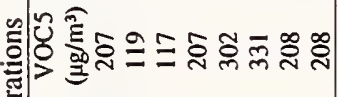

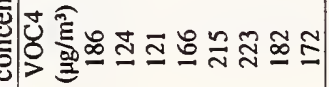

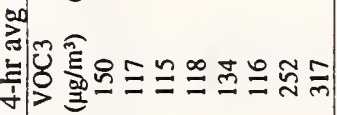

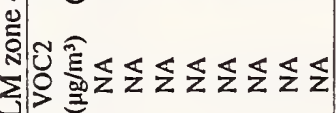

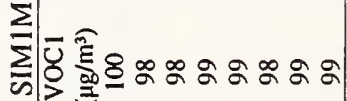
के

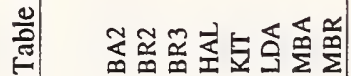

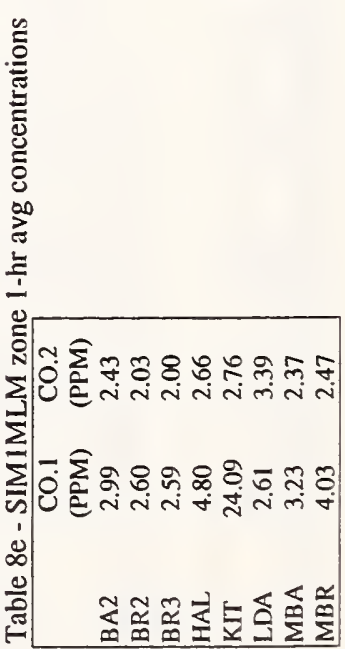




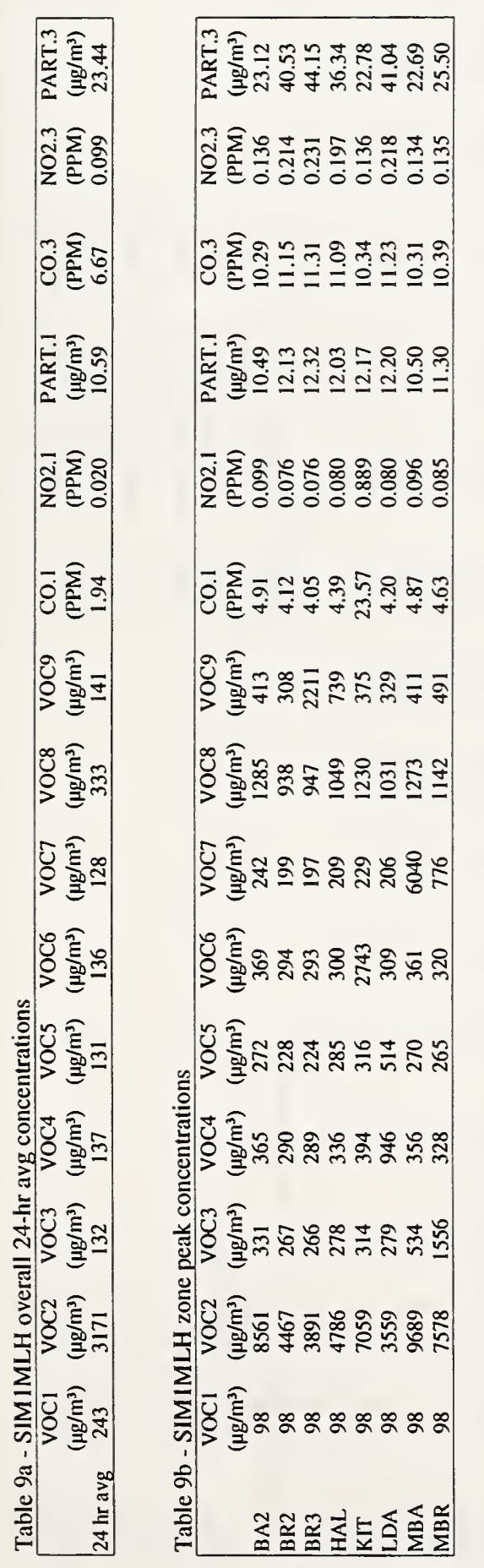

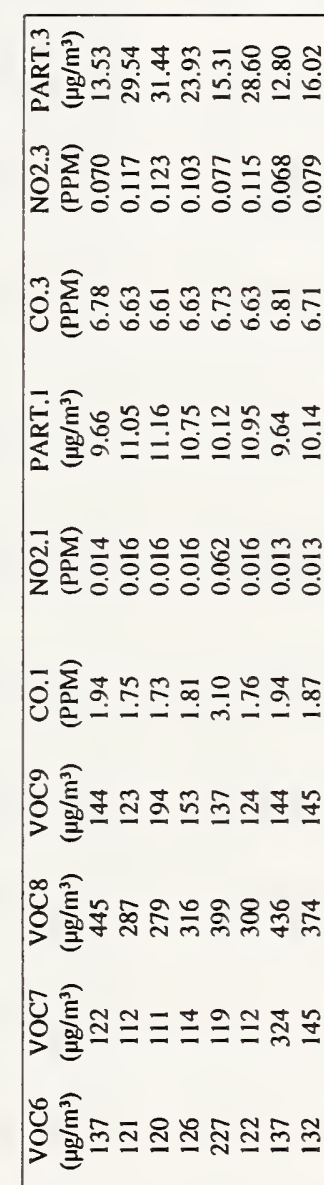

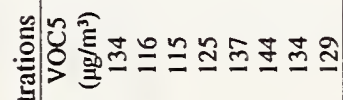

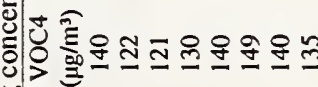

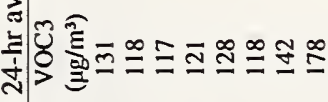

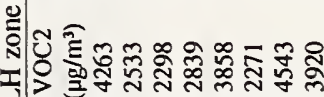

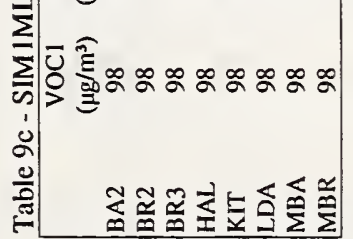

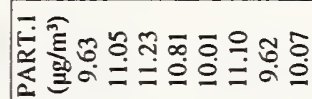

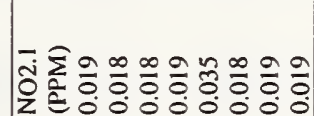

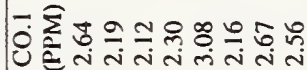

ఫิ

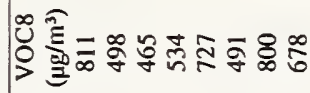

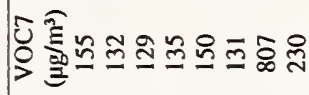

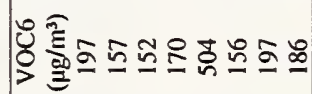

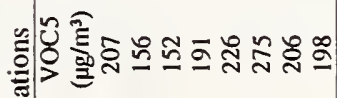

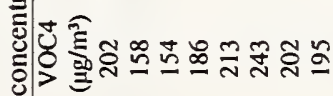

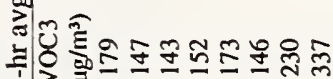

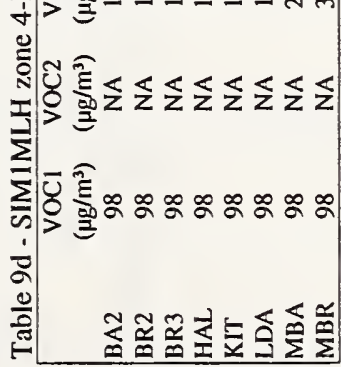

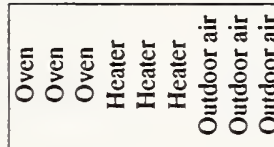

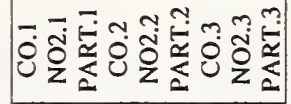

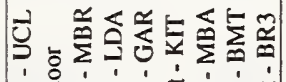

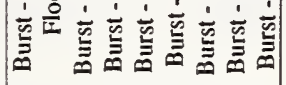

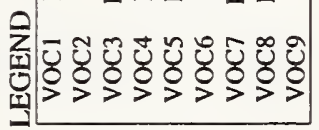

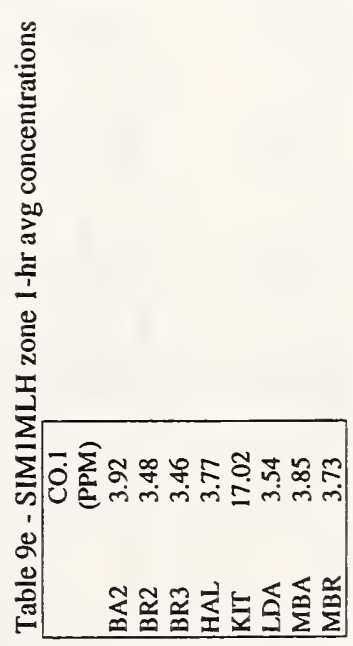



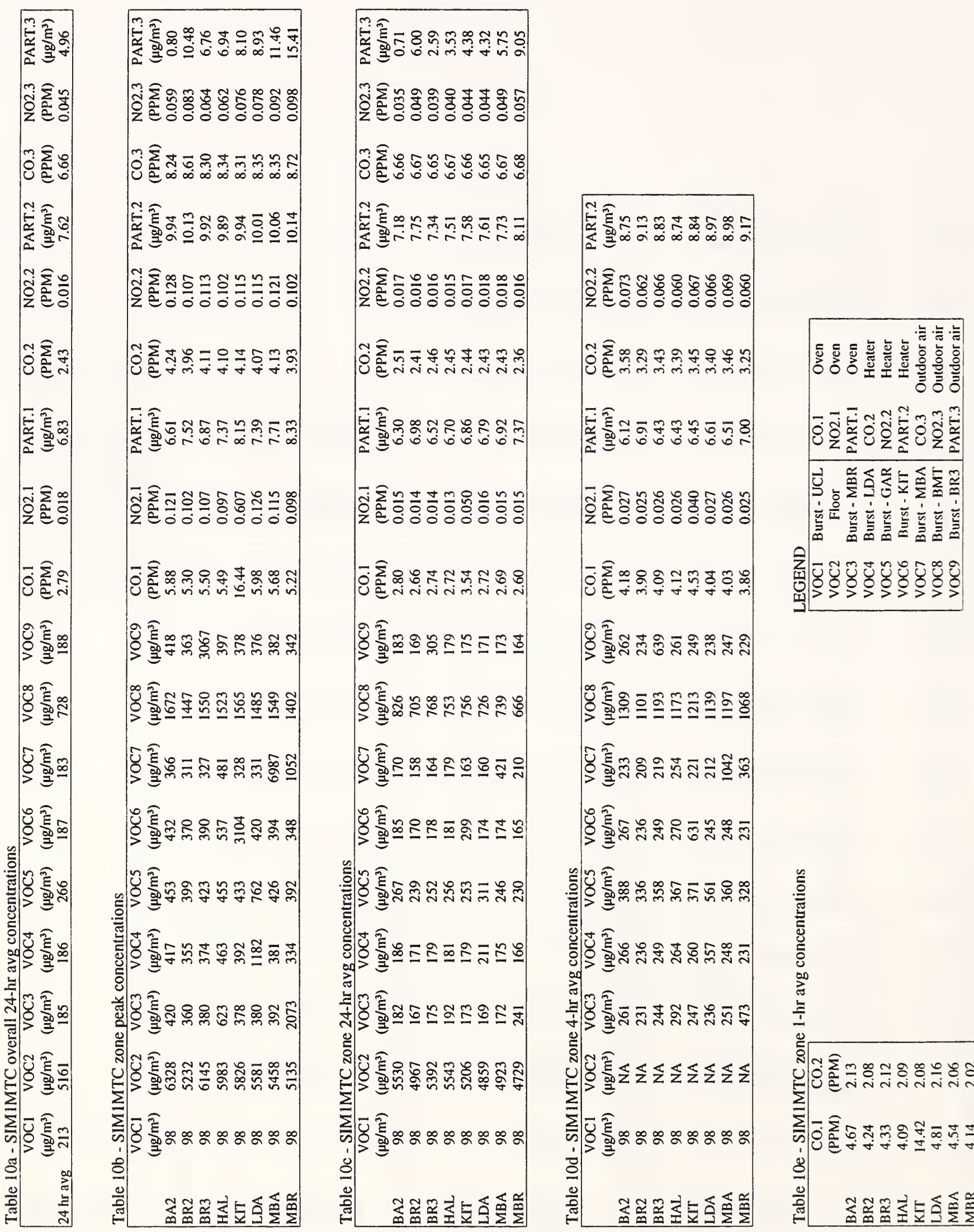

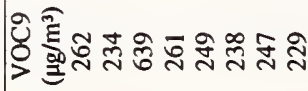

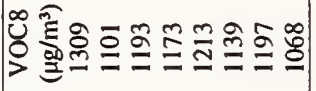

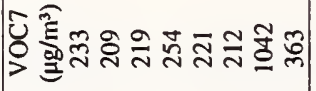

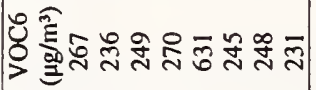

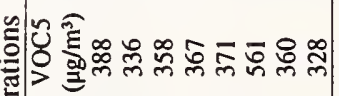

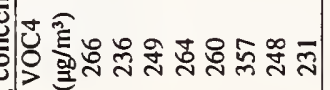

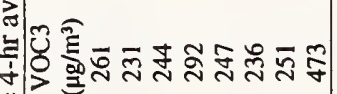

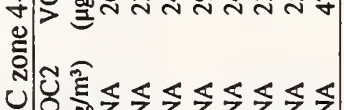

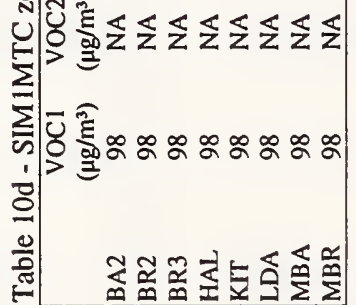

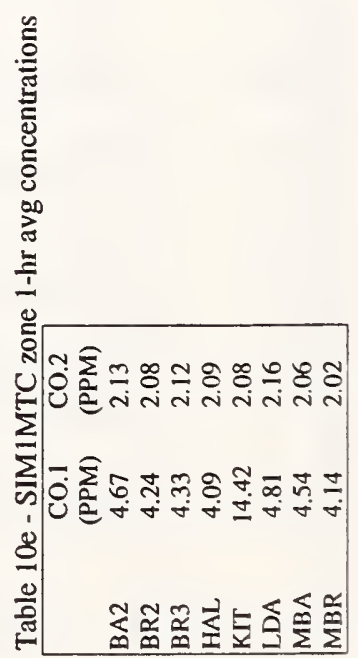




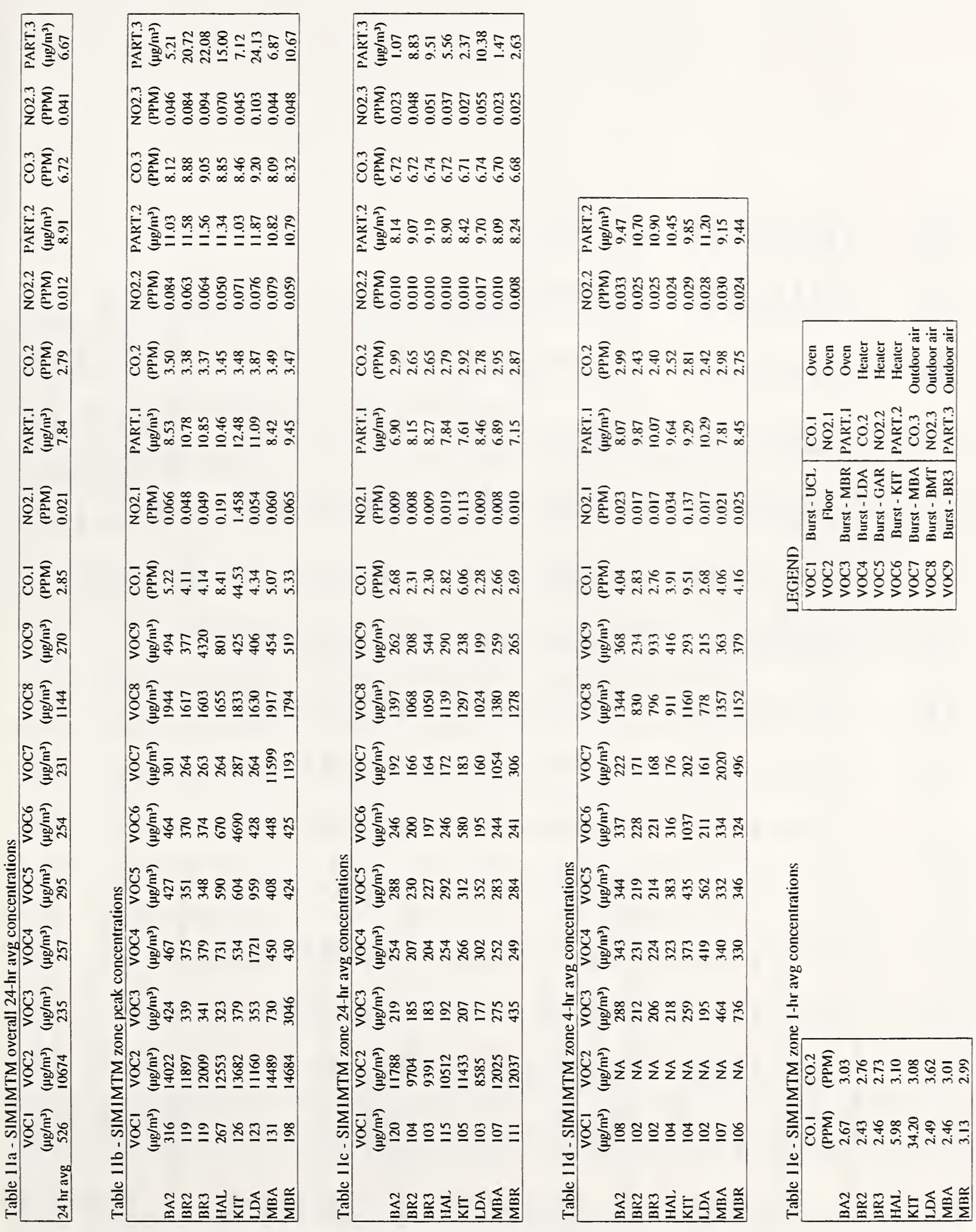




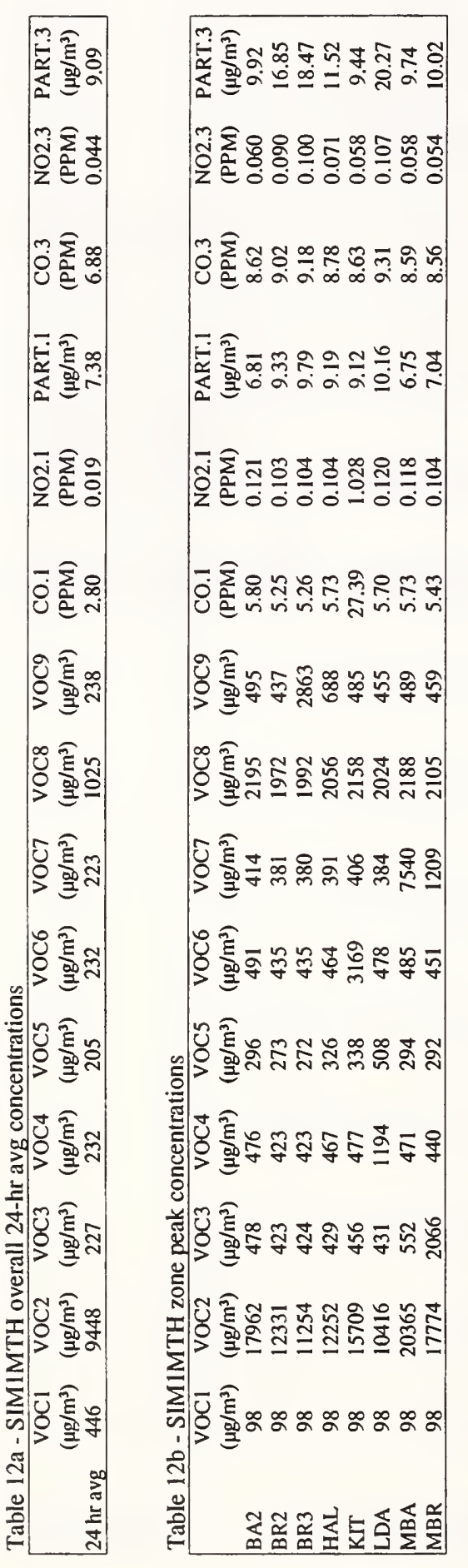

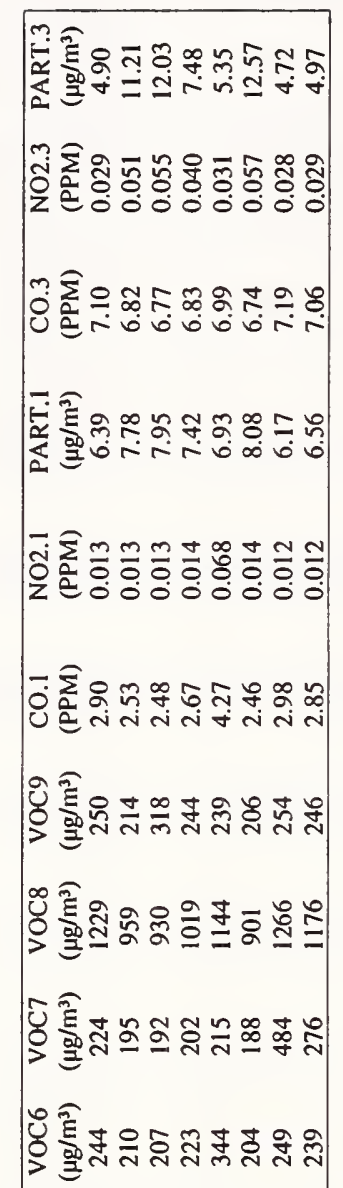

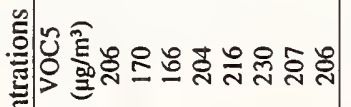

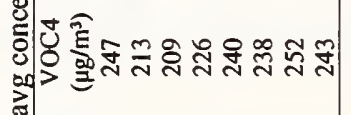

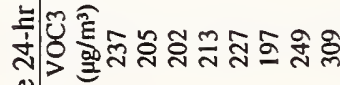

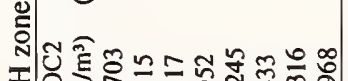

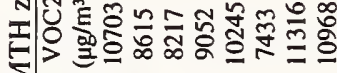

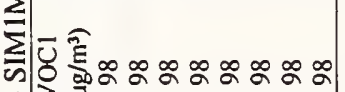

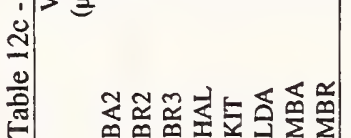

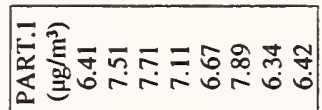

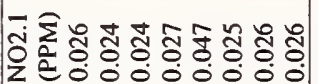

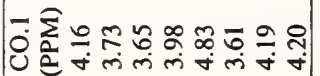

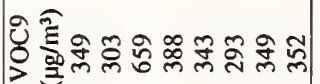

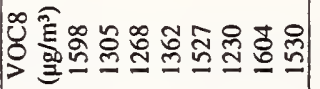

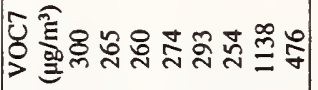

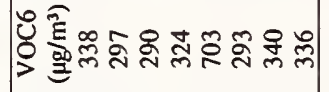

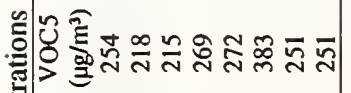

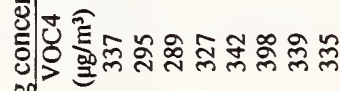
(ำ

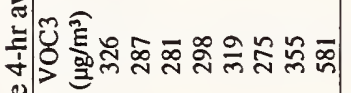

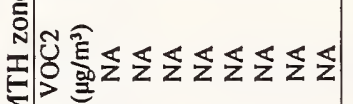
玹 로

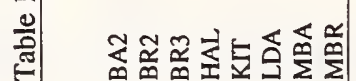

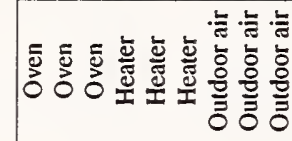

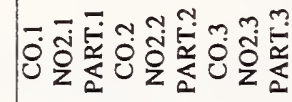

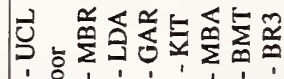

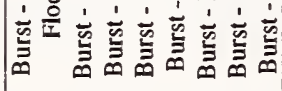

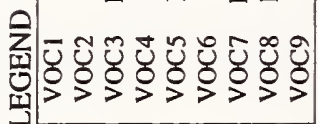

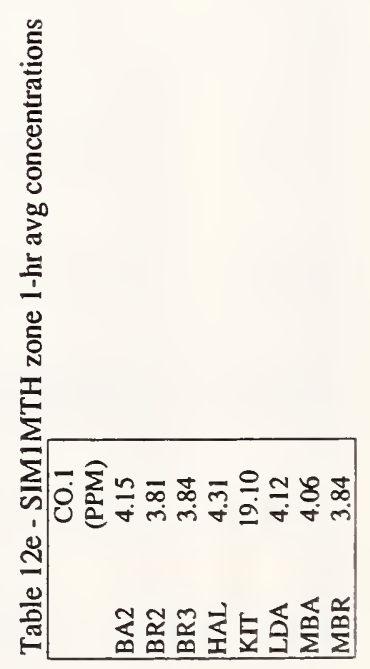



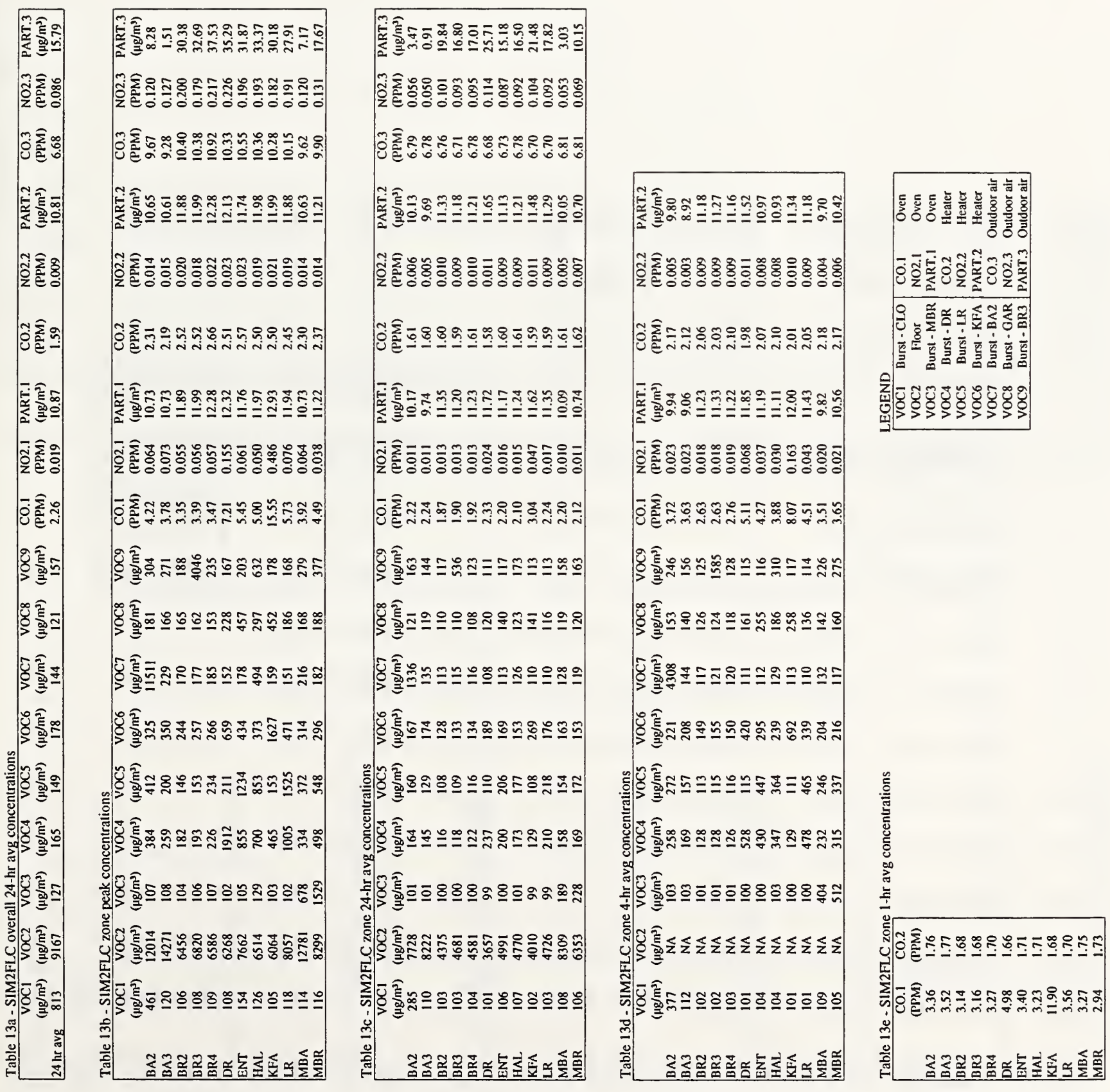

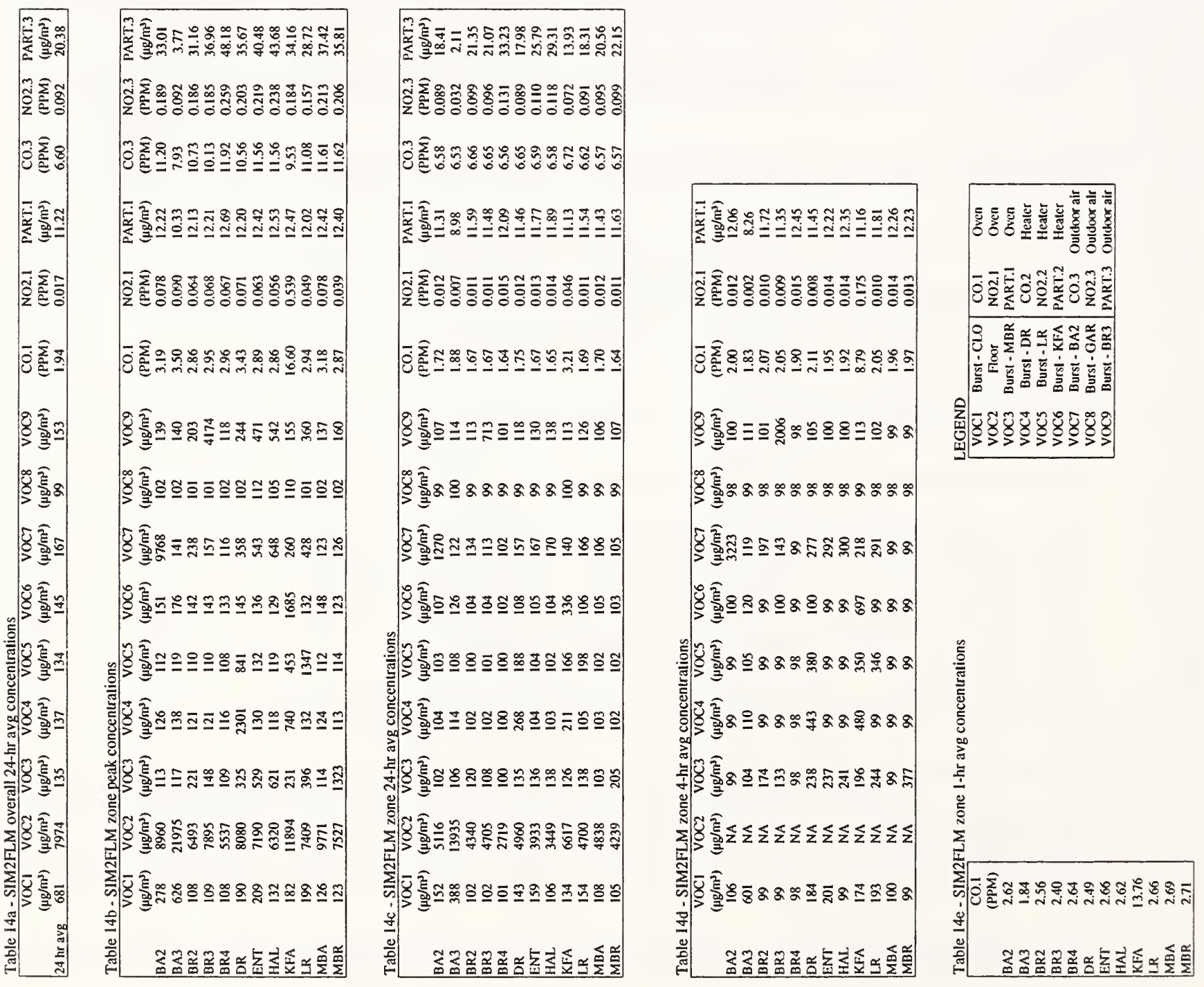


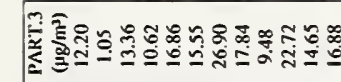

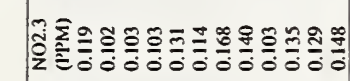

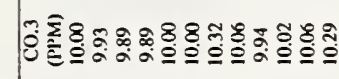

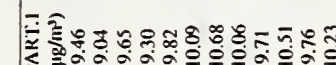

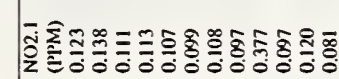

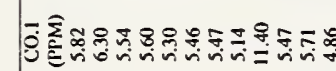

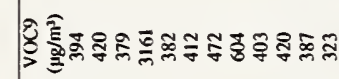

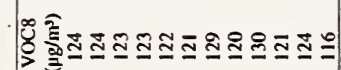

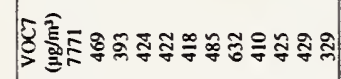

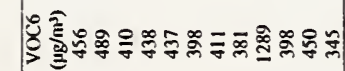

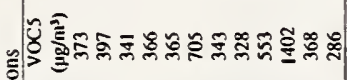

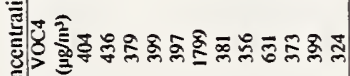

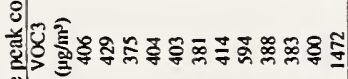

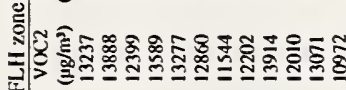

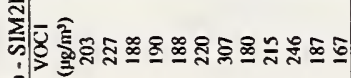
$\frac{\mathrm{n}}{2}$

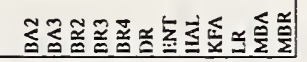

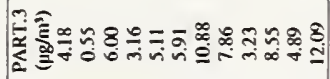

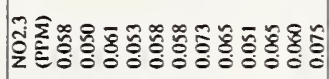

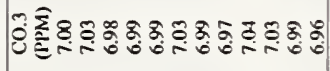

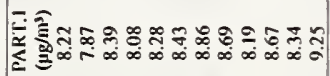

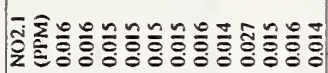

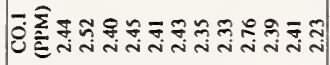

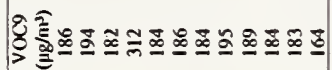

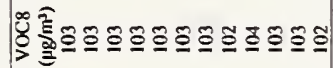

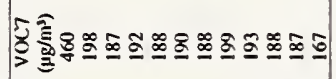

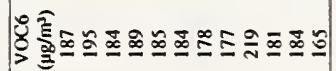

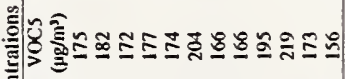

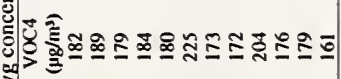

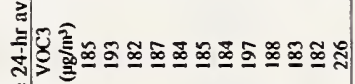

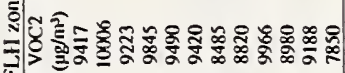

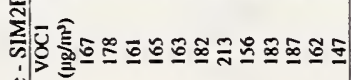
.

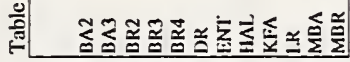

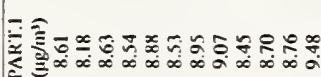

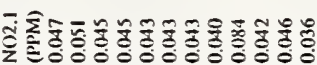

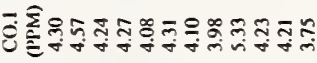

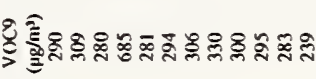

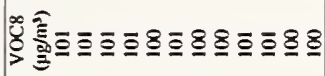

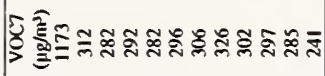

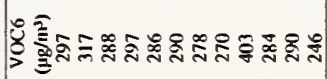

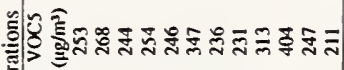

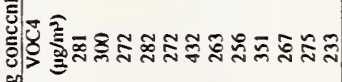

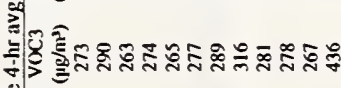

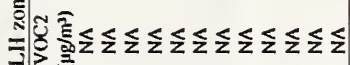

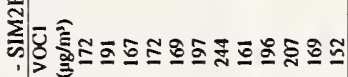

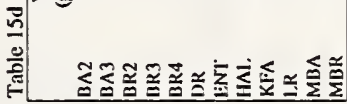

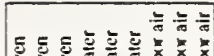

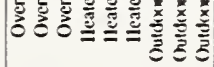

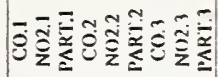
安

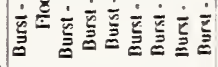

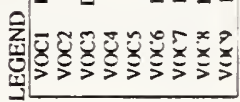

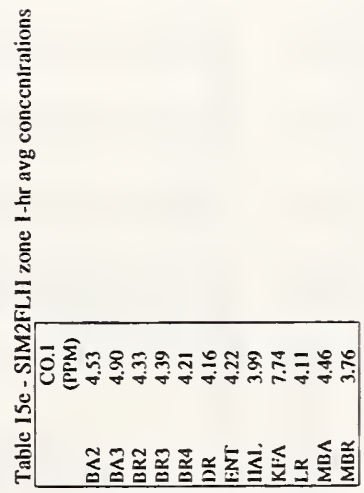



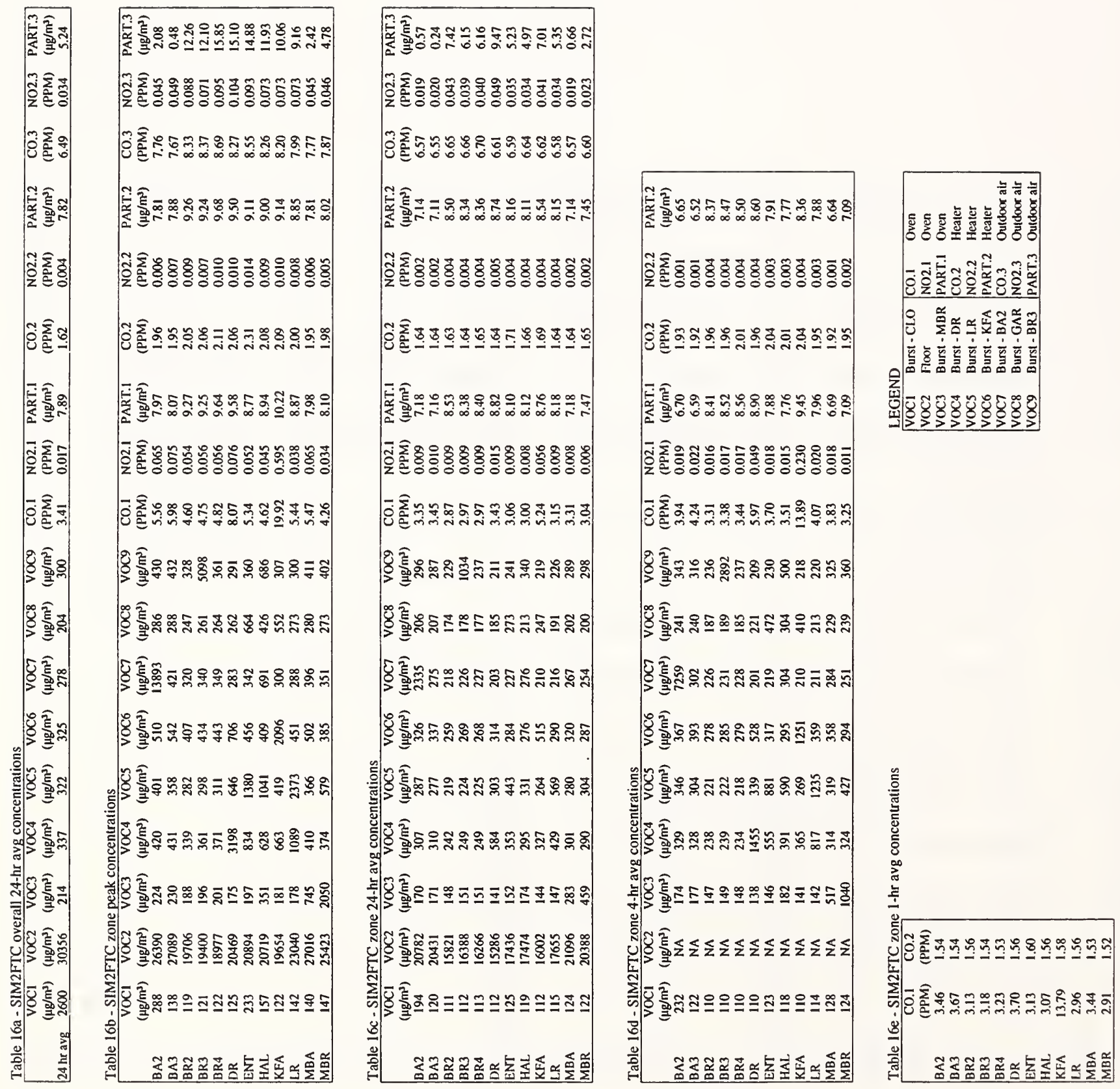


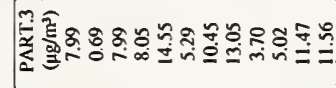

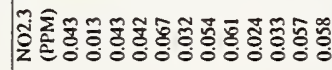

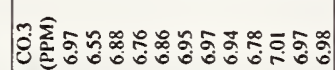

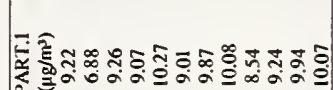

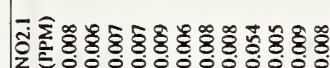
ชิ ชิ

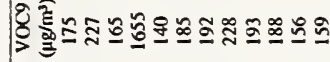

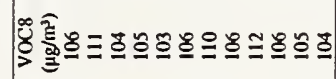

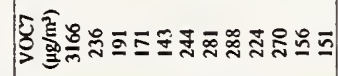

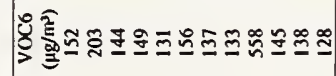

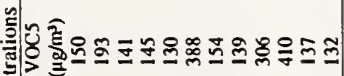

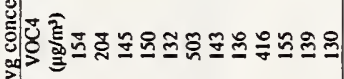

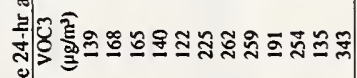

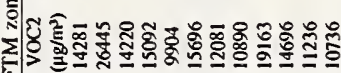

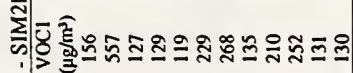

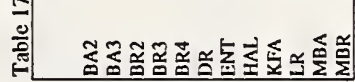

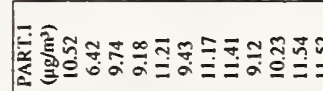

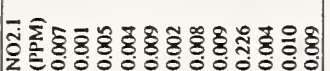

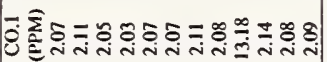
ชุำ

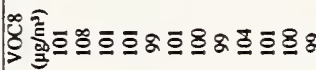

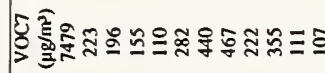

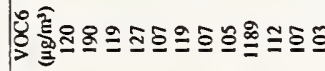

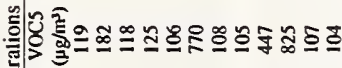

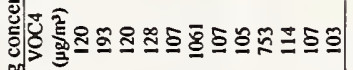

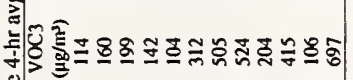

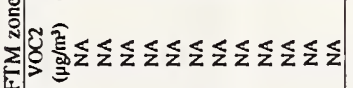

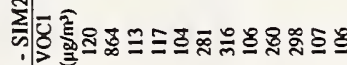

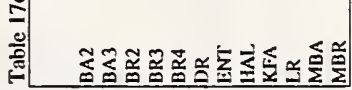

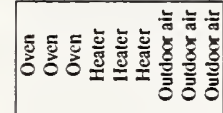

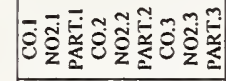

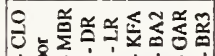

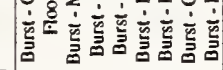

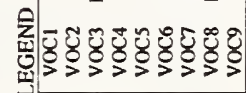

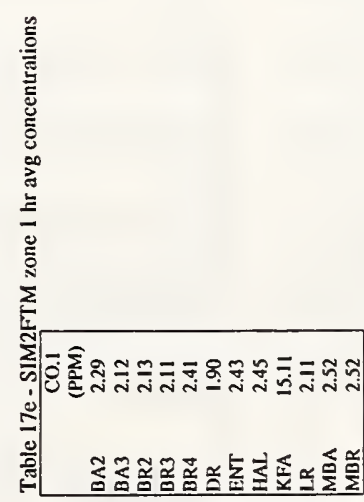



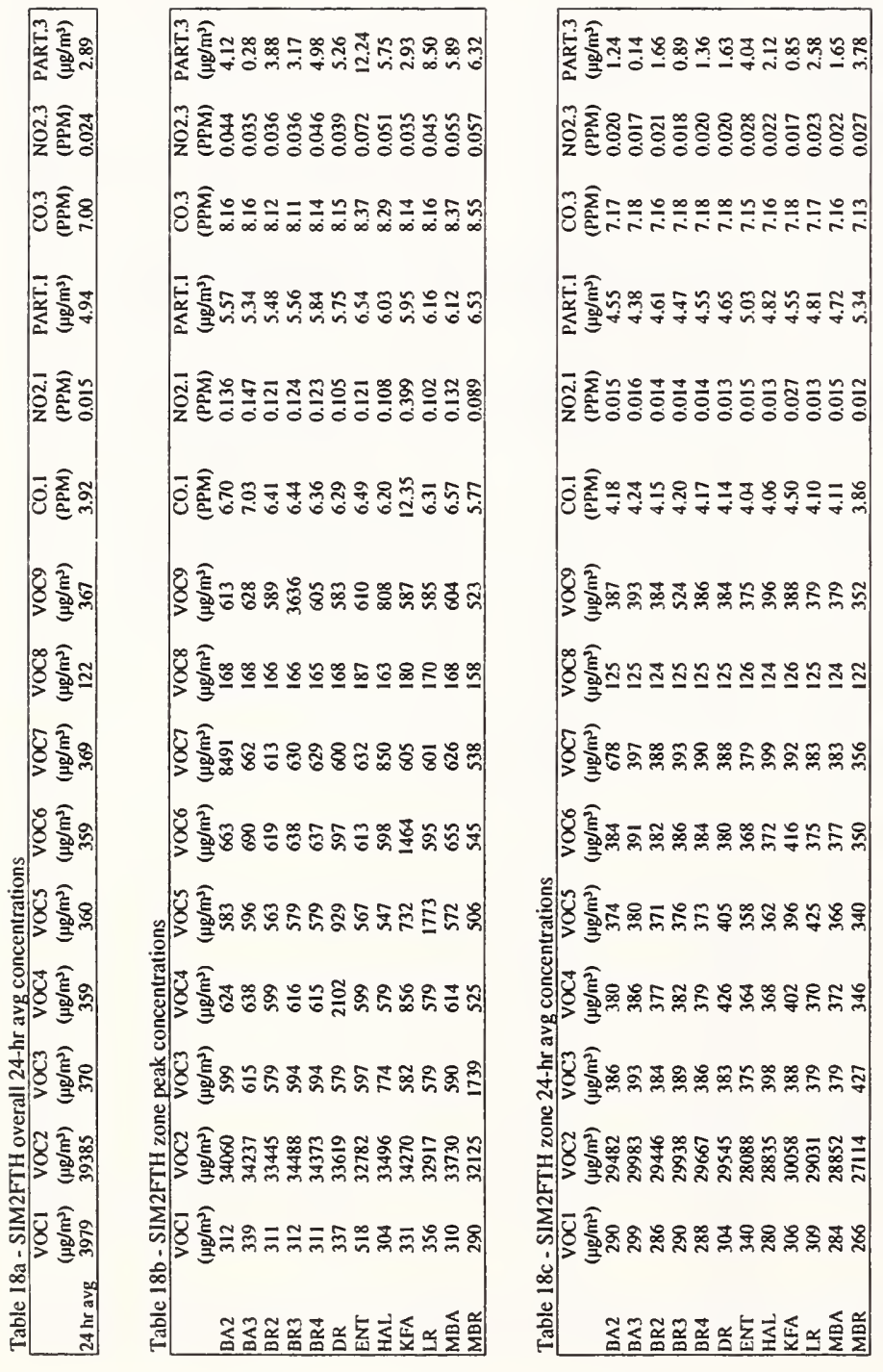

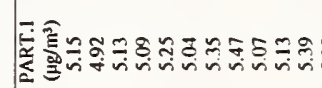

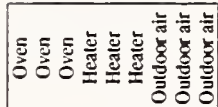

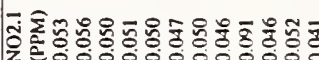

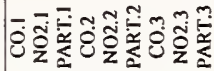

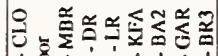

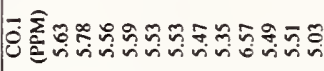

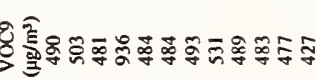

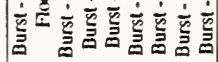

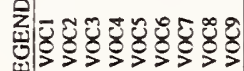

蒙

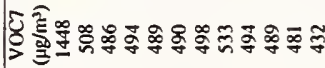

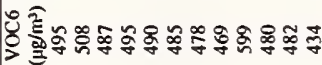

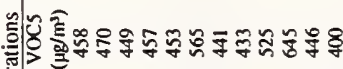

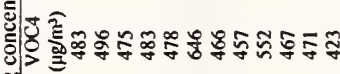

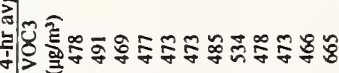

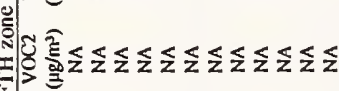

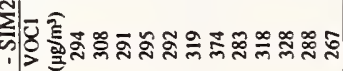

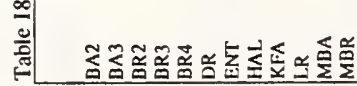

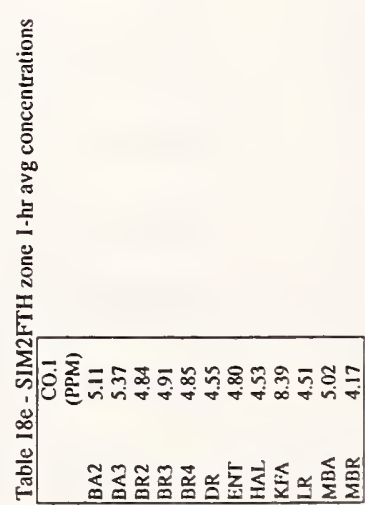




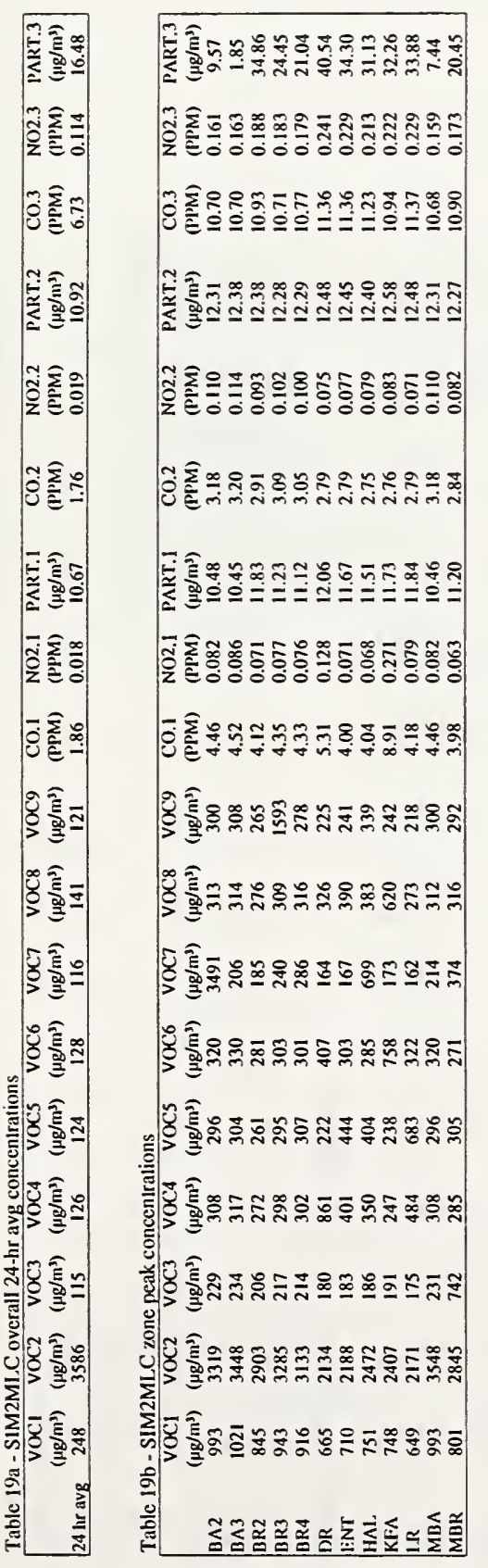

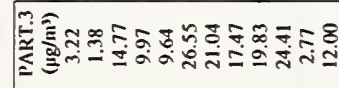
7ำำ

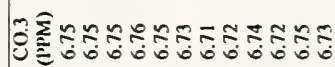

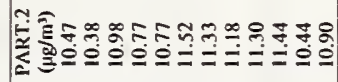
กิร

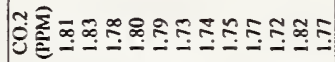

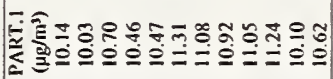

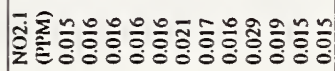

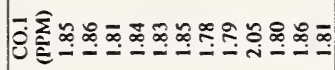

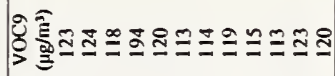

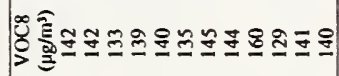

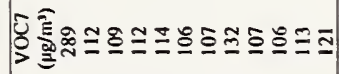

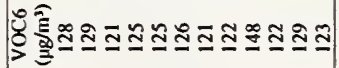

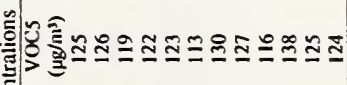

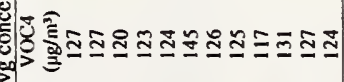

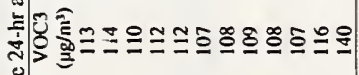

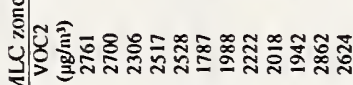

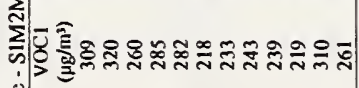

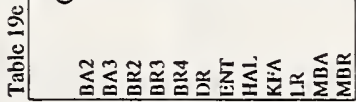

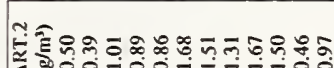

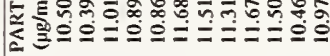

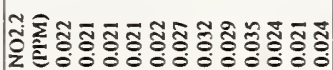

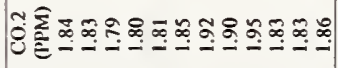

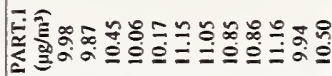

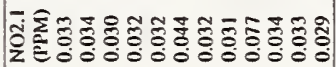

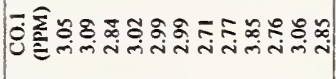

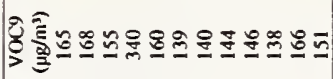

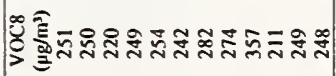

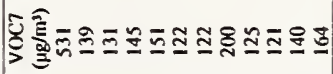

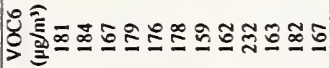

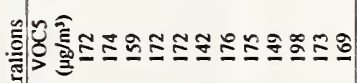

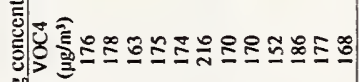

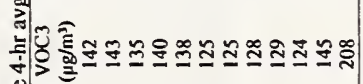

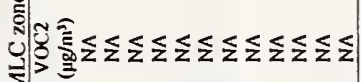

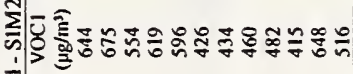

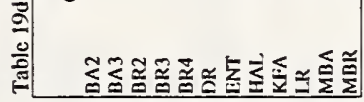
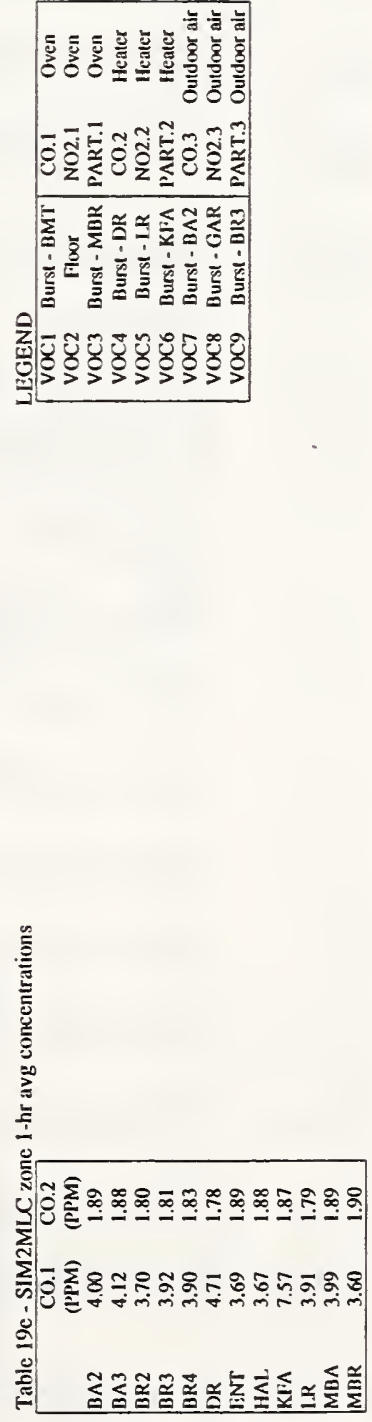

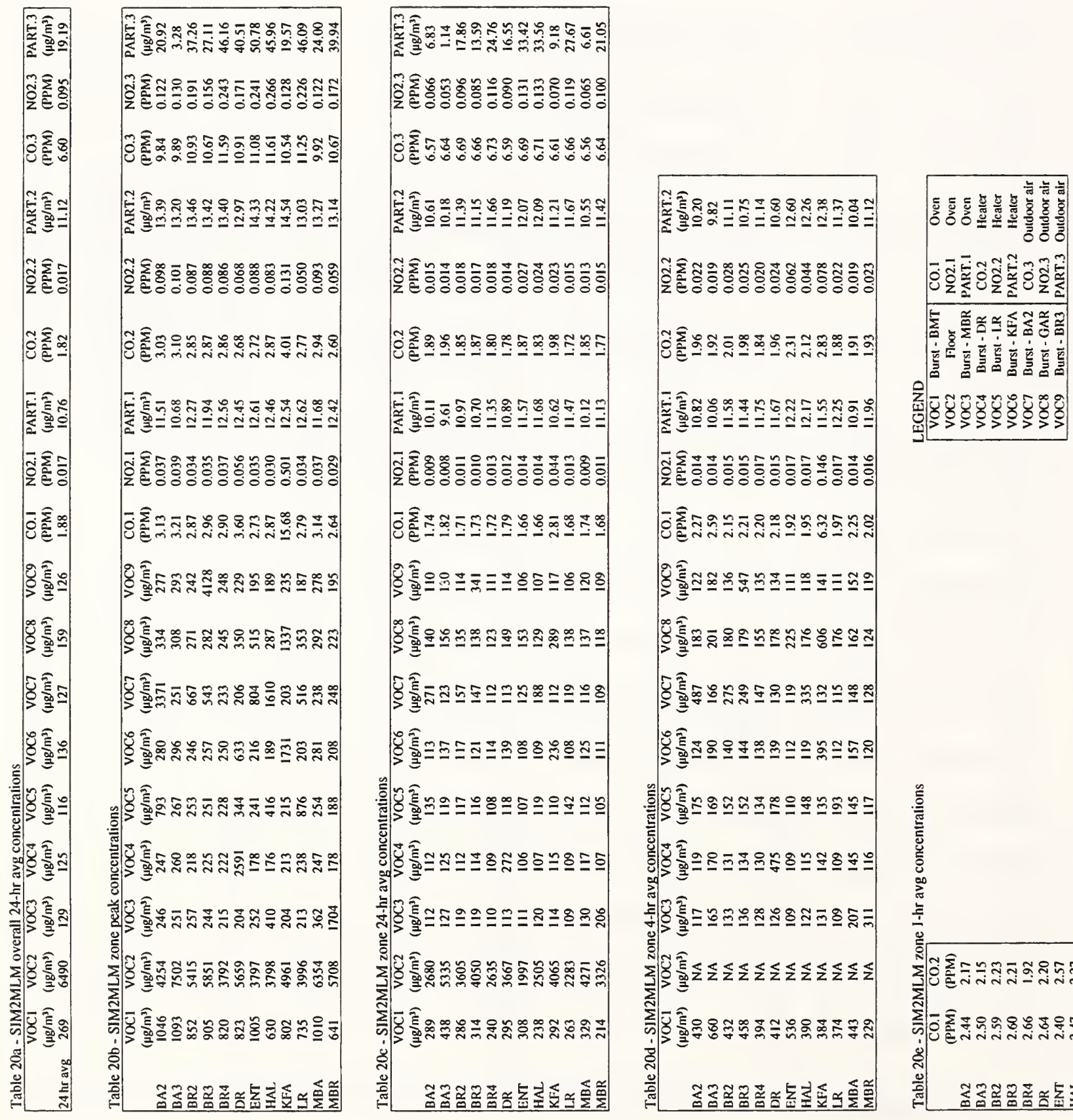

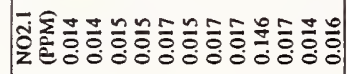

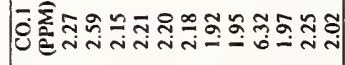

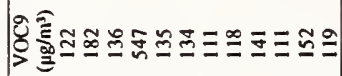

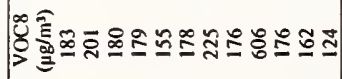

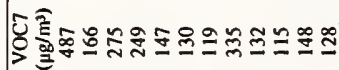

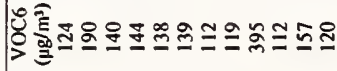

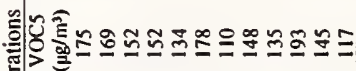

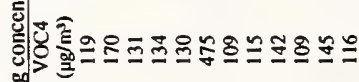

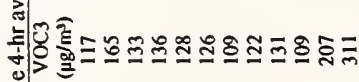

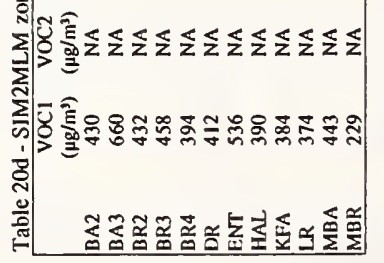

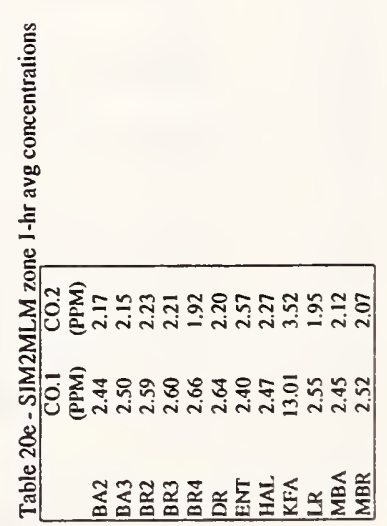




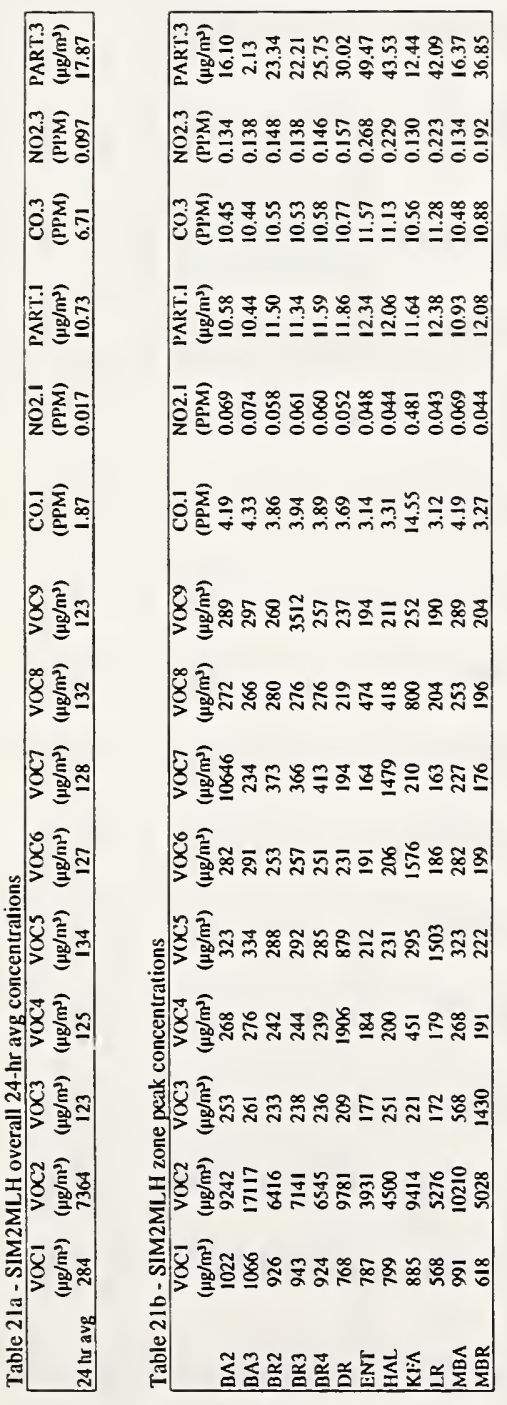

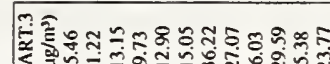

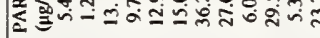

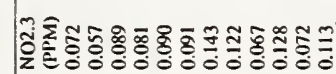

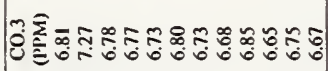

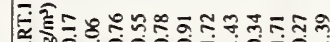

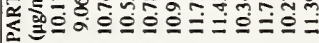

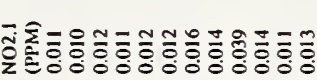

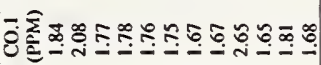
ช్ำ

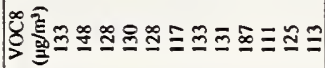

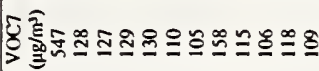

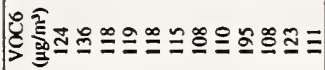

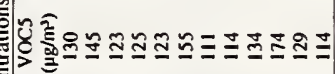

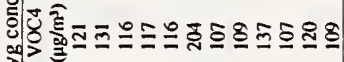

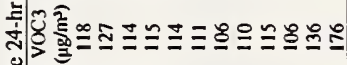

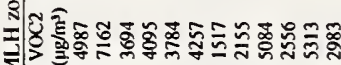

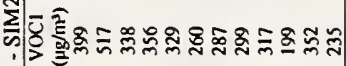
กับ

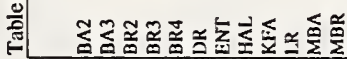

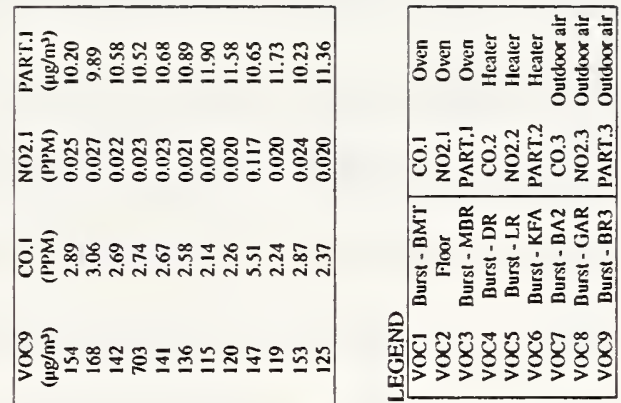

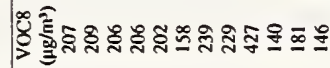

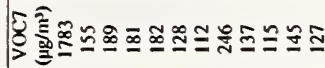

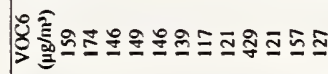

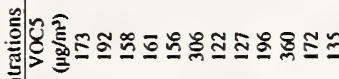

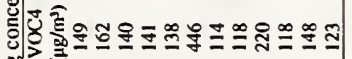

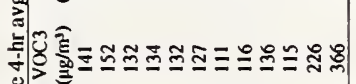

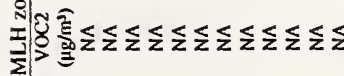

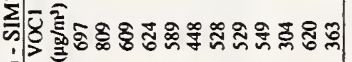

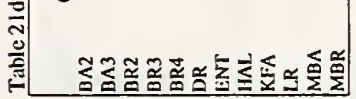

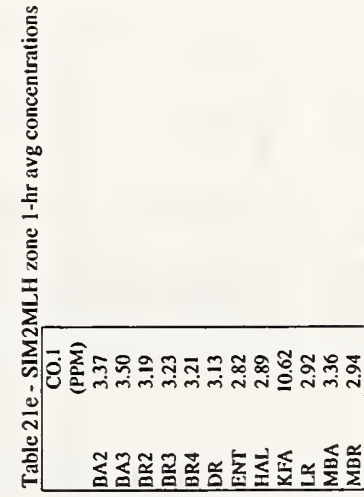



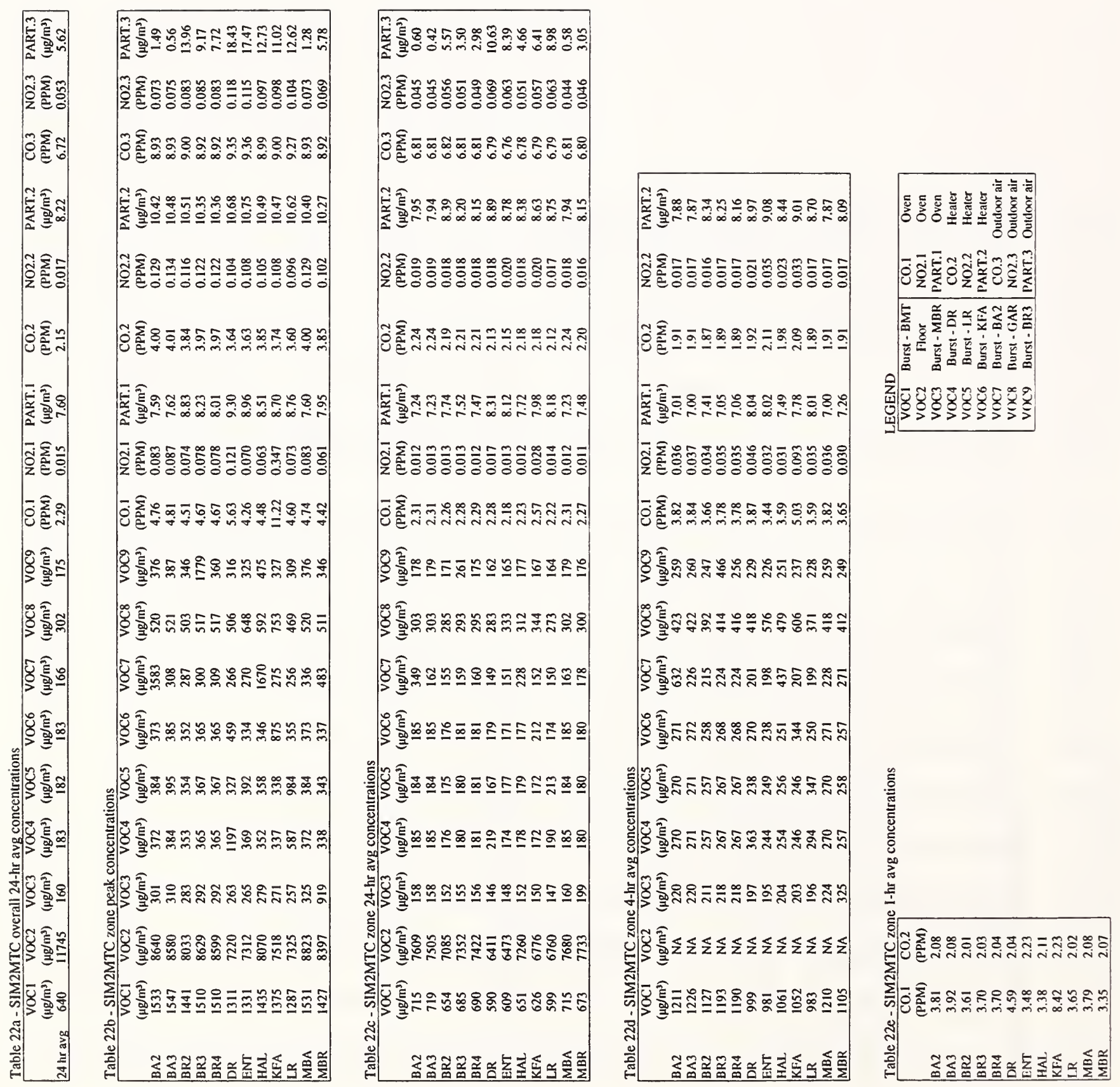


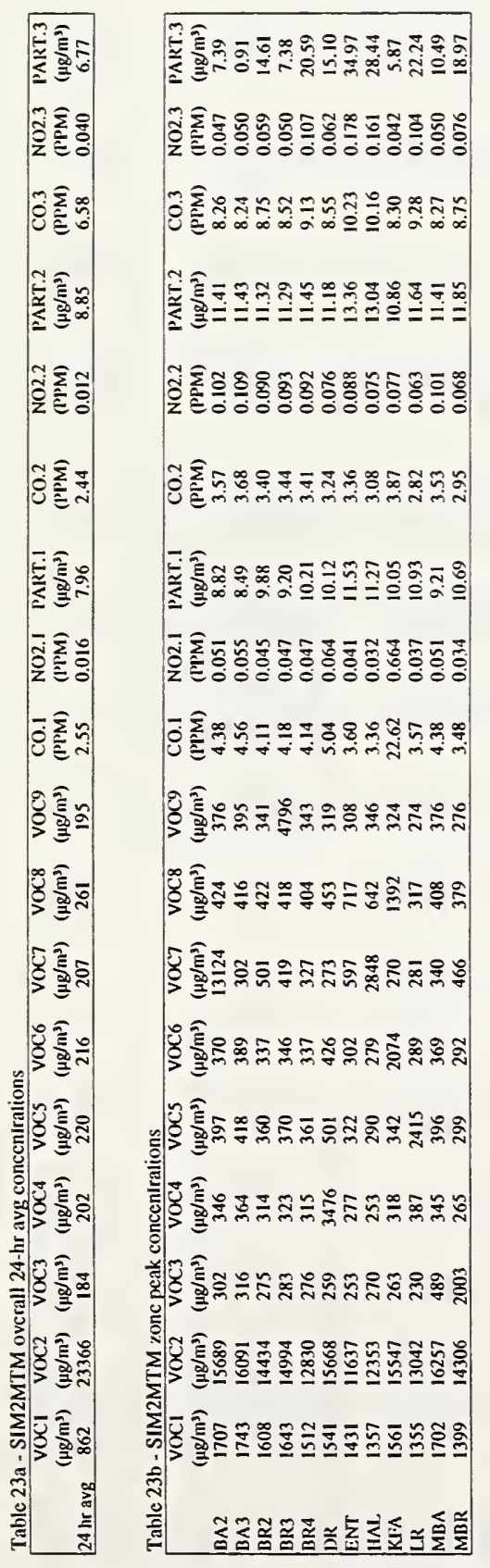

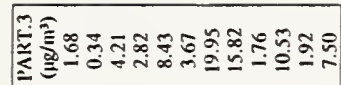

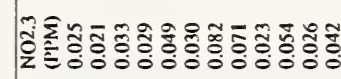

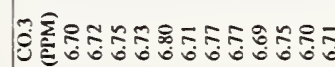

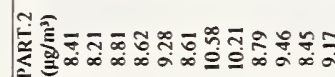

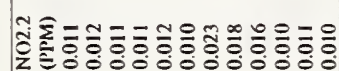

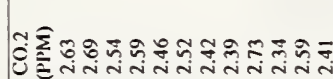

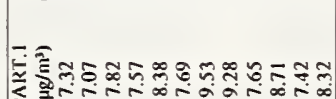

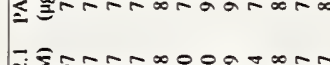

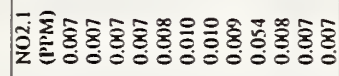

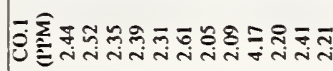

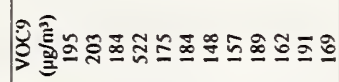

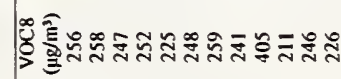

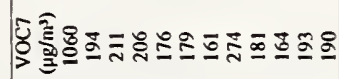

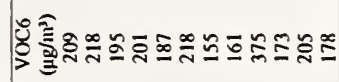

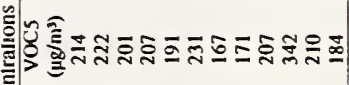

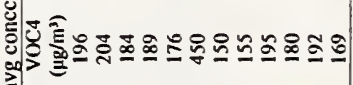

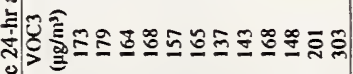

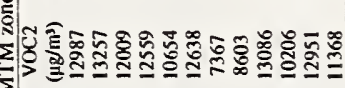

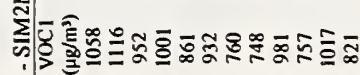
๑ั

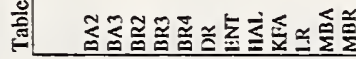

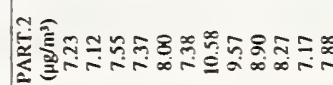

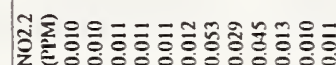

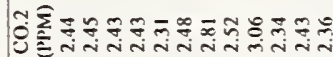

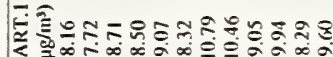

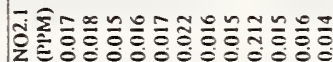

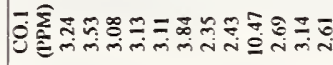

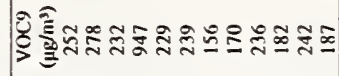

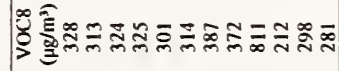

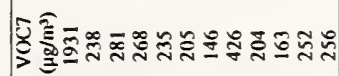

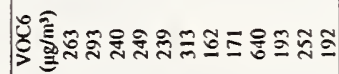

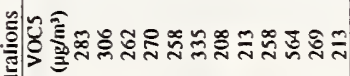

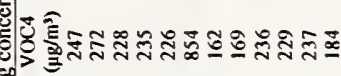

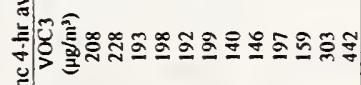

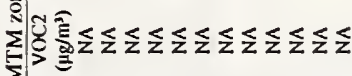

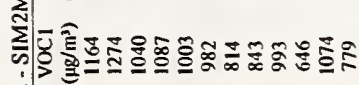
ข้

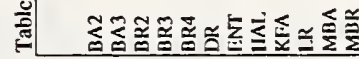
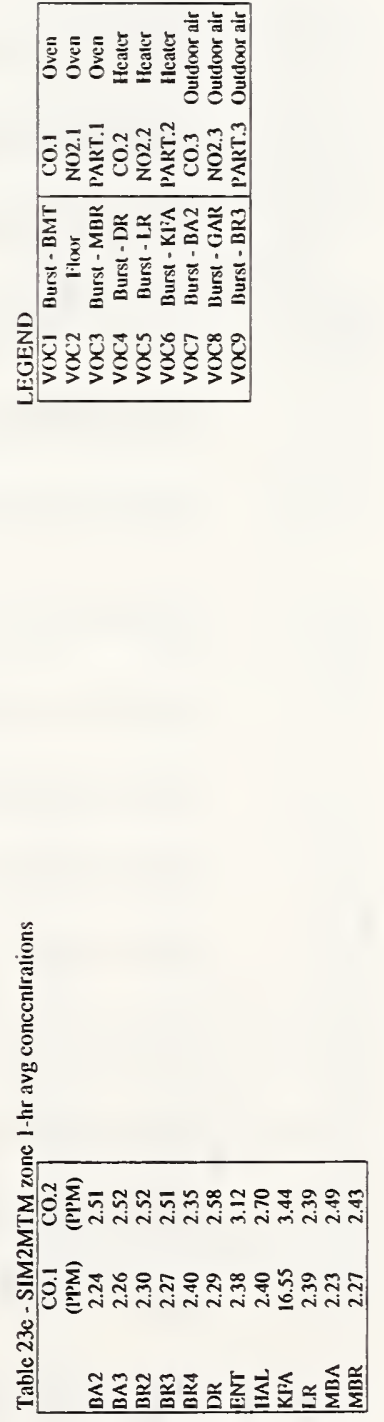

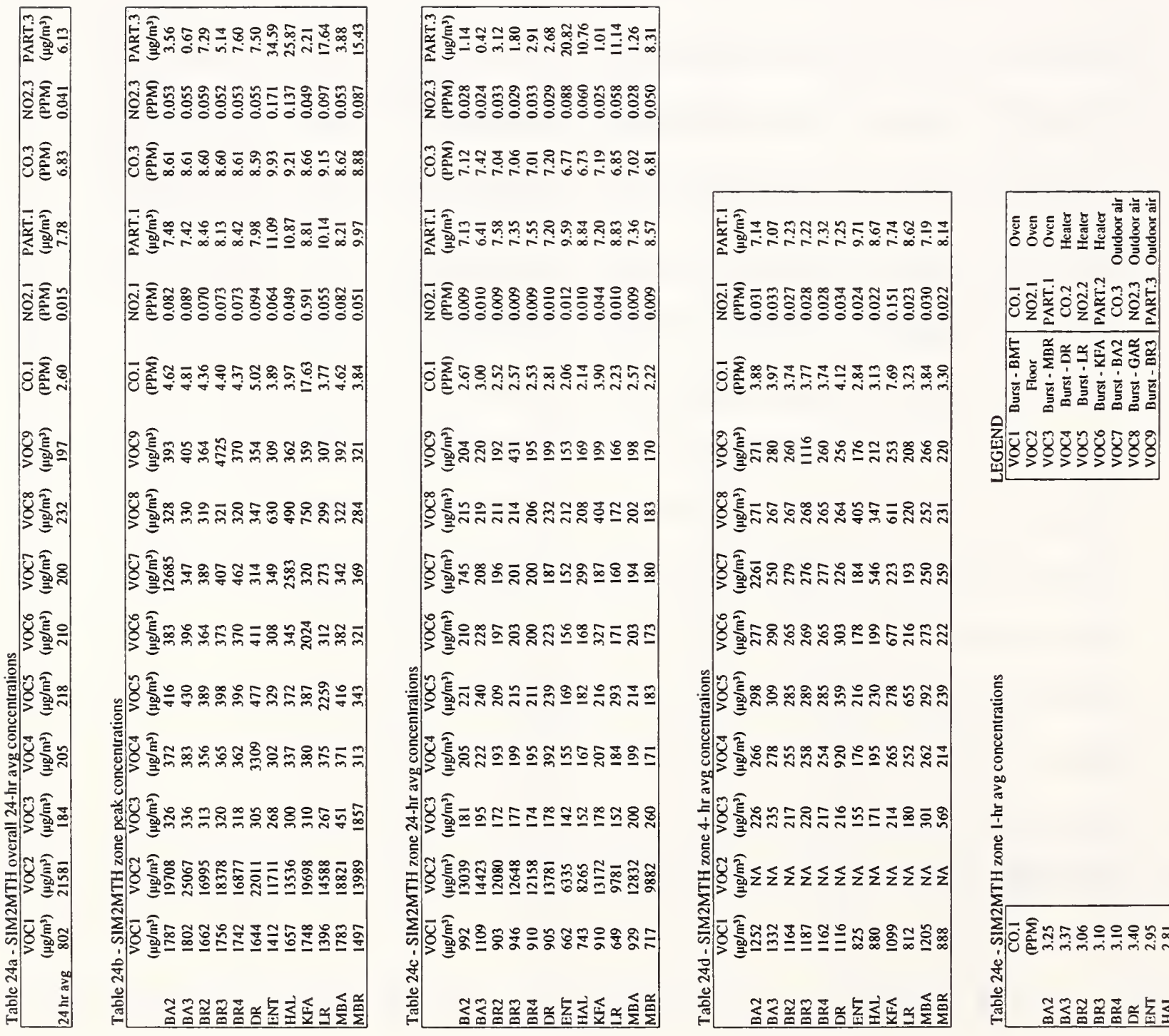

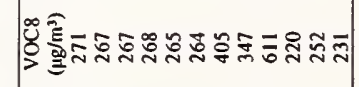

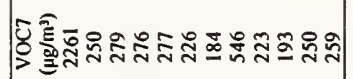

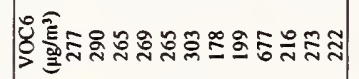

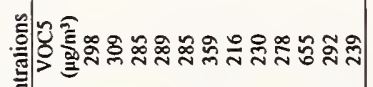

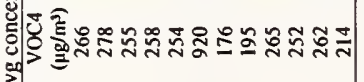

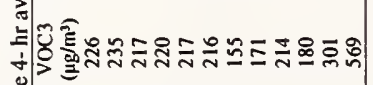

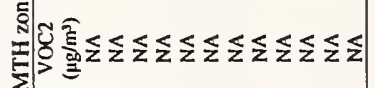

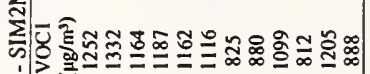
离

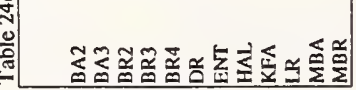

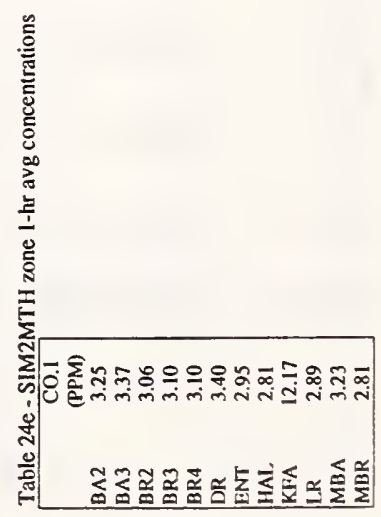



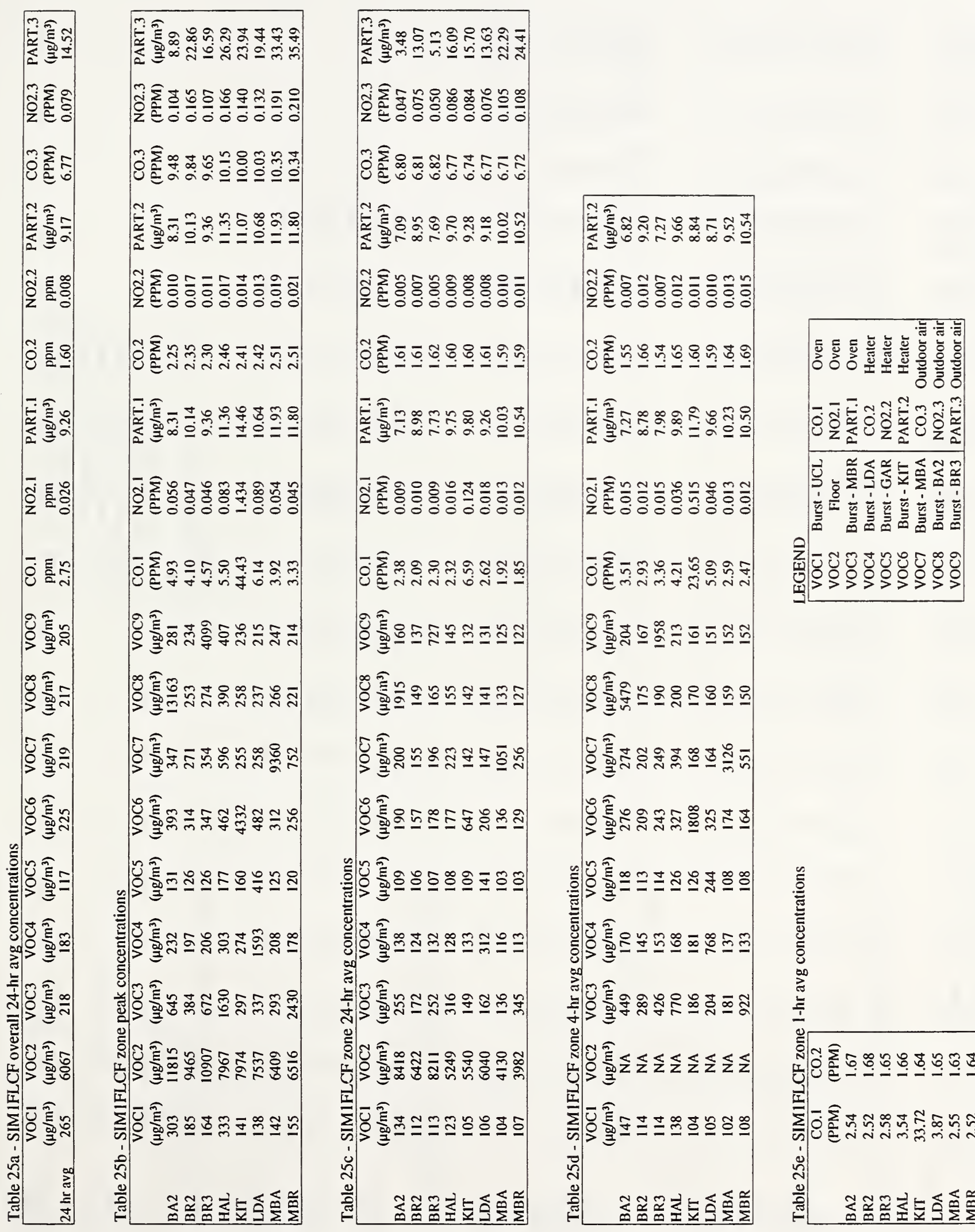

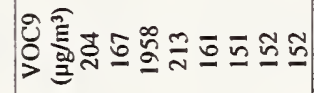

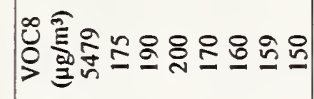

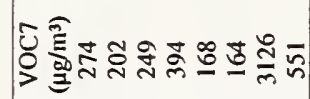

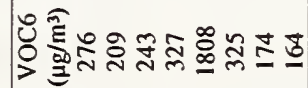

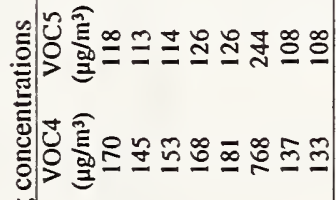

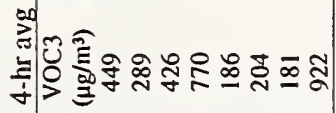

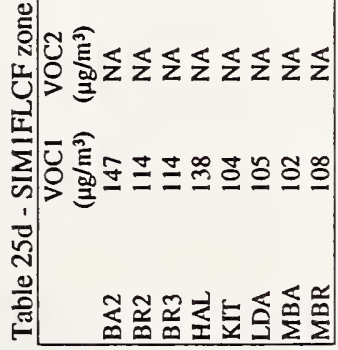

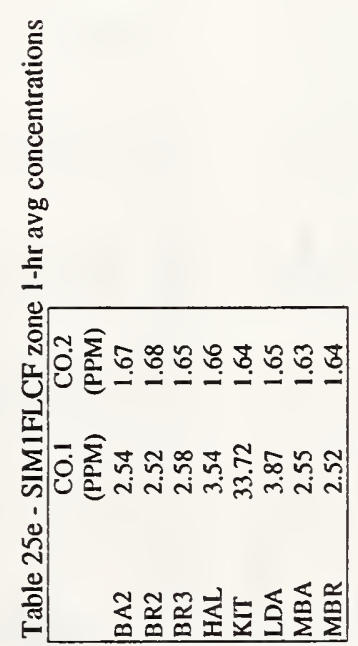




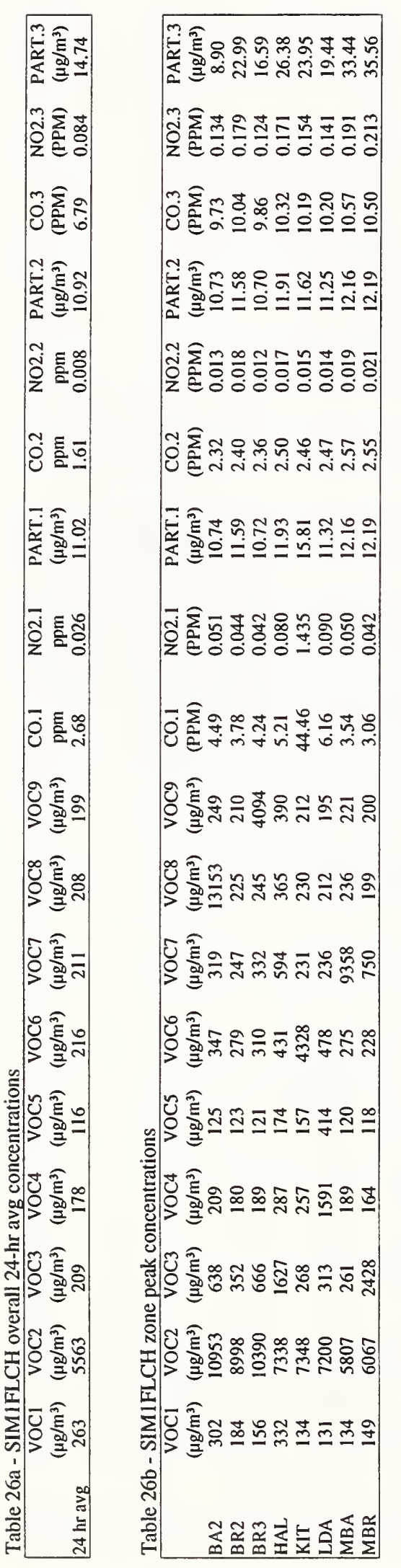

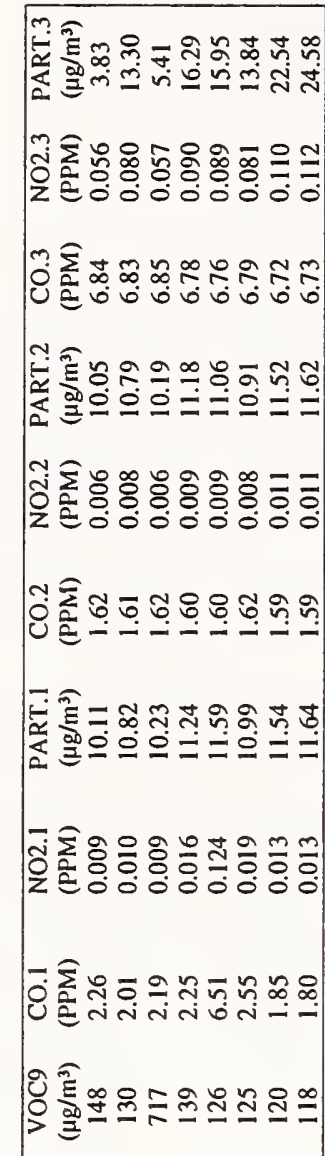

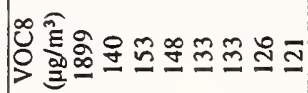

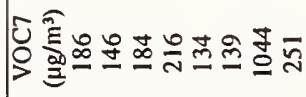

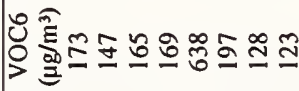

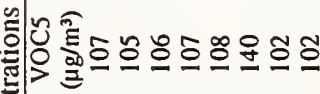

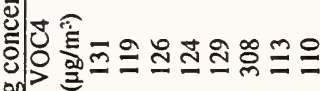
ता

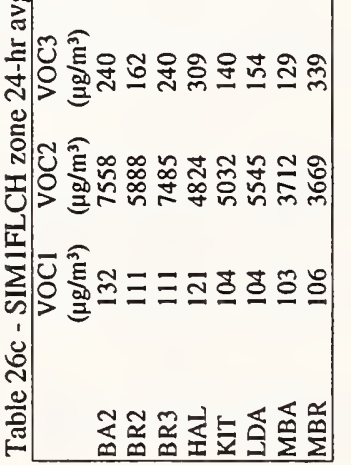

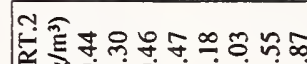

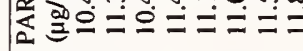

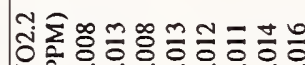

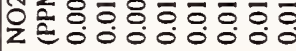

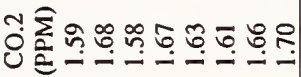

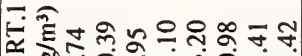

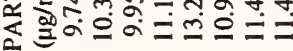

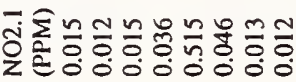

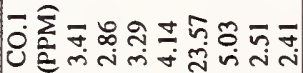

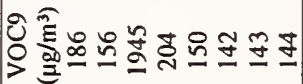

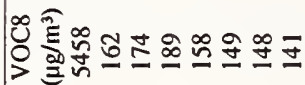

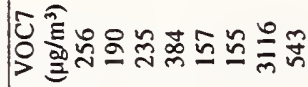

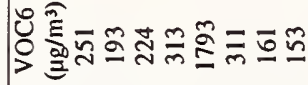

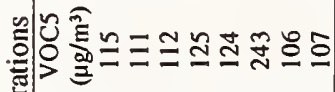

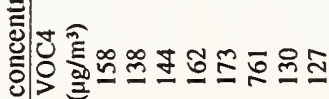

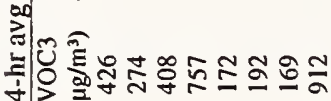

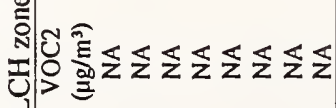

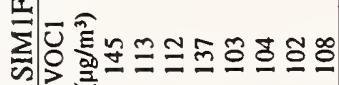
可

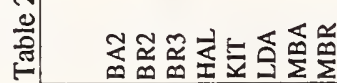
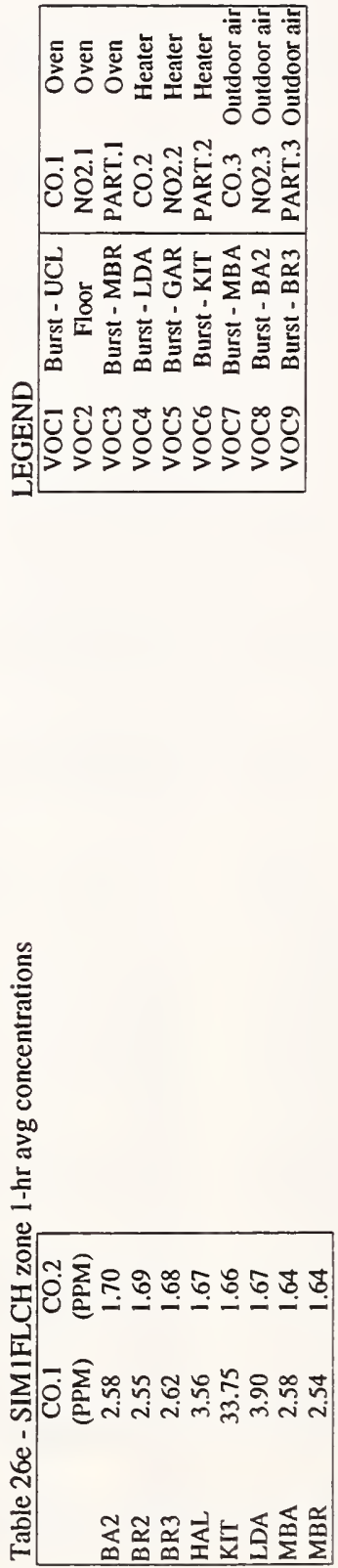


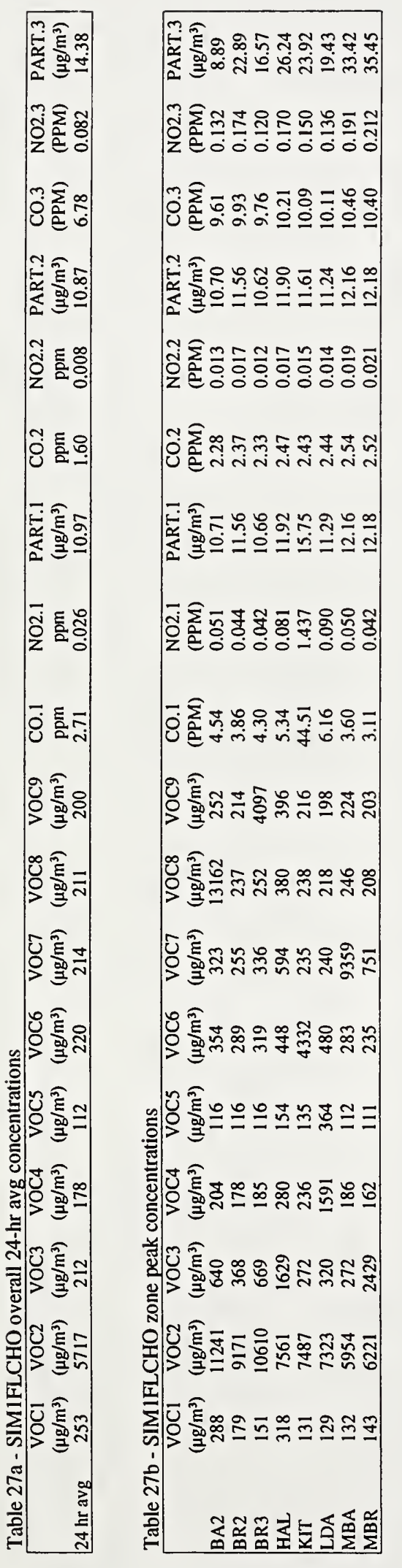

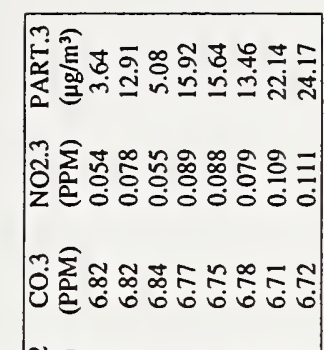

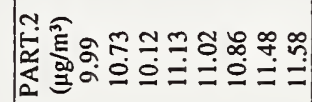

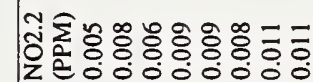

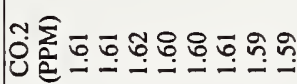

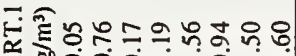

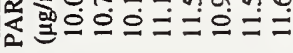

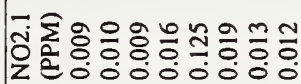
zeo.00000. z

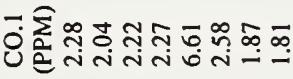

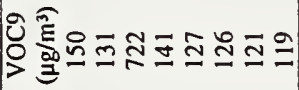

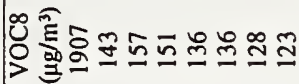

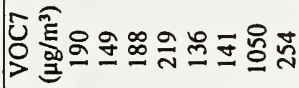

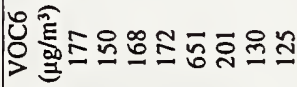

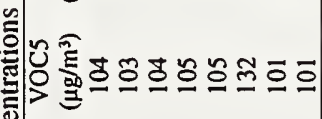
:

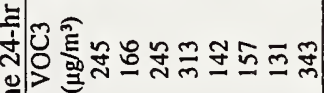

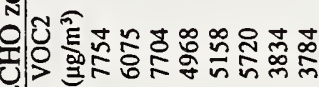

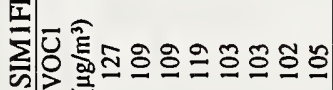
ลั

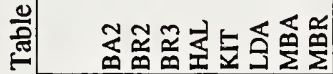

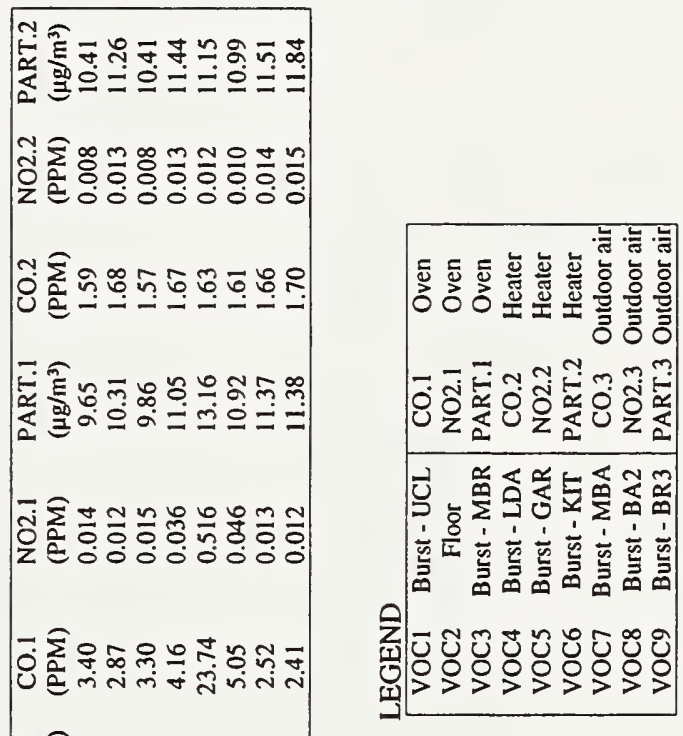

రิ

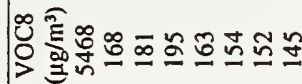

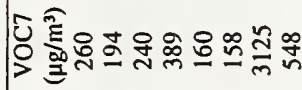

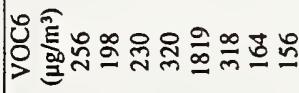

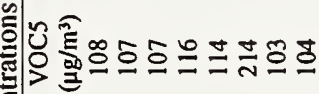
ปั

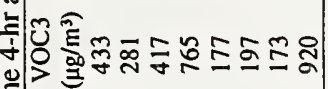

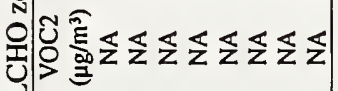

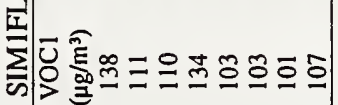
군

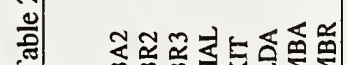

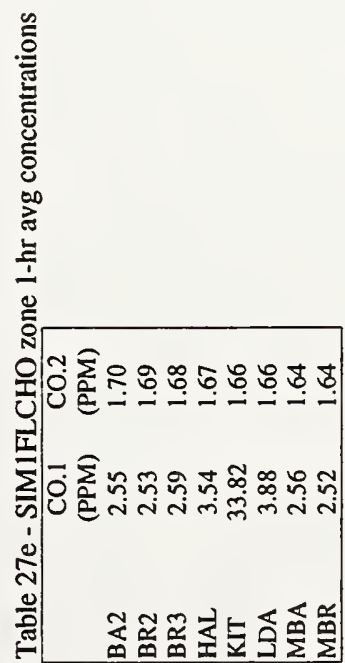




